\title{
A Qualitative Study of Medical Student Perceptions of the West Virginia University School of Medicine's Competency-Based Electronic Portfolio System's Design and Implementation
}

\author{
Carrie A. Calloway
}

Follow this and additional works at: https://researchrepository.wvu.edu/etd

\section{Recommended Citation}

Calloway, Carrie A., "A Qualitative Study of Medical Student Perceptions of the West Virginia University School of Medicine's Competency-Based Electronic Portfolio System's Design and Implementation" (2015). Graduate Theses, Dissertations, and Problem Reports. 5301.

https://researchrepository.wvu.edu/etd/5301

This Dissertation is protected by copyright and/or related rights. It has been brought to you by the The Research Repository @ WVU with permission from the rights-holder(s). You are free to use this Dissertation in any way that is permitted by the copyright and related rights legislation that applies to your use. For other uses you must obtain permission from the rights-holder(s) directly, unless additional rights are indicated by a Creative Commons license in the record and/ or on the work itself. This Dissertation has been accepted for inclusion in WVU Graduate Theses, Dissertations, and Problem Reports collection by an authorized administrator of The Research Repository @ WVU.

For more information, please contact researchrepository@mail.wvu.edu. 
A Qualitative Study of Medical Student Perceptions of the West Virginia University School of Medicine's Competency-Based Electronic Portfolio System's Design and

Implementation

Carrie A. Calloway

Dissertation submitted to the College of Education and Human Services at West Virginia University

in partial fulfillment of the requirements for the degree of

Doctor of Education in Curriculum and Instruction

Dr. James Rye, Ph.D., Chair

Dr. Patricia Obenauf, Ed.D.

Dr. Jeffrey Carver, Ed.D.

Dr. John Oughton, Ed.D.

Dr. Scott Cottrell, Ed.D.

Curriculum and Instruction/Literacy Studies

Morgantown, West Virginia

2015

Keywords: electronic portfolio, medical students, reflection

Copyright 2015 Carrie A. Calloway 


\begin{abstract}
A Qualitative Study of Medical Student Perceptions of the West Virginia University School of Medicine's Competency-Based Electronic Portfolio System's Design and Implementation
\end{abstract}

Carrie A. Calloway

The West Virginia University School of Medicine (WVU SoM) created and implemented medical student electronic portfolios in the 2012-2013 academic year as a means to stimulate self-reflection and life-long learning, document competency attainment using both formative and summative assessments of performance and facilitate career counseling and advising. Though existing research explores the benefits and challenges of electronic portfolios in medical education, few studies investigate them from the medical student perspective. This phenomenological qualitative research study examined medical student perceptions - through their stories of the electronic portfolio system as a tool for documenting and reflecting on performance - in order to better understand how electronic portfolios can be effectively designed and integrated in the medical doctor degree curriculum. Convenience sampling was used to recruit medical students $(\mathrm{n}=15)$ in years two and three of the curriculum for in-depth, semistructured interviews to discover student views, experiences and recommendations regarding the use of the portfolio in their medical education. A document analysis of student portfolio contents and structure was conducted as a means to corroborate findings from the interview process (method triangulation). Interviews with graduate medical education residents $(n=5)$ were also used in order to provide a retrospective view and to triangulate with findings obtained from medical student interviews (source triangulation). Inductive content analysis using a digital card sort was employed to uncover common themes and patterns in participants' lived experiences and a narrative description of findings was reported. The findings revealed that students considered the convenience of the electronic portfolio as an advantage, along with the capability of the electronic portfolio to store and organize documentation and evidence of competency. Medical students also credited the electronic portfolio for aiding them in tracking and selfcorrecting performance and behaviors based on evidence contained within the electronic portfolio. Five conclusions emerged from the findings, including: (1) convenient storage and organization promoted self-assessment of performance, (2) multiple barriers limited students access, and accordingly, the extent to which they embraced the tool; (3) electronic portfolio contents and reflection activities sufficiently demonstrated academic performance, but inadequately demonstrated personal growth and development; (4) limited training opportunities for electronic portfolio use and purpose inhibited student engagement; and (5) electronic portfolio integration and involvement minimally engaged students from all years of the curriculum. Future research should focus on (1) the development of open-ended reflection prompts that both prepare students for residency and aim to understand students as individuals, (2) effective integration strategies that enhance medical student engagement with portfolio activities and reflective practice during pre-clinical education and (3) the creation of training modules and mentoring or advising programs that will aid medical students in meaningful application of the electronic portfolio for residency preparation and reflection on learning. 


\section{Table of Contents}

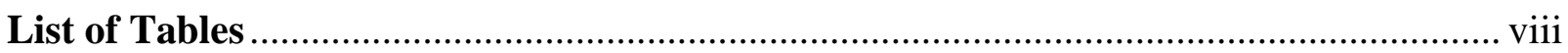

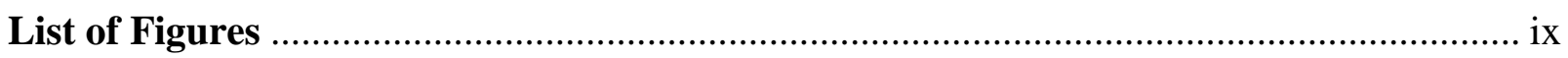

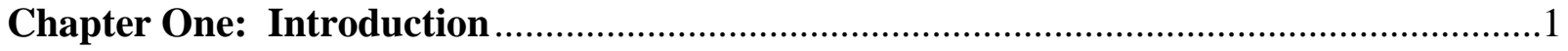

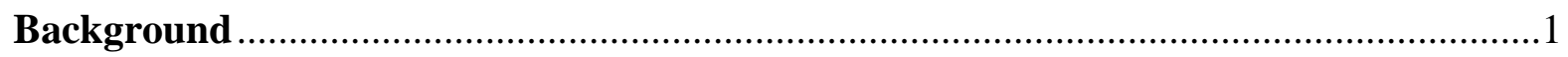

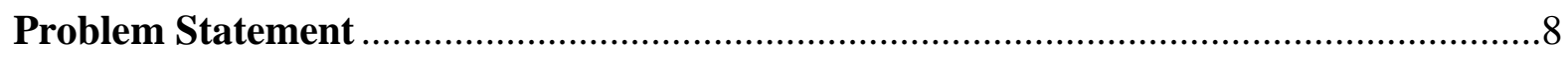

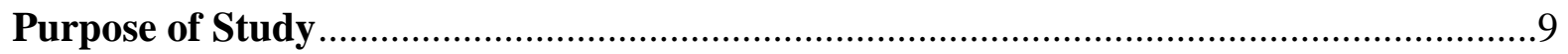

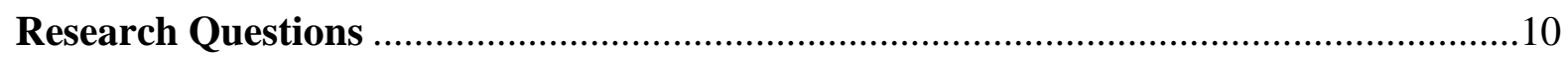

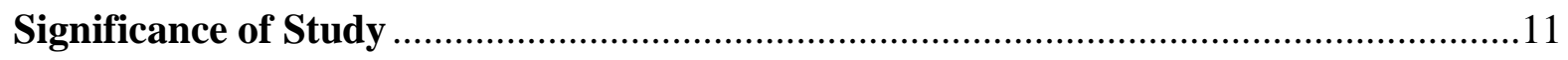

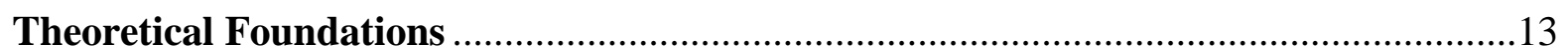

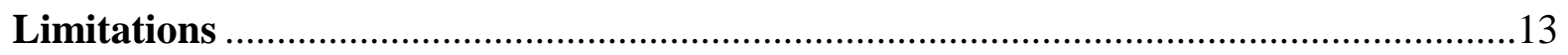

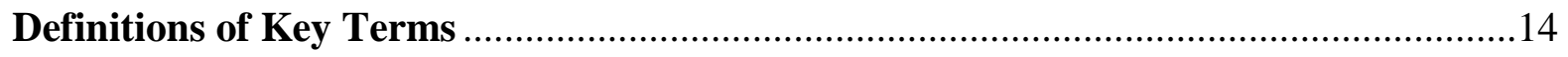

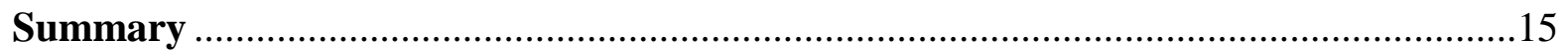

Chapter Two: Review of the Literature ....................................................................... 16

Procedures for the Literature Review .................................................................. 16

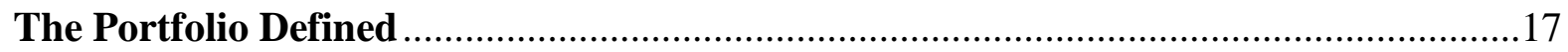

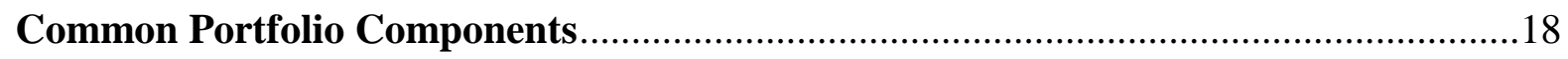

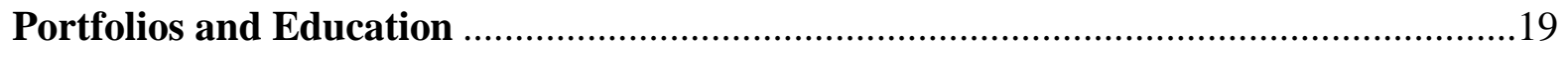

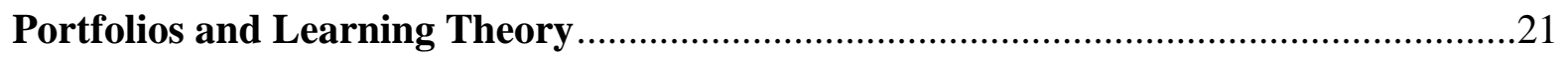

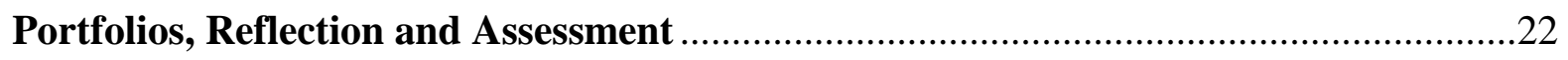

Portfolios for Career Planning and Advising ......................................................26

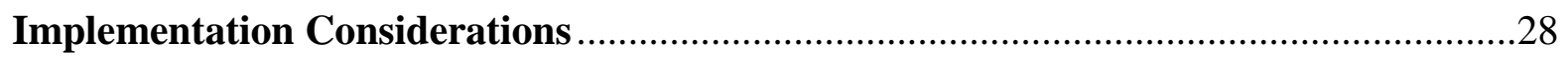

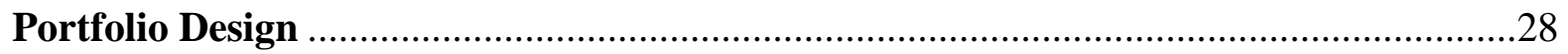


Benefits, Disadvantages and Challenges

Summary

Chapter Three: Methodology

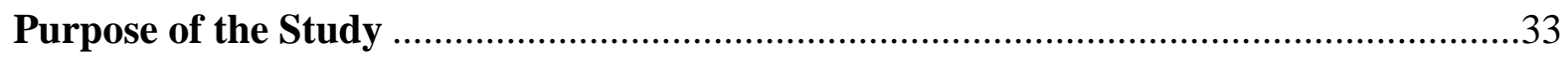

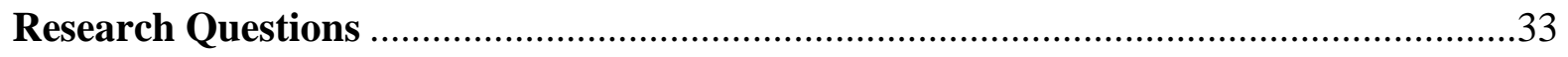

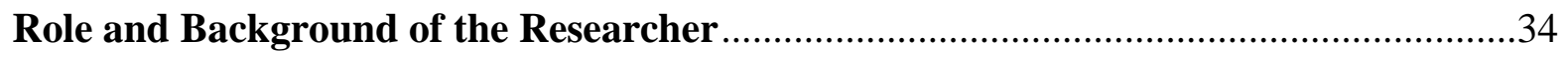

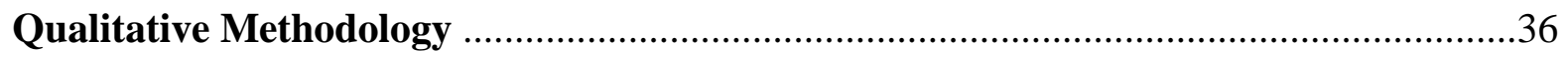

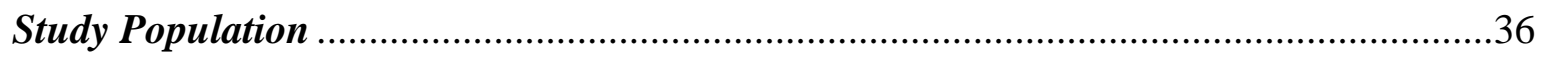

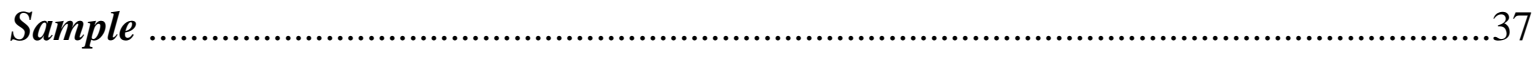

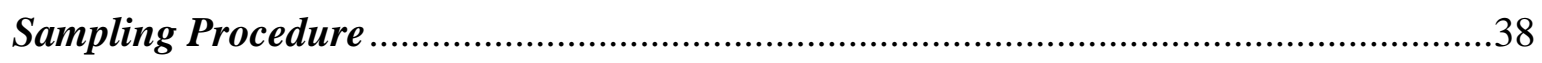

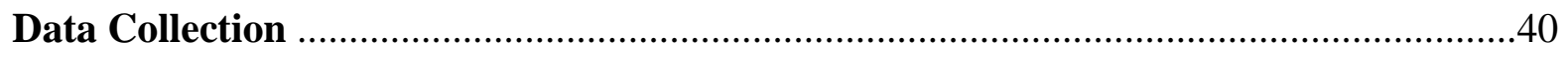

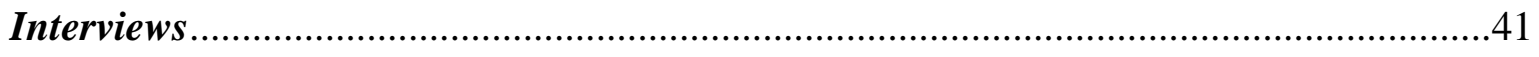

Existing portfolio structure and content ………………...........................................43

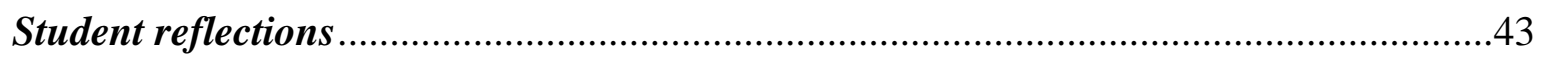

Researcher's personal reflections...............................................................................4

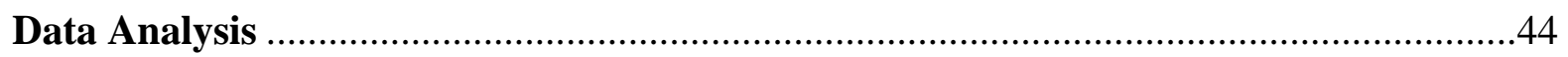

Interviews

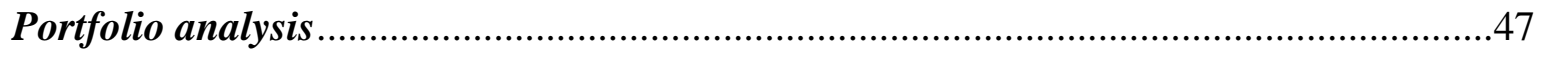

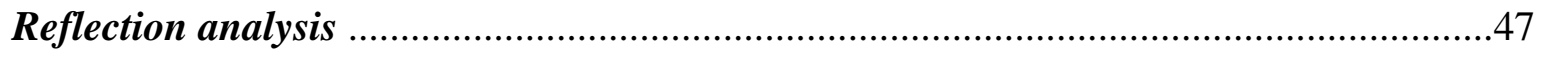

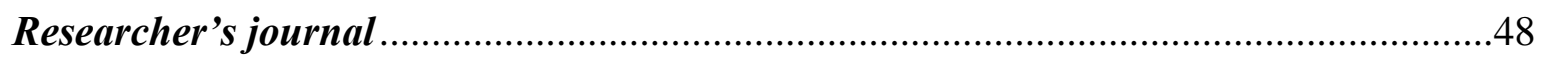

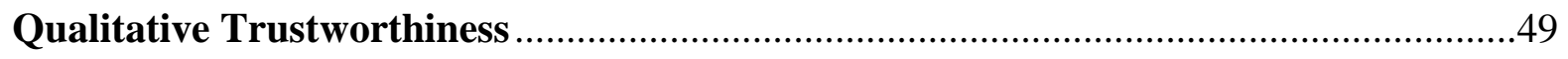

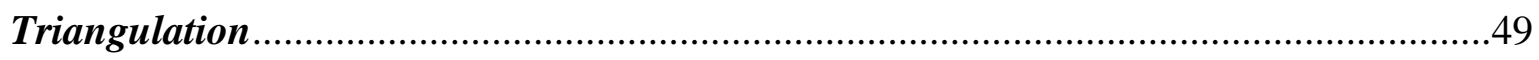

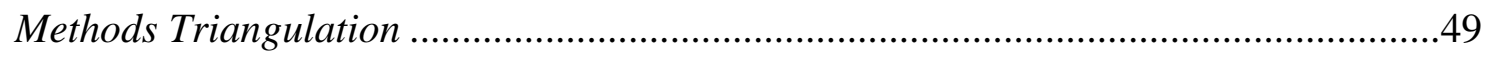




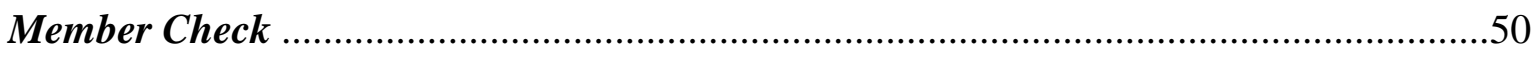

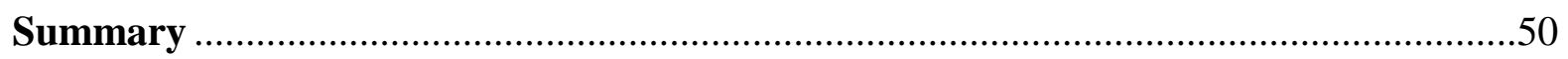

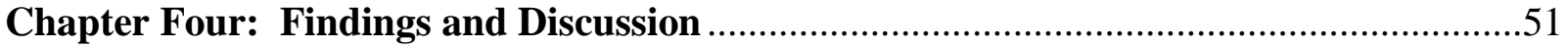

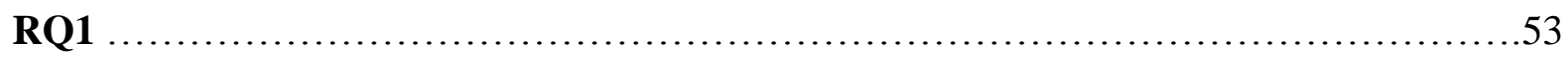

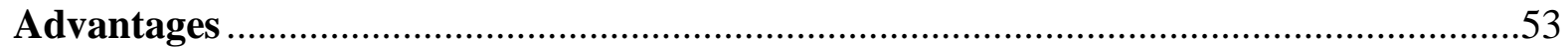

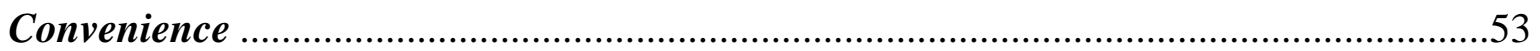

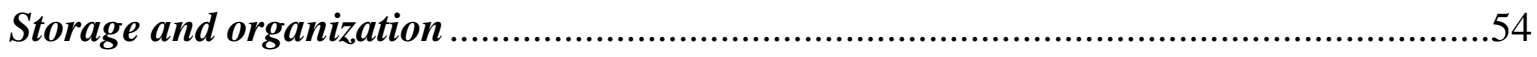

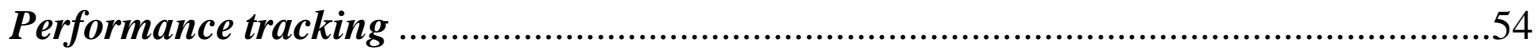

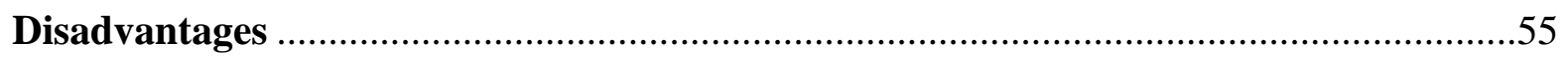

Interface accessibility and user friendliness .......................................................55

Limited access on mobile devices ........................................................................56

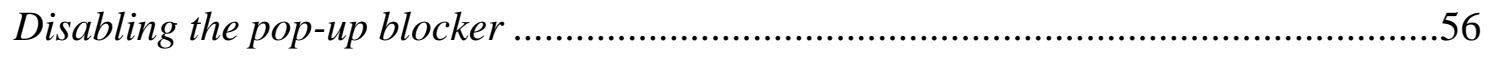

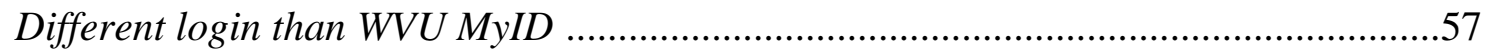

Confusing interface for uploading documents and entering reflective exercises ..........57

Knowledge of core competencies and use and purpose of electronic portfolio ..............58

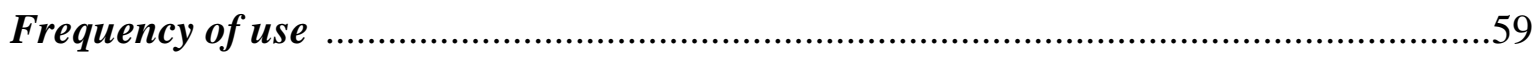

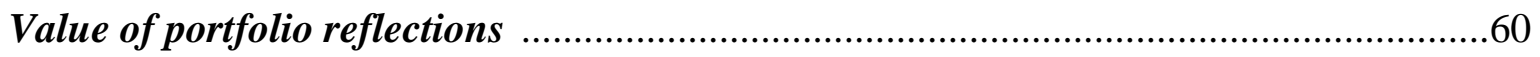

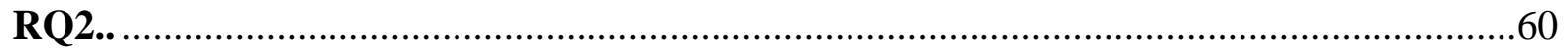

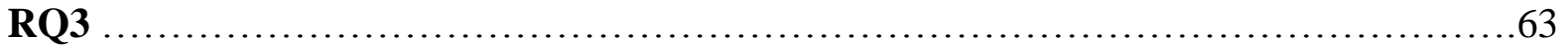

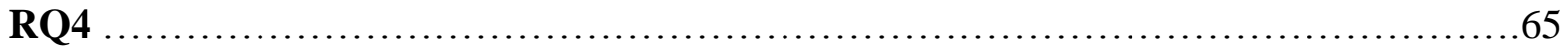

Medical students' attitudes and perceptions about act/purpose of reflection .................65

Alignment of reflections with program learning objectives ........................................70 
RQ5

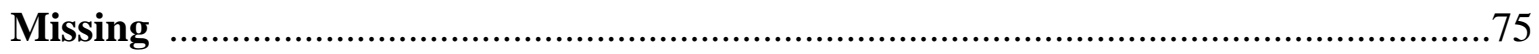

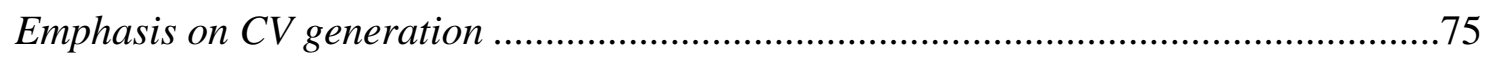

Focus on personal growth and character ……….......................................................75

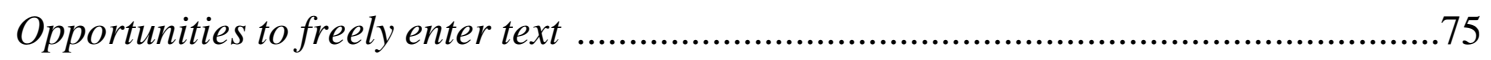

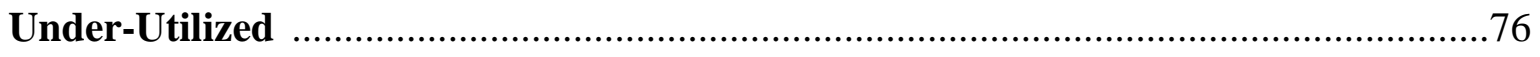

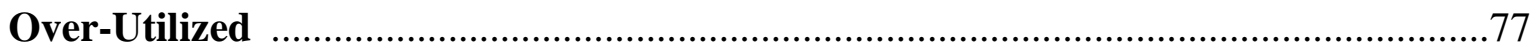

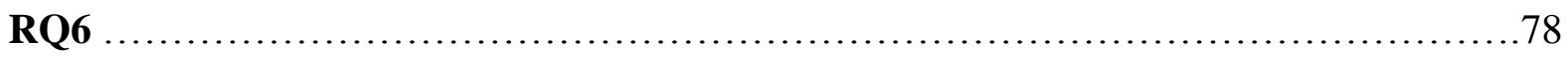

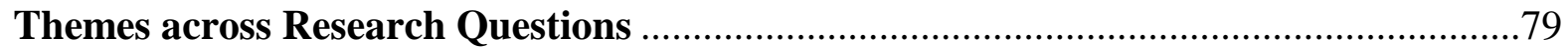

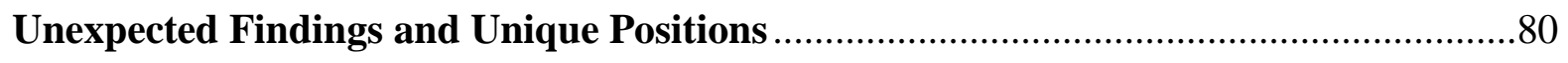

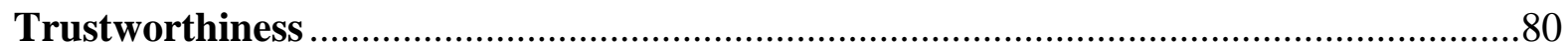

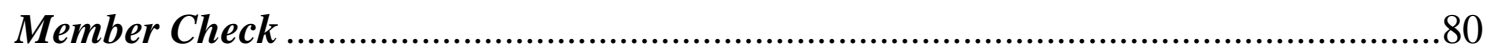

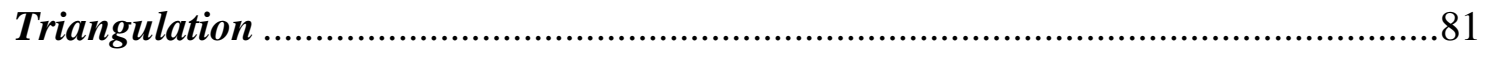

Chapter Five: Conclusions, Implications and Recommendations ...................................8

Summary

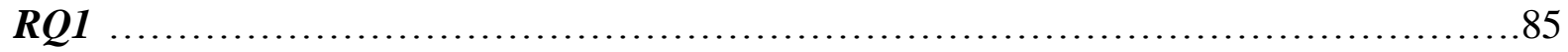

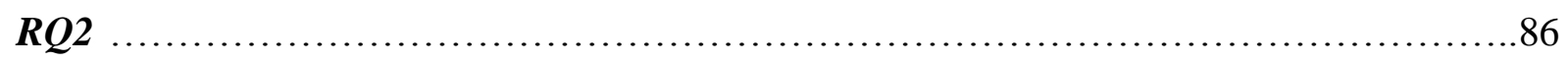

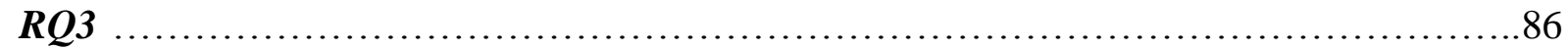

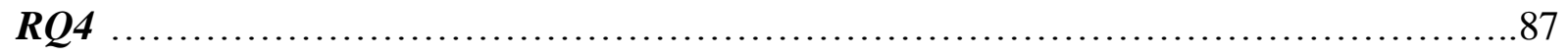

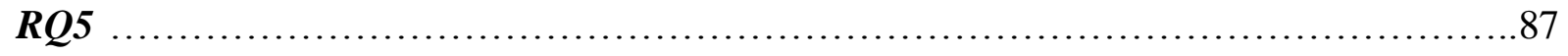

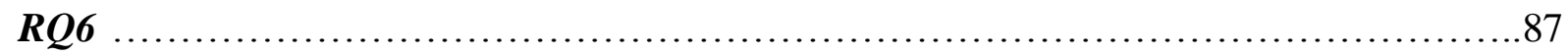

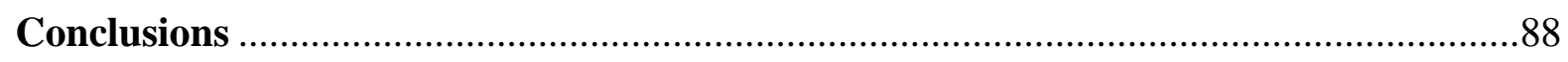

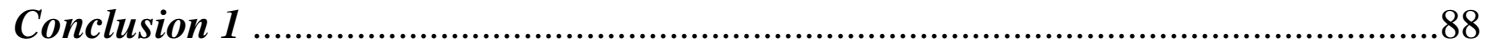




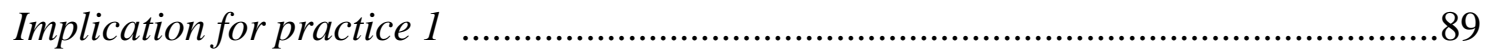

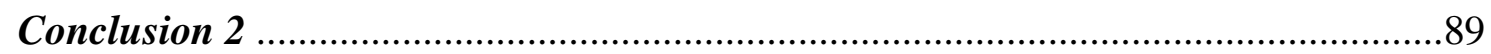

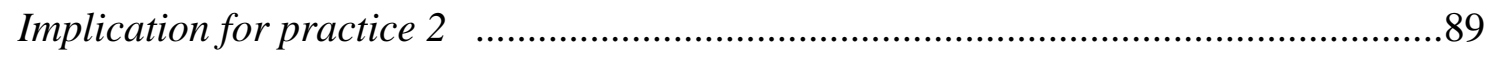

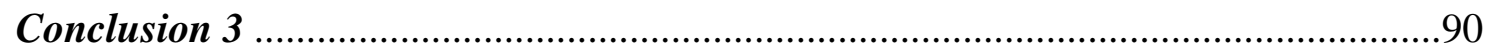

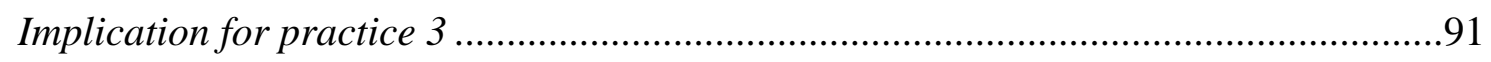

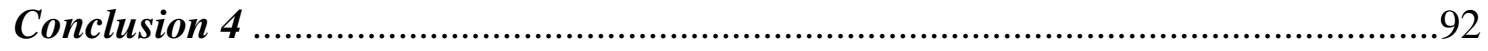

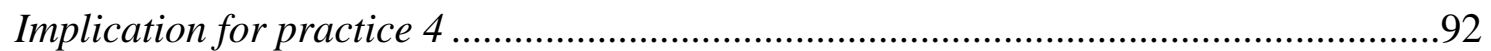

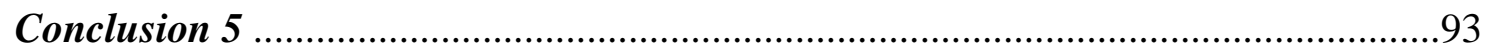

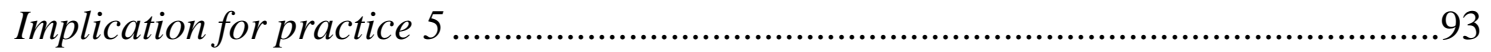

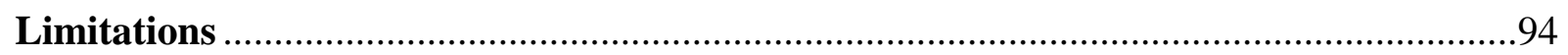

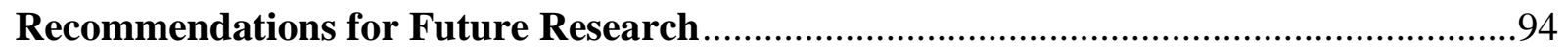

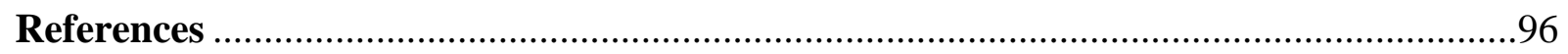

Appendix A: WVU SoM Program Learning Objectives ......................................... 104

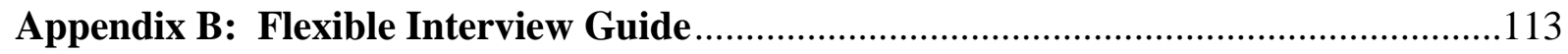

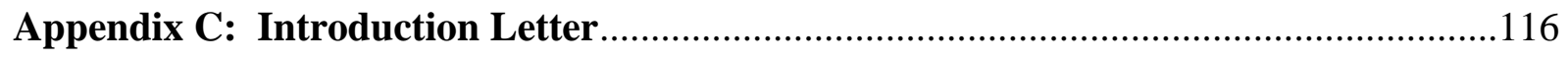

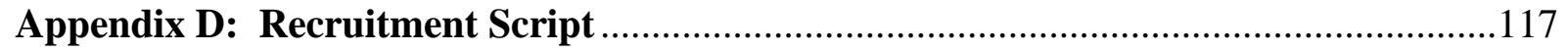

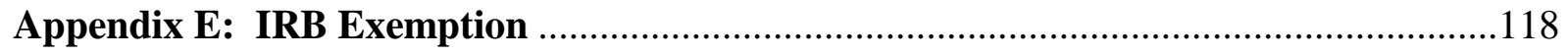

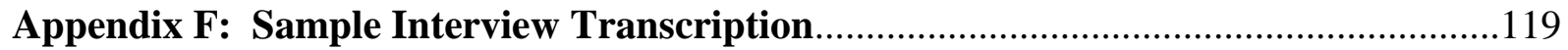




\section{List of Tables}

Table 1: Organization of electronic portfolio contents...............................4

Table 2: Reflection prompts..................................................

Table 3: Breakdown of student and resident participants............................... 38

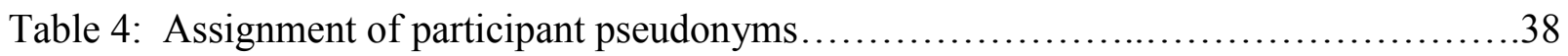

Table 5: Alignment of research and interview questions..............................40 


\section{List of Figures}

Figure 1. Congruency between portfolio goals and program learning objectives.................2

Figure 2. A screenshot of the portfolio design........................................

Figure 3. Step-by-step illustration for editing the WVU SoM electronic portfolio................6

Figure 4. Summary data collection process .......................................41

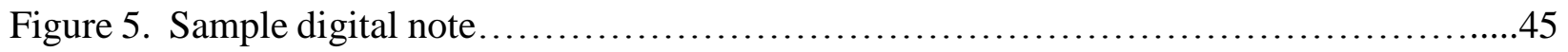

Figure 6. Sample of merged digital notes..........................................46

Figure 7. Summary of data analysis procedures................................................................48 


\section{Chapter One: Introduction}

The West Virginia University School of Medicine (WVU SoM) implemented electronic portfolios in the fall semester of 2012. The following phenomenological research study aims to understand second and third year medical students' perceptions of the design and implementation of the electronic portfolio for the documentation of and reflection on learning and performance. The succeeding pages detail the purpose, significance and theoretical underpinnings for the research, concluding with study limitations and relevant defined terms.

\section{Background}

In 1998, the Accreditation Council for Graduate Medical Education (ACGME) began its Outcome Project initiative which requires that resident physicians be competent in six domains: patient care, medical knowledge, professionalism, communication and interpersonal skills, practice-based learning and improvement, and systems-based practice (Swing, 2007). To prepare students for graduate medical education training, the WVU SoM adopted the ACGME's Outcome Project initiative when revising its Program Learning Objectives (PLOs) for the Medical Doctor (MD) degree (Appendix A). The PLOs drive the MD degree curriculum and guide the formative and summative assessment of student learning and development.

In medical education, the development of valid and reliable documentation and assessment tools for competency-based performance has proven to be a challenging task, with electronic portfolios at the forefront of considerations. Consequently, the WVU SoM approved the creation of electronic student learning portfolios to document competency, facilitate reflection and demonstrate progress in the medical education curriculum. During the spring term of 2012, the electronic medical student portfolios were created for implementation with the class of 2016. The resulting electronic portfolio established a platform for students to showcase 
competence in the six domains while simultaneously serving as an assessment tool for administrators, advisors, staff and students to document and monitor performance progression, offer constructive feedback, and facilitate career counseling and advising.

Unlike traditional systems where the learner both creates and maintains their own electronic portfolio, the system introduced by the WVU SoM was created for the student and is frequently populated with much of their performance reports in an effort to not distract from the four primary goals of its design: (1) to stimulate self-reflection, (2) to provide feedback on student performance and professionalism, (3) to document student achievement, and (4) to facilitate advising and career planning. As Figure 1 illustrates, portfolio components are connected to the six core competency domains and are intended to confirm compliance with the

\section{WVU SoM PLOs.}

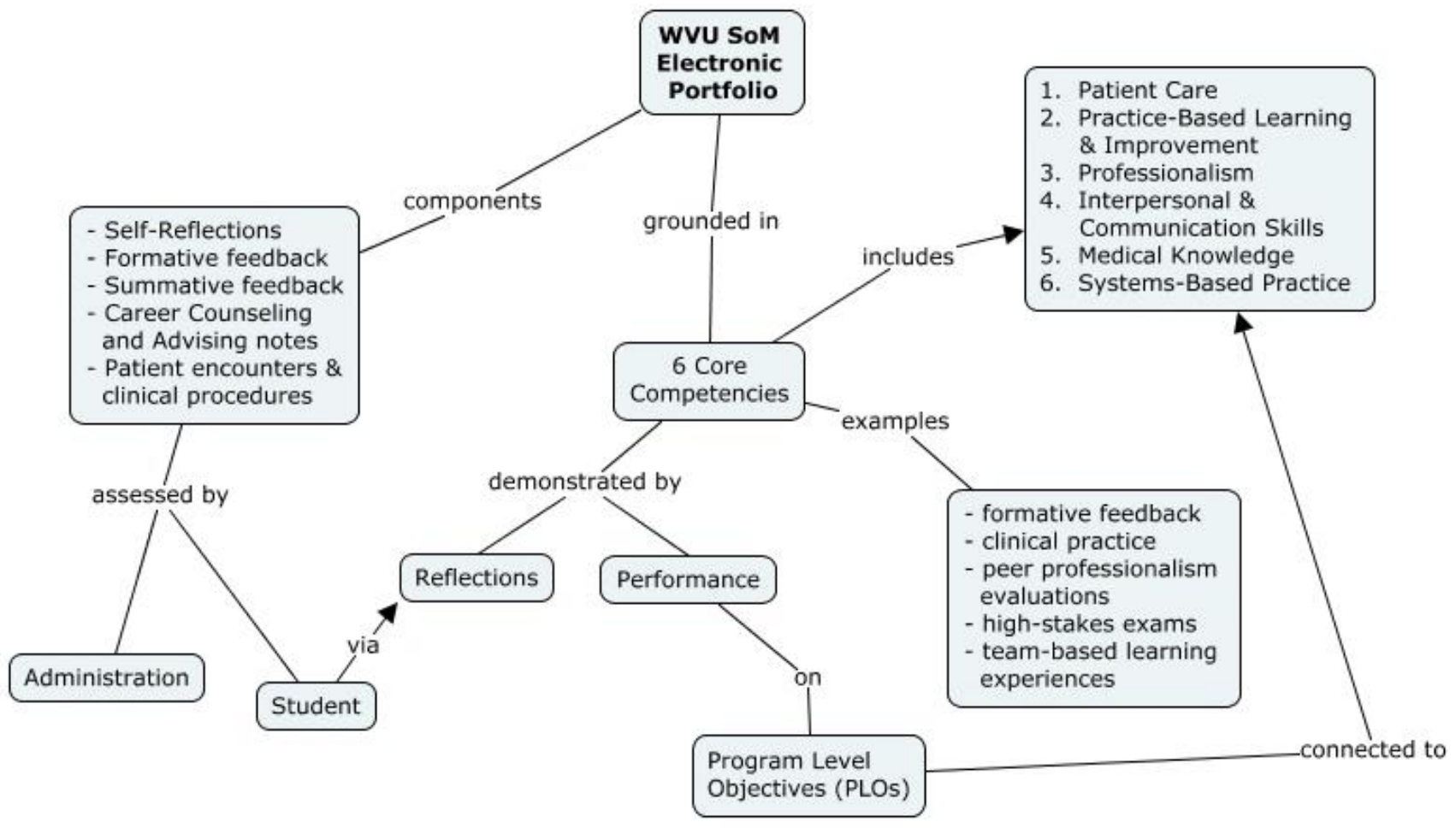

Figure 1. A graphic representation of the congruency between the goals of the portfolio and the components and tasks required to meet those goals. 
The electronic portfolio's design is structured to tell a story of the student's personal and professional growth over time. For example, a chronological listing of raw and percentile performance data across the first three years of the curriculum aims to assist administration and students in the identification of content areas where the student exhibits strength and weakness. Along with evidence of achievement, the medical student electronic portfolio houses other artifacts that are updated by either free text entry or document upload, such as awards and honors, advising notes and self-reflections. Table 1 provides a summarized listing of the folders and associated contents in the electronic portfolio in conjunction with the targeted core competencies for each. 
Table 1

Organization of Electronic Portfolio Contents

\begin{tabular}{|c|c|c|}
\hline Folder Name & Contents & Alignment with 6 Core Domains \\
\hline About Me & $\begin{array}{l}\text { Student biographic data, student } \\
\text { reflection on why they chose a career } \\
\text { and medicine }\end{array}$ & Interpersonal \& Communication Skills \\
\hline $\begin{array}{l}\text { Counseling and Career } \\
\text { Advising }\end{array}$ & $\begin{array}{l}\text { Curriculum vitae, professional goal } \\
\text { statement, and advising and counseling } \\
\text { notes }\end{array}$ & NA \\
\hline Professionalism & Peer evaluation reports & Professionalism \\
\hline Medical Knowledge & $\begin{array}{l}\text { Faculty evaluations of student's medical } \\
\text { knowledge }\end{array}$ & Medical Knowledge \\
\hline $\begin{array}{l}\text { Interpersonal \& } \\
\text { Communication Skills }\end{array}$ & Publications, presentations, and research & Interpersonal \& Communication Skills \\
\hline $\begin{array}{l}\text { Practice-Based Learning } \\
\& \text { Improvement }\end{array}$ & Self-reflections & Practice-Based Learning \& Improvement \\
\hline Patient Care & $\begin{array}{l}\text { Clinical procedure and patient encounter } \\
\operatorname{logs}\end{array}$ & Patient Care \\
\hline Systems-Based Practice & $\begin{array}{l}\text { Documentation on OSHA and HIPPA } \\
\text { training }\end{array}$ & Systems-Based Practice \\
\hline Academic Year 1 & Formative and summative assessment & Medical Knowledge; Patient Care; \\
\hline Academic Year 2 & data (narrative evaluations) documenting & Professionalism; Practice-Based Learning \\
\hline Academic Year 3 & achievement of program competency & \& Improvement; Interpersonal \& \\
\hline Academic Year 4 & domains and learning objectives & $\begin{array}{l}\text { Communication Skills; Systems-Based } \\
\text { Practice }\end{array}$ \\
\hline NBME Score Reports & $\begin{array}{l}\text { High-stakes exams score reports (e.g., } \\
\text { NBME shelf score reports, Step } 1 \text { score } \\
\text { report, etc.) }\end{array}$ & Medical Knowledge \\
\hline CAPS Documentation & Academic performance reports & NA \\
\hline Secure Documents & Other documents important for tracking & NA \\
\hline $\begin{array}{l}\text { Awards, Honors and } \\
\text { Recognitions }\end{array}$ & $\begin{array}{l}\text { Committee memberships, scholarships, } \\
\text { internships, etc. }\end{array}$ & NA \\
\hline Rebuttals & $\begin{array}{l}\text { Opportunity for students to refute } \\
\text { evaluations }\end{array}$ & NA \\
\hline MSPE & $\begin{array}{l}\text { The students final Medical Student } \\
\text { Performance Evaluation used when } \\
\text { applying for residency }\end{array}$ & $\begin{array}{l}\text { Medical Knowledge; Patient Care; } \\
\text { Professionalism; Practice-Based Learning } \\
\text { \& Improvement; Interpersonal \& } \\
\text { Communication Skills; Systems-Based } \\
\text { Practice }\end{array}$ \\
\hline
\end{tabular}


Figure 2 shows a screenshot of the portfolio homepage, including the folder structure along with a description of the goals of the portfolio. The design is intended to be simple in an effort to minimize student frustration with utility and navigation.

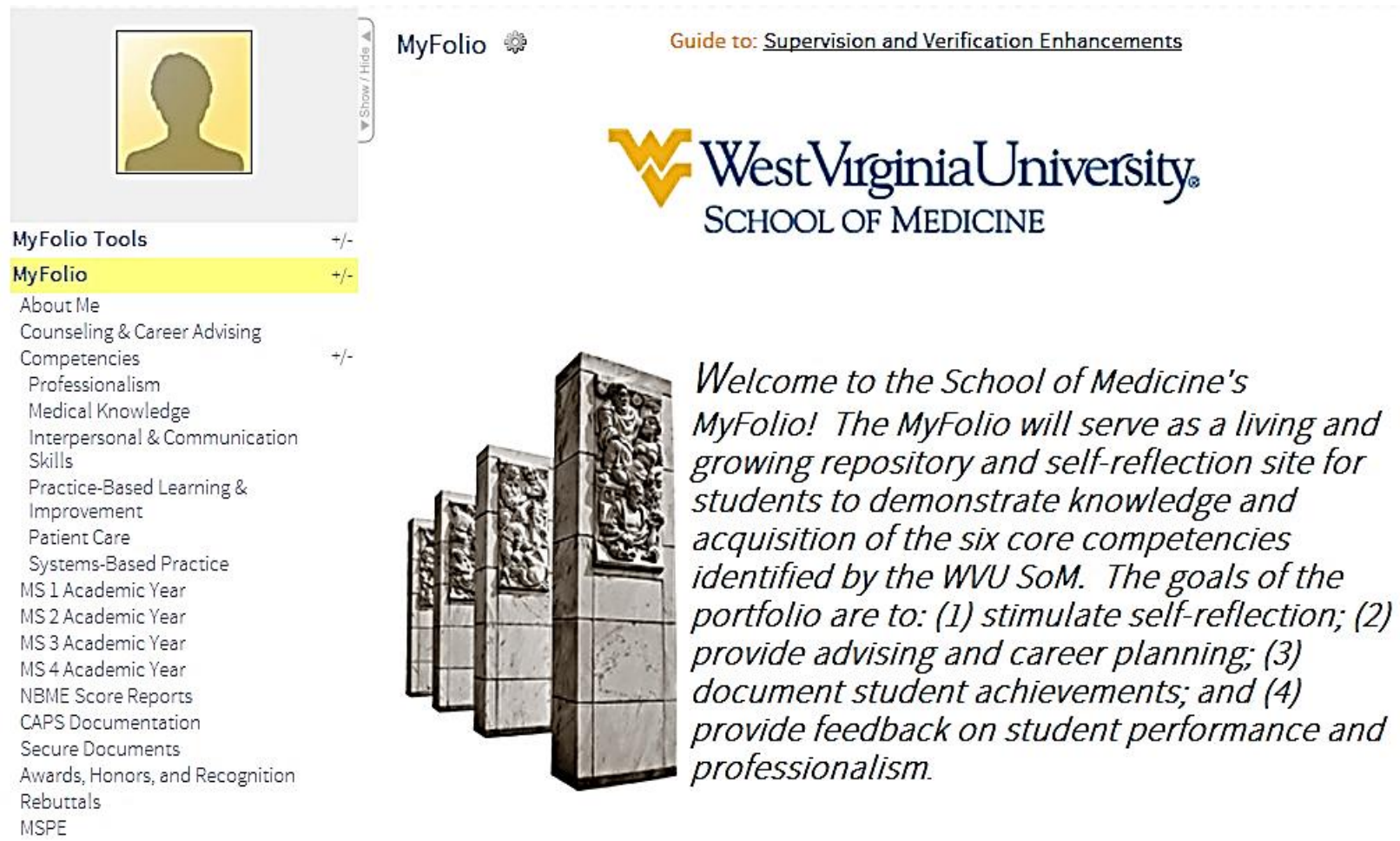

Figure 2. A screenshot of the homepage of the WVU SoM electronic portfolio illustrating folder organization and structure, as well as introduction to the purpose and goals of the portfolio.

To populate a grid or table in the electronic portfolio template, medical students or staff must click on the edit icon (image of pencil and paper) in the designated areas. For example, as shown in Figure 3, to upload a curriculum vitae to the portfolio the user must select the icon on the appropriate grid or table row, which will open a popup window where a predetermined form with required fields can be completed. 

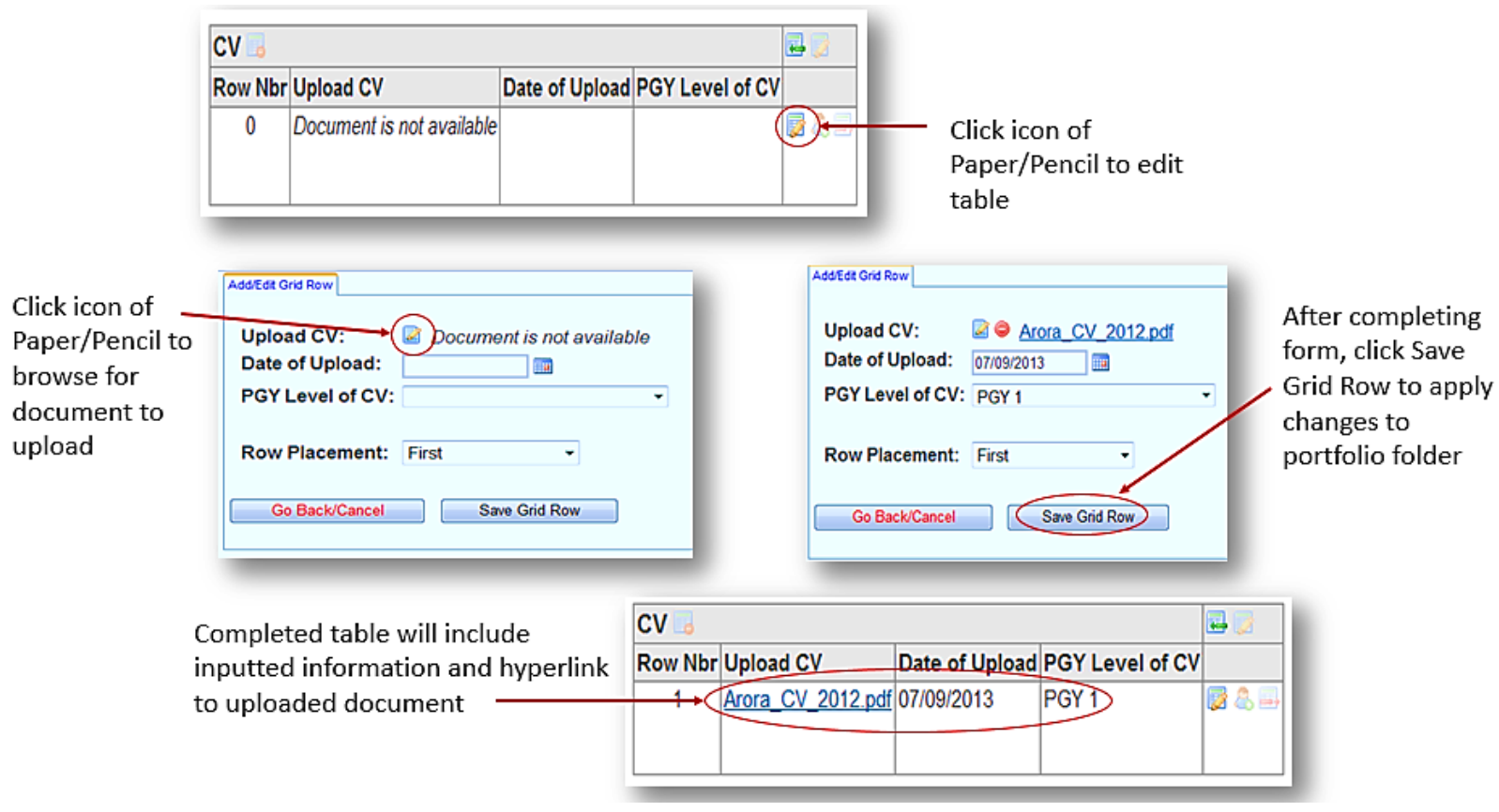

Figure 3. Step-by-step illustration of electronic portfolio population.

From the administrator perspective, the electronic portfolio provides a historical record of performance and a platform from which students can continuously evaluate growth over time. For students, the premise is to facilitate life-long learning habits through a framework of reflection activities designed to support their recognition of cognitive and behavioral strengths and weaknesses and to encourage deliberate actions for continued success and improvement.

Though not yet fully utilized, the interactivity of the portfolio system permits students to assign mentors or career counseling advisors access to the contents of their electronic portfolio so that they can analyze performance indicators, note evidence of satisfactory performance and make recommendations for graduate medical education career pathways. Moreover, both mentors and administrators can use the electronic portfolio to formulate suggestions and strategies for improvement or remediation in areas deemed deficient. The electronic portfolio system has the capability to alert mentors and students when modifications or new information is updated in or uploaded to the portfolio. Such immediate notification is anticipated to inspire 
active participation and communication within the electronic portfolio environment once fully employed.

Planned activities constructed within the portfolio are designed to nurture student selfassessment and reflection. One example of how the electronic portfolio is used to facilitate student reflection in alignment with PLOs is in the area of practice-based learning and improvement. Practice-based learning and improvement activities within the WVU SoM portfolio require that students reflect on self-directed learning experiences, as well as documented performance on high stakes National Board of Medical Examiners (NBME) subject exams. The intention of the reflection activities is to help students identify gaps in learning and articulate a blueprint for improvement. Secondary activities, such as the development of a professional goal statement and curriculum vitae, are also supported by continued selfassessment and reflection activities, as well as advising notes recorded in the portfolio.

The structure of the current reflection prompts permits the student to progressively target various competency and career planning goals over the course of their professional preparation. For instance, the students are asked to first reflect on their selective experience (self-directed study) and later they are asked to reflect on their performance on NBME exams (identification of strength and weakness). The reflection activities developed to date are presented in Table 2. 
Table 2

Reflection prompts constructed within the electronic portfolio to support competency development over time.

\begin{tabular}{|c|c|c|}
\hline $\begin{array}{c}\text { Medical } \\
\text { School } \\
\text { Level }\end{array}$ & Sample Reflection Prompts & $\begin{array}{l}\text { Targeted Competency and/or } \\
\text { Portfolio Component Addressed }\end{array}$ \\
\hline $\begin{array}{l}\text { Entering } \\
\text { MS1 } \\
\text { students }\end{array}$ & $\begin{array}{l}\text { On the Careers in Medicine website, you completed the } \\
\text { Medical Specialty Preference Inventory (MSPI-R) and the } \\
\text { Physician Values in Practice Scale (PVIPS). What medical } \\
\text { specialties are you interested in learning more about? What } \\
\text { have you done or plan to do to explore these specialties, such } \\
\text { as participate in student interests groups and review the } \\
\text { "Spotlight on Advisors" reflections? }\end{array}$ & Career Counseling and Advising \\
\hline $\begin{array}{l}\text { Entering } \\
\text { MS2 } \\
\text { students }\end{array}$ & $\begin{array}{l}\text { Reflecting on your first-year grades and narratives and your } \\
\text { summer experiences, what are your goals as a second year } \\
\text { student? How will achieving your goals help you pursue } \\
\text { career interests? }\end{array}$ & $\begin{array}{l}\text { Medical Knowledge; Practice- } \\
\text { Based Learning and Improvement; } \\
\text { Career Counseling and Advising }\end{array}$ \\
\hline $\begin{array}{l}\text { Entering } \\
\text { MS3 } \\
\text { students }\end{array}$ & $\begin{array}{l}\text { Reflecting on your second-year grades and narratives and } \\
\text { Step } 1 \text { performance, what are your goals as a third-year } \\
\text { student? What resources will you use to inform your career } \\
\text { development, such as Careers in Medicine web } \\
\text { resources? How will achieving your goals help you pursue } \\
\text { career interests? }\end{array}$ & $\begin{array}{l}\text { Medical Knowledge; Practice- } \\
\text { Based Learning and Improvement; } \\
\text { Career Counseling and Advising }\end{array}$ \\
\hline $\begin{array}{l}\text { Entering } \\
\text { MS4 } \\
\text { students }\end{array}$ & $\begin{array}{l}\text { Reflecting on your third-year grades, narratives and clinical } \\
\text { experiences, what are your goals as a fourth-year } \\
\text { student? How will achieving your goals help you pursue } \\
\text { career interests? }\end{array}$ & $\begin{array}{l}\text { Medical Knowledge; Practice- } \\
\text { Based Learning and Improvement; } \\
\text { Career Counseling and Advising; } \\
\text { Patient Care }\end{array}$ \\
\hline
\end{tabular}

Upon graduation from the MD degree program, students can export their electronic portfolio to a zipped file folder and maintain and continue to build upon their record of performance throughout their professional career. A prime objective is to help students develop the skills needed for continued personal and professional growth along the continuum of their professional training and practice.

\section{Problem Statement}

Medical schools are increasingly adopting electronic portfolios as a means to assess competency attainment and promote student self-reflection despite the amount of time required to successfully develop and implement them in the curriculum. While there is a growing body of research that addresses the impacts of electronic portfolio initiatives for medical student 
professional growth and development (Dannefer \& Henson, 2007; Izatt, 2007; Snadden \& Thomas, 1998), few studies examine medical students' perceptions of their use in their own words. Student feedback on the design, utilization and integration of the electronic portfolio in the medical doctor degree program is limited, yet critical to ensuring successful and meaningful application.

\section{Purpose of Study}

The purpose of this phenomenological research study is to describe, in their own words, the perceptions of medical students toward the use of an electronic portfolio for learning, including the impact its design and implementation has on their ability to self-reflect, as well as the overall effectiveness it might have on their competency development and career preparedness. In order to discover innovative strategies for integrating activities that will help students self-direct learning, display theoretical and experiential knowledge, and substantiate that learning competencies have been met, the researcher will consider how the electronic portfolio design and embedded activities can initiate development via documentation of and reflection on learning experiences.

Student perceptions of electronic portfolio activities and components can help shape how the medical education community addresses the increased demands for assessing students' readiness to practice medicine. There is a shortage of research examining the medical student perception of the use of electronic portfolios to document competency attainment, as well as how the design and integration influences learning. The research that does exist regarding student perceptions primarily employs a quantitative approach offering limited insights into their lived experiences using an electronic portfolio. To improve utilization and understanding of the 
influence electronic portfolio components and tasks have on competency attainment, medical student perception is crucial.

Though research reveals that the amount of time invested in portfolio development is a disadvantage for implementation, it is not compelling evidence to discredit its use in the MD degree curriculum. What other disadvantages can students identify based on their experiences? Does the portfolio prohibit students from experiential learning due to its rigid structure? Does it prevent opportunities for true reflective practice due to its formal and/or electronic nature? These are areas missing in the research that will be explored in this study.

\section{Research Questions}

The central research question is concerned with how to design and integrate electronic portfolios in the medical doctor degree curriculum so that the learner experience is captured in a way that minimizes frustration, yet maximizes reflective practice and documentation of competency attainment. In order to advance understanding of the impacts electronic portfolio design and integration has on student learning and competency attainment, the following research questions will guide the study:

1. What are the advantages and disadvantages of using electronic portfolios to document and self-assess competency and performance as perceived by medical students? (Interview)

2. In what ways do students feel the portfolio components will help them prepare for and identify a suitable residency program? (Interview)

3. How does the structure and organization of the portfolio influence how medical students engage with portfolio activities and self-monitor performance and competence? (Interview) 
4. How do student attitudes and perceptions (elicited from the interviews) about the act/purpose of reflecting in the electronic portfolio compare to the content and alignment of their reflections to the corresponding Program Learning Objectives? (Document analysis and interview)

5. According to the researcher and medical students, which electronic portfolio components are missing and/or over/under utilized in the electronic portfolio that limits their engagement in documenting competency attainment and reflective practice? (Interview and document analysis)

6. What can be gleaned from graduate medical education residents when asked to retrospectively reflect on electronic portfolio components they feel will be beneficial to a medical student? (Interview)

To strengthen findings, the researcher will examine the portfolio structure and students' reflections for content congruence with the narrative data obtained during semi-structured interviews. Interviews with medical residents will also be conducted to support findings from medical student interviews regarding beneficial components of the electronic portfolio. The results will help to better understand how electronic portfolio design and utilization can impact the ways students engage with their portfolio during their medical training and how components can be better structured to encourage ongoing reflection and skill development.

\section{Significance of Study}

Over the past two decades reform in medical education has taken shape to prepare medical students for the life-long learning demands of the practicing physician who faces an ever changing field dominated by advancing technologies, cultural influences and professional interactions. The latest medical education paradigm has shifted from knowledge acquisition to 
knowledge application, from emphasis on summative assessment to more formative measures, and from a teacher-driven to learner-centered curricular experience. In short, medical education has evolved from a structure- or process-based educational program to an outcomes- or competency-based framework (Carraccio, Wolfsthal, Englander, Ferentz, \& Martin, 2002).

Medical students are no longer being assessed using a single objective measure; today's medical students are benefiting from multi-source assessments that provide not only normreferenced criteria (e.g., performance on NBME subject exams), but also evaluative feedback on their skills, attitudes and behaviors. In order to capture the learner's experience and engage them in reflective practice, many institutions have adopted the electronic portfolio. The central question concerns how we design an electronic portfolio so that the learner's experience is captured in a way that promotes reflective practice and competency attainment, thus preparing them for their next phase of training.

Having worked closely with administrators, faculty and staff, I am knowledgeable of the benefits and challenges for implementing the electronic portfolios from their perspectives; however, the voices of the students have yet to be heard. The research study will help identify areas of need in portfolio design and implementation and will help to make recommendations for future development and utilization based on student experiences using the WVU SoM portfolio system thus far. The findings will aid other institutions in the development of comprehensive portfolio systems that keep the learners' needs in the forefront so that the goal of developing and maintaining reflective skills throughout their careers is not abandoned once the student graduates from the medical doctor degree program. 


\section{Theoretical Foundations}

The research plan is based on the interpretivist paradigm. The interpretivist paradigm emerged from the philosophy of Edmund Husserl's phenomenology (Mertens, 2005) and aims to understand "the world of human experience" (Cohen \& Manion, 1994, p.36). The interpretivist researcher therefore relies on the "participants' views of the situation being studied" (Creswell, 2003, p.8) and distinguishes how their own experiences and background may impact the research. In essence, the researcher works to acknowledge, reconstruct and understand subjective experiences (Goldkuhl, 2012).

In qualitative phenomenological research "all meaning is situated in a particular perspective or context, and because different people...often have different perspectives and contexts," such methods permit the researcher to gain richer insights into a phenomenon of interest (Gay, Mills, \& Airasian, 2012,p. 7). The use of a phenomenological research design is appropriate for this study since the focus is to garner medical students' perceptions on the use of electronic portfolios (phenomenon experienced) in the medical school curriculum (Gay et al., 2012). As such, the researcher will better understand how electronic portfolios can effectively be used to stimulate self-reflection, document competency attainment and facilitate career counseling and advising through the medical students' personal stories, and simultaneously uncover the optimal design structure and integration methods of electronic portfolios for the general medical student population.

\section{Limitations}

The main limitation to the study is time. It is not within the scope of this study to examine the long-term implications of electronic portfolio design and implementation on student perceptions as they progress to residency education and on to a career as a practicing physician. 
To abate this limitation, graduate medical residents $(n=5)$ will be interviewed and their responses will be triangulated with the findings from medical students. Another potential limitation is the use of data from students who selected to participate in the study. The research participants may also have selective memory about the use of their portfolios since some questions may pertain to experiences occurring in previous years when their perceptions were influenced by alternative variables. A final limitation of the study is the potential bias of the researcher who designed and implemented the electronic portfolio. The limitation will be overcome through the use of neutral, open-ended interview questions and the use of a researcher's journal to record personal reactions and observations.

\section{Definitions of Key Terms}

Accreditation Council for Graduate Medical Education (ACGME): private organization that oversees graduate medical education accreditation (https://www.acgme.org/acgmeweb/tabid/116/About.aspx)

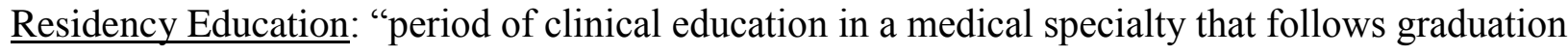
from medical school, and prepares physicians for the independent practice of medicine" (https://www.acgme.org/acgmeweb/tabid/116/About.aspx).

Program Learning Objectives (PLOs): the expected program level outcomes that students must master before graduating from the WVU SoM Medical Doctor (MD) degree program National Board of Medical Examiners (NBME): "independent, not-for-profit organization that serves the public through its high- quality assessments of healthcare professionals" (http://www.nbme.org/about/index.html) 
Committee on Academic and Professional Standards (CAPS): A committee of the WVU SoM that semi-annually assesses student performance and professionalism to determine their readiness for progression to the next level of training.

\section{Summary}

The WVU SoM's electronic portfolio was designed and implemented as a tool to help students document performance and reflect on learning experiences. The phenomenological study will uncover students' perceptions of the utility and organization of the portfolio in an effort to enhance portfolio design and integration in the MD degree curriculum. 


\section{Chapter Two: Literature Review}

The use of electronic portfolios as instruments for documentation, assessment and reflection is recognized in the literature (Barrett, 2006; Driessen, Van Tartwijk, Van Der Vleuten, \& Wass, 2007) and evidence supports their use as a scaffold for developing competency in medical education (Izatt, 2007; Rees \& Sheard, 2004); however, little research exists concerning medical students' perceptions of their benefits, disadvantages and overall applications for self-reflection and documentation of competency attainment.

Teacher education programs have contributed considerably to the theoretical base, development, advancement and implementation of portfolios for documenting and assessing learning and personal and professional growth (Barrett, 2006; Black, 1994). This survey of the literature will center on portfolio use in medical education, but will exploit the literature where the focus has been on the use of portfolios for the learning and development of pre-service teachers (Milman \& Kilbane, 2005; Sherry \& Bartlett, 2005), particularly where assessment and reflection is concerned. In addition, the uses, benefits, disadvantages and challenges for implementation will be evaluated, primarily from the learner's perspective. A chapter summary will provide a literature summation that offers a framework for the study.

\section{Procedures for the Literature Review}

The findings included in the literature review were obtained using various education research databases. A search in the Academic Search Complete database, for example, with the search terms (1) electronic portfolio (5,474 results), (2) student electronic portfolio (474 results), and (3) medical student electronic portfolio (48 results), generated a broad range of results. Narrowing the search to medical student perceptions of electronic portfolios resulted in two articles, one focusing on the perceptions from faculty and administrative standpoints, and the 
other from graduate medical education residents. Google Scholar and other electronic databases were also searched using various combinations of the above search terms. Refereed journals dedicated to medical education, including Academic Medicine, Medical Teacher, and Medical Education were also explored.

\section{The Portfolio Defined}

Various types of portfolios exist and several disciplines utilize them. For example, the artist's portfolio represents a collection of original artwork or photographs that captures the style of the artist. A teacher's portfolio, alternatively, depends greatly on reflection and displaying exemplar modules of instruction (Barrett, 2006). The portfolio, both paper and electronic versions, is simply defined as "a collection of material, made by a professional that records and reflects on, key events and processes in that professional's career" (Hall, 1992, p. 81). In other words, a portfolio provides evidence that learning, or more precisely, personal and professional growth is occurring (Butler, 2006; Snadden \& Thomas, 1998).

The diversity of portfolio applications has earned them the nickname "cameleons who change colours according to the view of knowledge and learning they are based on" (Dysthe, 2002). Though great variations exist in the design and application of electronic portfolios in education, one thing they all have in common is their ability to demonstrate learning over the knowledge continuum. For this reason, it is important that an individual's electronic portfolio "represents a purposeful collection of authentic and diverse evidence drawn from a larger archive representing learning over time" (Pitts \& Ruggirello, 2012, p. 49).

According to Dr. Helen Barrett (2004), electronic portfolios can be best classified under three broad categories — assessment, reflection, and showcase of achievement — each of which offers multiple applications. For instance, implementation of an electronic portfolio for purposes 
of reflection can yield opportunities for personal and professional development and the expression of self-identity (Grant, 2005). The use of an assessment portfolio can aid in the valuation of competency attainment in medical education (Snadden \& Thomas, 1998); while a portfolio designed to showcase achievement can support career planning and advising (Ambrose \& Ambrose, 2013). Whatever the purpose of electronic portfolios, evidence supports their use as a valued learning tool.

\section{Common Portfolio Components}

Many artifacts can be considered in a student learning portfolio and several researchers have made suggestions as to the necessary components. According to Pitts and Ruggirello (2012), the electronic portfolio must contain evidence of reflective processes, among other documentation. Snadden and Thomas (1998) provide examples of the artifacts that should be included in a learning portfolio, suggesting the following as important elements:

- Records of events or experiences;

- Lists of critical reviews or articles read;

- Projects carried out;

- $\quad$ Teaching sessions attended;

- Videoclips, educational events and patients seen;

- Written reflective accounts of the events documented;

- Personal reflections kept in the form of a journal or diary (p. 192).

Other components, such as the curriculum vitae, certifications, personal learning plans, logs and checklists of clinical procedures and patient encounters, are also worthwhile components to illustrate student competence in medical education. Concisely, the components or artifacts documented in the student's electronic portfolio ought to provide evidence of 
competence and reflective practice (Barrett, 2006; Pitts \& Ruggirello, 2012; Snadden \& Thomas, 1998).

\section{Portfolios and Education}

Teacher education programs have broadly used electronic portfolios to create a nexus between professional growth and the act of teaching using reflective practice and improvement activities as a guide (Pitts \& Ruggirello, 2012). An analysis of the quality of evidence in preservice teacher portfolios conducted by Delandshere and Arens (2003) revealed that pre-service teachers' portfolios do not always focus meaningfully on the theory of teaching. In fact, they tend to lack much of the evidence, explanation and reflection that highlight the interrelationships between curriculum, assessment and pedagogy.

To illustrate and make more visible the connections between curriculum, assessment and pedagogy, teacher education programs are increasingly embracing the electronic portfolio as a tool to not only enhance their education programs, but to also satisfy the National Council for Accreditation of Teacher Education (NCATE) standards. In fact, the portfolio can function as an instrument to validate competency with the NCATE standard that requires pre-service teachers to demonstrate knowledge, skills and professional dispositions. Stolle and colleagues (2005) describe the electronic portfolio in teacher education as:

A personal document in which creativity and innovation demonstrate professional teaching characteristics and style that capitalize on pre-service teachers' potential. The final product prepares teachers for continued documentation of their progress toward meeting local, state and national standards. More importantly, it helps prepare teachers for the reflection and analysis necessary for professional 
development and provides a systematic method for on-going improvement of our teacher education program (p. 42).

In medical education, the use of the electronic portfolio gained popularity in the 1980s and 1990s, but was used primarily as a certification tool for compliance or as a document repository for storing evidence and artifacts of performance. The role of the portfolio is shifting in response to assessment demands to a tool that promotes a much richer evaluation of preparedness and competency by involving students in self-reflection and other self-assessment activities (Driessen, Van Tartwijk, Overeem, Vermunt, \& Van Der Vleuten, 2005). According to Pinsky and Fryer-Edwards (2004), medicine "must learn from the field of teacher education where teachers in training have adapted the portfolio approach to make the activity of teaching visible" (p. 585). In medicine, the electronic portfolio can make the activity of learning to practice medicine visible and help prepare students for their professional role as physicians through reflection activities aimed at developing life-long learning skills.

Studies documenting the impacts of electronic portfolios on learning reveal that their implementation must be assessed and continuously revised for optimal results. For example, Carney (2005) insists that:

Electronic portfolios show promise for enhancing learning, but if we fail to critically evaluate our uses of the device, we may find that they...become yet another educational fad — an innovation poorly understood and often implemented in ways contrary to its theoretical underpinnings (p. 4).

Zeichner and Wray (2001) agree that although electronic portfolios are popular, "few systematic studies of the nature and consequences of their use for either assessment or development purposes" (p. 615) has been fully explored. 


\section{Portfolios and Learning Theory}

Both positivist and constructivist learning theories influence the use of electronic portfolios (Barrett \& Wilkerson, 2004; Biggs, 2003). According to positivist theory, the electronic portfolio is used to focus on the outcomes of learning with an emphasis on cause and effect. Consequently, learning is assessed using rubrics or artifacts. The rubrics measure proficiency, while the artifacts illustrate level of mastery. The positivist theory also supports the use of electronic portfolios as tools for both formative and summative assessment (Barrett \& Wilkerson, 2004; Lorenzo \& Ittelson, 2005).

In contrast, the constructivist approach views electronic portfolios as tools for examining the process of learning with an emphasis on analytical and problem-solving skills. The constructivist view describes learning as occurring through assimilation and accommodation, with assessment occurring through self-reflection and peer evaluation (Barrett $\&$ Wilkerson, 2004; Ward \& Ellis, 2007). This approach is grounded in 'constructive alignment' where the 'constructive' aspect deals with how students "construct meaning through relevant learning activities" and the 'alignment' aspect focuses on how learning activities are structured so that students achieve the desired learning outcomes (Biggs, 2003, p. 2).

A framework presented by Barrett, Wilkerson, and Lang (2004) differentiates the positivists and constructivists paradigms for portfolio assessment and learning. The framework illustrates how the constructivist paradigm is oriented to the portfolio as a story of learning focused on the development of "life-long self-directed learning" skills with an "internal locus of control". In essence, the constructivist view of the portfolio is to make meaning through the inclusion of artifacts selected by the learner in an effort to celebrate their uniqueness. In contrast, the positivist paradigm represents the portfolio as a test with a "limited-term 
evaluation" of learning by an assessor. The portfolio therefore is used to make inferences about student learning with an "external locus of control" and with prearranged artifacts and rubrics to assist in the formative and summative evaluation of student learning.

Trent Batson (2011) provides a rich portrait of how electronic portfolio technology utilizes the constructivist theory of learning where the student experience is at the center. He states that:

Learning occurring at all times in all situations, because it is beyond the reach of the teacher, cannot be captured and assessed well by traditional testing technologies, but can be captured, shared, revised, assessed, presented, reassessed, reflected upon, and integrated using electronic portfolios and the technologies that feed data to the portfolios (p. 109).

In Batson's (2011) view, electronic portfolios can be used to encourage self-regulated learning, and in so doing, students are self-monitoring performance and developing metacognition skills facilitated by the portfolio learning process. Metacognition, or "thinking about thinking," is one way the portfolio can help students develop the life-long learning skills descriptive of the constructivist paradigm.

\section{Portfolios, Reflection and Assessment}

Medical education programs use electronic portfolios to assess competency attainment and reflection on patient encounters and other significant events (Burch \& Seggie, 2008; Grant, Vermunt, Kinnersley, \& Houston, 2007). One competency, practice-based learning and improvement, requires that medical students, graduate medical residents and practicing physicians evaluate and continuously improve patient care based on self-evaluation and life-long 
learning (Swing, 2007). To accomplish these tasks, medical students and professionals are asked to:

- identify strengths and deficiencies in knowledge;

- set goals for learning and improvement;

- analyze performance and implement changes with the goal of improvement;

- incorporate scientific evidence into patient care activities; and

- participate in the education of patients and the community (Swing, 2007).

Graduate medical education research conducted by Jarvis, O'Sullivan, McClain, and Clardy (2004) suggests that the portfolio can effectively measure five of the six core competencies for residents in a psychiatry training program based on 80 portfolio entries. Of the six competency domains, their findings show that the practice-based learning and improvement competency is not well represented in the portfolio entries. The authors state that modifying guidelines for the portfolio may better serve the practice-based learning competency. Other researchers have shown that the practice-based learning and improvement competency actually includes objectives centered on reflection about strengths and weaknesses concerning the core competencies (Driessen, 2005). Assignment of advising mentors to students and their portfolios can help identify how competence is documented and measured.

The common methodologies employed for assessing the effectiveness of the electronic portfolio in medical education range from document review and oral examination (Burch \& Seggie, 2008), interviews, (Altahawi, Sisk, Poloskey, Hicks, \& Dannefer, 2012; Burch \& Seggie, 2008), and questionnaires (Davis, Ponnamperuma \& Ker, 2009; Rees and Sheard, 2004). The results of studies vary, but findings do support electronic portfolios despite documented limitations. 
In a study conducted at Case Western Reserve University (Altahawi et al., 2012), researchers interviewed medical students $(n=4)$ to share their personal viewpoints about the competency-based portfolio assessment model. The narrative findings reveal that students, though initially uncertain of the competency-based system of assessment, learned to actively seek formative feedback from residents and attendings in the transition from a traditional gradebased model to competency-based assessment. Another study centered on the development and implementation of a competency-based portfolio assessment system in a family medicine residency program. The findings suggested that the portfolio assessment support system (PASS) implemented helped to develop competency, scaffold self-regulated learning of residents, and promoted professional identity formation (McEwen, Griffiths, \& Schultz, 2015).

A questionnaire was used in a family medicine clerkship to ascertain the effectiveness of electronic portfolios on student learning. Students reflected on patient encounters in their electronic portfolios and completed a questionnaire. The resulting student feedback indicates that the amount of written work is too much for the time available, thus taking them away from time with patients and did not significantly benefit their learning. The authors suggest that the use of a questionnaire restricted the data since follow-up questioning was not possible in their quantitative design (Grant, Vermunt, Kinnersley, \& Houston, 2007). Their research supports a qualitative approach to evaluating the effects of portfolio learning.

Davis, Ponnamperuma, and Ker (2009) conducted a study to analyze students' attitudes about portfolio assessment over a four year period using a questionnaire with open-ended questions. The findings show that building portfolios helped students with their understanding of learning objectives and enabled reflection on learning. The findings also show that student perceptions of the electronic portfolio evolved over time; however, students felt that the process 
of portfolio building interfered with their clinical learning due to the excessive amounts of evidence and time required. Similarly, a study conducted by Elango, Jutti, and Lee (2005) looked at the perceptions of medical students concerning the use of the portfolio as a learning tool. Through a questionnaire survey $(n=143)$, they uncovered that though students perceived the portfolio as a good learning tool, its development is time consuming and stressful.

The MedBiquitous Curriculum Inventory Working Group Standardized Vocabulary Subcommittee (2012), a not-for-profit international group founded by Johns Hopkins Medicine, state that reflection in medical education is:

examination by the learner of his/her personal experiences of a learning event, including the cognitive, emotional, and affective aspects; the use of these past experiences in combination with objective information to inform present clinical decision-making and problem-solving (p. 5).

The notion of self-reflection is one of the more important components of the electronic portfolio system. Rickards, Diez, Ehley, Guilbault, Loaker, Hart, and Smith (2008) reasoned that the electronic portfolio offers a foundation for reflection, which serves as "both an educational outcome and a means to continued learning" (p. 31). Dr. Helen Barrett (2008) explained that electronic portfolio reflection is intended to raise self-awareness and is "a prerequisite to building up lifelong learning capabilities" (para 3).

Research by Rees and Sheard (2004) shows that students can be negative about portfolio learning and assessment, but a correlation exists between their comfort level with self-reflection and their attitude toward portfolio use. Their conclusions reveal that students' views are "somewhat neutral" towards the use of electronic portfolios, with significant relationships existing between an 18-item reflective portfolio questionnaire's total scores and students' ratings 
of their reflection skills. In short, students who feel comfortable with the reflective aspect of portfolio assessment exhibit a positive attitude compared to those who do not rate their reflective skills high.

The electronic portfolio also serves as an effective indicator of students' professional growth. Reflection activities assist students in the identification and articulation of competencies, skills, behaviors and effective decision-making. Further, the electronic portfolio provides self-directed control of learning. According to Izatt (2007), the reflective piece of portfolio-based assessment "allows physicians at all stages of training to learn from their actions and promotes continued review of the literature to keep up to date" (p. 406). A study published in Medical Education found that "the conditions for successful reflective use of portfolios...falls into 4 categories: coaching; portfolio structure and guidelines; relevant experiences and materials; and summative assessment" (Driessen, Van Tartwijk, Van Der Vleuten, \& Wass, 2005, p. 1230).

A 2014 study examined the impact of an authentic electronic portfolio in undergraduate medical education across four medical schools using authentic electronic portfolios and found several barriers, including students' lack of knowledge and understanding regarding the purpose of a portfolio. Though positive findings were also revealed, including helping students with professional identity formation, accessibility barriers, particularly in clinical settings posed a problem and limited engagement (Belcher, Jones, Smith, Vincent, Naidu, Montgomery, Haq, \& Gill, 2014).

\section{Portfolios for Career Planning and Advising}

The electronic portfolio has been viewed as an advising tool in recent years (Hall, Byszewski, Sutherland, \& Stodel, 2012; Ward, 2008). Advisors or mentors help students 
identify learning goals and needs, validate the portfolio contents, provide career-planning advice, and develop remediation plans. As a coaching/academic counseling instrument, advisors or mentors can provide career advice based on the student's longitudinal growth. In medical education, the portfolio allows students to self-assess and reflect on learning by documenting competency in the six core areas.

The Undergraduate Advising and Research (UAR) program at Stanford University introduced electronic portfolios as advising tools for students in their first two years before declaring a major. Each student was assigned an advising mentor to explore how electronic portfolios can "reveal insights into the nature of pre-major advising from the perspective of both students and their advisors... [and] enhance the face-to-face interactions students have with their advisors" (Chen \& Black, 2010, para 4). It is the belief of the authors that learning occurs in various forms and that the promotion of "folio thinking" will enhance students' "sense of belonging" in the academic community and "more engaged and interconnected with the people with whom they live, interact, and learn from" (Chen \& Black, 2010, para 6).

A different study of interest looked at the impact of student reflective electronic portfolios on medical student advisors. It was revealed that medical student advisors garnered a better understanding of students' thinking and attitudes based on their reflections to specific questions in their electronic portfolios (Bashook, Gelula, Joshi, \& Sandlow, 2008). Such findings support the notion that a coach or mentor be assigned to students to help them develop their reflective and lifelong learning skills and to help them develop professionally and personally for residency specialization. The use of electronic student portfolios enriches the advising and mentoring process by allowing both face-to-face and electronic mentoring and communication to occur. 


\section{Implementation Considerations}

According to a report published by Lorenzo and Ittelson (2005) in Educause, there are several questions programs must consider before committing to the implementation of electronic portfolios. From how might the electronic portfolio system impact other widely-used systems across the program, to ownership and training on how to use the system? The program must clearly define expectations and promote acceptable use. Another consideration when implementing electronic portfolios with today's students is mobility. A study conducted by Garrett and Jackson (2006) examined nursing and medical students' attitudes towards a mobile electronic portfolio in the clinical setting using Personal Data Assistants (PDAs). Their findings revealed positive reactions, even though the interface of the PDA presented limitations in use and accessibility.

\section{Portfolio Design}

According to the Conference on College Composition and Communication (CCCC) (2007), a standard design for electronic portfolios does not exist since they are dynamic projects that change depending on institution needs and resources; however, there are guiding principles and best practices that can inform their design:

\section{- Learning Outcomes}

- Digital Environments

- Virtual Identities

- Authentic Audiences

- Reflection and Electronic Portfolio Pedagogy

- Integration and Curriculum Connections

- Stakeholders' Responsibilities 
- $\quad$ Lifelong Learning (CCCC, 2007)

Despite some basic rules of thumb for portfolio design, there is a debate among medical educators regarding who is responsible for the design of the portfolio and its contents. Research by Driessen et al. (2007) suggests medical students view the design and construction of electronic portfolios as more work if they are not actively engaged in decision making regarding portfolio contents; however, some medical educators are concerned that students are unable to adequately identify the appropriate performance measures for inclusion (Friedman, Davis, Harden, Howie, Ker, \& Pippard, 2001). It is evident that a clear, yet flexible design structure will give learners' opportunities to describe their development (Driessen et al., 2005; Grant et al., 2007; Pearson \& Heywood, 2004).

Lewis and Baker (2007) identified several criteria for evaluating a student-designed electronic portfolio and developed an assessment rubric for this purpose. The rubric assesses design, navigation and layout, as well as included artifacts and the captions used to describe contents. Implementing best practices in interface design to improve usability is imperative to ensuring positive experiences with the electronic portfolio system.

\section{Benefits, Disadvantages and Challenges}

The benefits of using portfolios for learning and assessment are abundant in the research literature, especially in teacher education programs. One study found that the development and implementation of electronic portfolios in teacher education increased faculty collaboration, innovation in teaching, peer dialogue, quality data for program assessment and improvement, and continuous engagement with the conceptual framework and its integration throughout the program (Stolle et al., 2005). 
According to Driessen et al. (2007), portfolios in medical education continue to be met with mixed success. Their work concludes that electronic portfolios are effective tools for both scaffolding and assessing development of competence among medical students, but only if portfolio activities are integrated in the curriculum and if the support of a tutor or mentor is available.

As for learning benefits, the Association for Medical Education in Europe (1999) found that portfolio-based learning has benefits that are not found in other education experiences including:

- it recognizes and encourages the autonomous and reflective learning that is an integral part of professional education and development;

- it is based in the real experience of the learner, and so enables the consolidation of the connection between theory and practice;

- it allows a range of learning styles to be used according to the preferences of the learner;

- it enables assessment within a framework of transparent; and declared criteria and learning objectives;

- it can accommodate evidence of learning from a range of different contexts;

- it provides a process for both formative and summative assessment, based on either personally derived or externally governed learning objectives; and

- it provides a model for lifelong learning and continuing professional development (Challis, 1999, p. 370). 
Though many benefits for the use of electronic portfolios are recognized in the literature, they are primarily derived from the perceptions of administrators and evaluators, rather than the students who are required to use them.

A number of disadvantages for electronic portfolio integration have been identified and include, but are not limited to: (1) ambiguous learning outcomes and assessment, (2) reduced validity due to vulnerability to plagiarism, (3) minimized face-to-face interactions that eliminate non-verbal cues, and (4) development of a specific skill set for using various hardware and software applications (Sewell, Marczak, \& Horn, 2007). An additional disadvantage is student maturity level and ability to reflect in a way that promotes professional identity development and life-long learning. In combination with the amount of time invested to create development files that support student performance and growth, as well as the creation of reliable and valid assessment instruments to measure student performance and growth, the electronic portfolio may not prove useful for some applications or situations (Kampschuur \& Chatterton, 2007).

The creation of an electronic portfolio system is an arduous task and the culture of change that must ensue to ensure buy-in from faculty, students, and staff is time-consuming and challenging. Additionally, effectively communicating the purpose of the portfolio, its uses and capabilities, and the long term benefits prove to be a challenge in many settings (Meyer \& Latham, 2008). The educational literature pertaining to the benefits and challenges of electronic portfolios is generally confined to educator and administrator perspectives; however, one study analyzed students' perceptions of the challenges of electronic portfolio engagement and uncovered four emerging themes: buy-in, motivation, assessment and electronic portfolio technology. They concluded that failure to engage students with their electronic portfolio will 
result in it becoming "another hoop to jump through" (Tosh, Light, Fleming, \& Haywood, 2005, Conclusion, para 4).

\section{Summary}

The literature reveals that the electronic portfolio is a valid tool for self-reflection, assessment and showcasing student achievement. It is apparent from the literature that additional research is needed to gain a deeper understanding of the role the design and implementation of the electronic portfolio has on facilitating reflective practice and self-assessment of competency attainment. The inclusion of qualitative methods, particularly the use of focus groups or interviews, will shed more insight on the role of the electronic portfolio for assessing medical student competency. Student perceptions will help support the creation of a learner centered system. 


\section{Chapter Three: Methodology}

The qualitative research design is based on the interpretivist paradigm which emerged from the philosophy of Edmund Husserl's phenomenology (Mertens, 2005) and aims to understand "the world of human experience" (Cohen \& Manion, 1994, p. 36). As such, the interpretivist researcher relies on the "participants' views of the situation being studied" (Creswell, 2003, p.8) and distinguishes how their own experiences and background may impact the research. In this chapter, the research methodology is described. In addition, the purpose of the study and the research questions that guide data collection and analyses are restated from Chapter One. The role of the researcher and methods incorporated to ensure trustworthiness are also discussed.

\section{Purpose of the Study}

The purpose of this research study is to develop a better understanding of how the design and implementation of electronic portfolios for competency attainment and self-reflection can be enhanced based on the views and lived experiences of medical students. Through their lens, it will be possible to uncover the perceived benefits, disadvantages and challenges of portfolio design, utilization and implementation.

\section{Research Questions}

This research is concerned primarily with how electronic portfolios are designed and integrated in the medical doctor degree curriculum so that the learner experience is captured in a way that minimizes frustration and maximizes reflective practice and documentation of competency attainment. In order to advance understanding of how the electronic portfolio design and integration impacts student reflection and competency attainment, the following research questions (with respective data sources) will guide the study: 
1. What are the advantages and disadvantages of using electronic portfolios to document and self-assess competency and performance as perceived by medical students? (Interview)

2. In what ways do students feel the portfolio components will help them prepare for and identify a suitable residency program? (Interview)

3. How does the structure and organization of the portfolio influence how medical students engage with portfolio activities and self-monitor performance and competence? (Interview)

4. How do student attitudes and perceptions (elicited from the interviews) about the act/purpose of reflecting in the electronic portfolio compare to the content and alignment of their reflections to the corresponding Program Learning Objectives? (Document analysis and interview)

5. According to the researcher and medical students, which electronic portfolio components are missing and/or over-/under-utilized in the electronic portfolio that limit their engagement in competency attainment and reflective practice? (Interview and document analysis)

6. What can be gleaned from graduate medical education residents when asked to retrospectively reflect on electronic portfolio components they feel will be beneficial to a medical student? (Interview)

\section{Role and Background of the Researcher}

As the former Director of Evaluation for the West Virginia University School of Medicine, I developed an interest in tools and methods that promote reflection, improvement and documentation of competency attainment. In the spring of 2012, I embarked on a journey to 
design, develop and implement competency-based electronic portfolios for medical students as a way for them to self-reflect on their professional growth, document their learning experiences, and virtually interact with advisors for career counseling and advising (yet to be implemented). The electronic portfolio permits students access to their academic record whenever they would like, thus allowing them ongoing opportunities for reflection and improvement.

As the designer of the electronic portfolio, I am interested in students' perspectives and experiences with its use. As articulated in chapter one, having worked closely with administrators, faculty and staff, I am knowledgeable of the benefits and challenges for implementing electronic portfolios from their perspectives; however, the voices of the students have yet to be heard. This research study will provide a deeper understanding of the uses, benefits and challenges of the portfolio that will support the expansion and modification of its use for future generations of medical students, as well as other programs of study wishing to adopt electronic portfolios as a showcase of student growth and development.

On December 21, 2014, the West Virginia University Institutional Review Board acknowledged the study as exemption level (IRB protocol number: 1412508006; Appendix E). In order to minimize bias and predispositions concerning the benefits and challenges of electronic portfolios, I conscientiously maintained objectivity during the interview process with the use of an impartial and flexible interview guide (Appendix B) and assured students that their opinions and experiences are important to the research study, whether positive or negative. Steps were taken to keep participants identities confidential to protect them from judgement or retaliation from other sources. Since the removal of all potential biases is beyond my control, I have striven to conduct the research study in a neutral and professional manner. Finally, the research findings emerged directly from the data and not my own predispositions. 


\section{Qualitative Methodology}

As Gay et al. explained, in qualitative phenomenological research "all meaning is situated in a particular perspective or context, and because different people...often have different perspectives and context," (2012, p. 7), such methods permit the researcher to gain richer insights into a phenomenon of interest. The use of a phenomenological research design is appropriate for this study since the focus is to garner medical students' perceptions on the use of electronic portfolios (the phenomenon) in the medical school curriculum based on their lived experiences (Gay et al., 2012). As such, the researcher will be able to understand medical students' views of the electronic portfolio as a means to stimulate self-reflection and document competency attainment through the experiences and knowledge they share during semistructured interviews. The research study will use a narrative to report the stories of medical students' understandings and involvements with the electronic portfolio to date.

Study Population. The WVU SoM's curriculum is distributed over four academic years. During medical school, students are identified by the initials for medical school (MS), followed by the academic year in which they are currently enrolled. For example, students in the second and third year of medical school are referred to as MS2 and MS3 students, respectively. Approximately 115 students matriculate into the program each academic year, with a total population size of nearly 450 students at any given time. The SoM is also distributed across three campuses: Morgantown, Eastern (Martinsburg), and Charleston. All medical students complete the first two years of the curriculum on the Morgantown campus and are then dispersed among the other campuses for MS3 and MS4 for focused clinical experiences. Students are first introduced to their electronic portfolios during their MS1 orientation and reintroduced each academic year. 
The population of WVU SoM graduate medical residents is approximately 400 within 47 graduate medical education specialties. Depending on medical specialty, residency education can span from three to seven or more years. The WVU SoM refers to residents by their postgraduate year (PGY) from medical school. For example, a second year resident is referred to as a PGY2.

Sample. The research study involved fifteen $(n=15)$ medical students from the second (MS2) and third (MS3) years of the WVU SoM curriculum. For convenience, only those students studying on the Morgantown campus were considered for participation in the study. In addition, graduate medical education residents $(n=5)$ were recruited to offer retrospective feedback on the portfolio components they feel would have been useful to them as a medical student preparing for residency and to triangulate findings. The residents represented PGYs 1-4.

The student $(\mathrm{n}=15)$ and resident $(\mathrm{n}=5)$ sample size was determined based on appropriate sample size guidelines for phenomenology-based qualitative research studies. According to Creswell (1998, p. 64), five to 25 participants is necessary for data collection. Similarly, Morse (1994, p. 225) advises that at least six participants are included in phenomenological studies. Based on the above recommendation, a sample size of fifteen medical students and five residents was chosen to provide the depth of understanding needed to answer the research questions of interest.

A breakdown of participants is shown in Table 3 . There was a relatively equal distribution of participants among second year (53.3\%) and third year (46.7\%) students. Gender was also distributed similarly, with $46.7 \%$ female and $53.3 \%$ male participation. Participants from graduate medical education (i.e., residents) included females $(n=3)$ and males $(n=2)$. The 
resident participants are continuing their medical training in the obstetrics and gynecology $\operatorname{program}(n=3)$ and family medicine program $(n=2)$.

Table 3 .

Breakdown of student and resident participants by year and gender.

\begin{tabular}{|cccc|}
\hline Year & $\#$ & Male & Female \\
\hline MS2 & 8 & 4 & 4 \\
\hline MS3 & 7 & 4 & 3 \\
\hline MS4 & 2 & 0 & 2 \\
(Pilot) & & & \\
\hline PGY1 & 1 & 0 & 1 \\
\hline PGY2 & 2 & 2 & 0 \\
\hline PGY4 & 2 & 0 & 2 \\
\hline TOTAL & $\mathbf{2 2}$ & $\mathbf{1 0}$ & $\mathbf{1 2}$ \\
\hline
\end{tabular}

Table 4 illustrates the coding used by the researcher for participant identification along with their corresponding pseudonym, which will be used in Chapter Four.

Table 4

Assignment of pseudonym for each student identification code.

\begin{tabular}{|c|c|c|c|c|c|c|c|c|}
\hline $\begin{array}{l}8 \\
8 \\
8\end{array}$ & $\begin{array}{l}\text { S1MS3m } \\
\text { Alex }\end{array}$ & $\begin{array}{l}\text { S2MS2m } \\
\text { Byron }\end{array}$ & $\begin{array}{l}\text { S3MS2m } \\
\text { Chris }\end{array}$ & $\begin{array}{l}\text { S4MS3m } \\
\text { Darrin }\end{array}$ & $\begin{array}{l}\text { S5MS3f } \\
\text { Emily }\end{array}$ & $\begin{array}{l}\text { S6MS2f } \\
\text { Frieda }\end{array}$ & $\begin{array}{l}\text { S7MS2f } \\
\text { Greta }\end{array}$ & $\begin{array}{l}\text { S8MS3f } \\
\text { Harriett }\end{array}$ \\
\hline 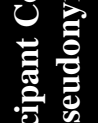 & $\begin{array}{l}\text { S9MS2m } \\
\text { Isaac }\end{array}$ & $\begin{array}{l}\text { S10MS2f } \\
\text { Julie }\end{array}$ & $\begin{array}{l}\text { S11MS2f } \\
\text { Kathy }\end{array}$ & $\begin{array}{l}\text { S12MS3f } \\
\text { Lois }\end{array}$ & $\begin{array}{l}\text { S13MS3m } \\
\text { Mike }\end{array}$ & $\begin{array}{l}\text { S14MS3m } \\
\text { Nick }\end{array}$ & $\begin{array}{l}\text { S15MS2m } \\
\text { Oliver }\end{array}$ & \\
\hline$E^{4}$ & $\begin{array}{l}\text { R1PGY2m } \\
\text { Patrick }\end{array}$ & $\begin{array}{l}\text { R2PGY4f } \\
\text { Queta }\end{array}$ & $\begin{array}{l}\text { R3PGY1f } \\
\text { Rachel }\end{array}$ & $\begin{array}{l}\text { R4PGY4f } \\
\text { Sarah }\end{array}$ & $\begin{array}{l}\text { R5PGY2m } \\
\text { Tyler }\end{array}$ & & & \\
\hline
\end{tabular}

Sampling Procedure. Participants were selected using a convenience sampling technique where invitation for participation was distributed via email until the sample size was full. The researcher oversampled by two participants and arranged interviews with the first 15 
students who volunteered. One of the original 15 participants canceled the interview for unknown reasons, so the next participant on the list was contacted for an interview.

The invitation to participate included an introductory letter requesting participation and providing an explanation of the study (Appendix C). Since the population size of MS2 and MS3 students is large $(\mathrm{N}=215)$, it was unlikely that 15 students dispersed among the second and third years of the curriculum would not be willing to participate; however, to combat the potentiality that students would not immediately volunteer to participate, the researcher sent three waves of requests for participation via email to MS2 and MS3 students through the SoM student listserv. Additionally, the invitation to participate was included in the January 20, 2015 Message of the Week, an electronic newsletter containing general announcements that is distributed weekly by Student Services to students on all three campuses. Students were asked to respond to the initial invitation within one week if interested in participation.

Since all SoM students have an assigned portfolio and the ability to access it from any Internet-enabled device, it was expected that all students had adequate experiences and exposure to the electronic portfolio over the past year so that few restrictions need be applied to the recruitment of a student sample that could offer insights helpful to the researcher. The medical students were required to meet only four criteria in order to participate:

a) Available to participate in a face-to-face or Skype interview during the Spring 2015 term, with a member check follow-up,

b) Currently in good academic standing,

c) Enrolled in the second or third year of the curriculum, and

d) If a third year medical student, they are completing their clinical rotations on the Morgantown campus. 
Recruitment of graduate medical residents also occurred through an email invitation distributed by the residency program coordinator for each of the following graduate medical residency programs: family medicine, internal medicine, obstetrics and gynecology, pediatrics, and/or surgery. Since all WVU SoM graduate medical education programs require that each resident maintain an electronic portfolio, residents have the necessary background knowledge and experiences to serve as a data source to corroborate findings obtained from the medical student interviews and the document analysis of the portfolio structure and components.

\section{Data Collection}

Qualitative research utilizes a variety of methods of data collection, including observations, textual or visual analysis, and interviews (Marshall \& Rossman, 1999; Silverman, 2005). For the purpose of this research, individual semi-structured interviews were used to obtain student and resident perspectives of the benefits and challenges of electronic portfolio design and implementation for the documentation of and reflection on competency attainment. Additionally, the portfolio structure and contents, medical student reflections, and the researcher's journal of personal reflections and observations, were used as data sources. A summary of data collection activities is depicted in Figure 4 and each method will be discussed individually. 


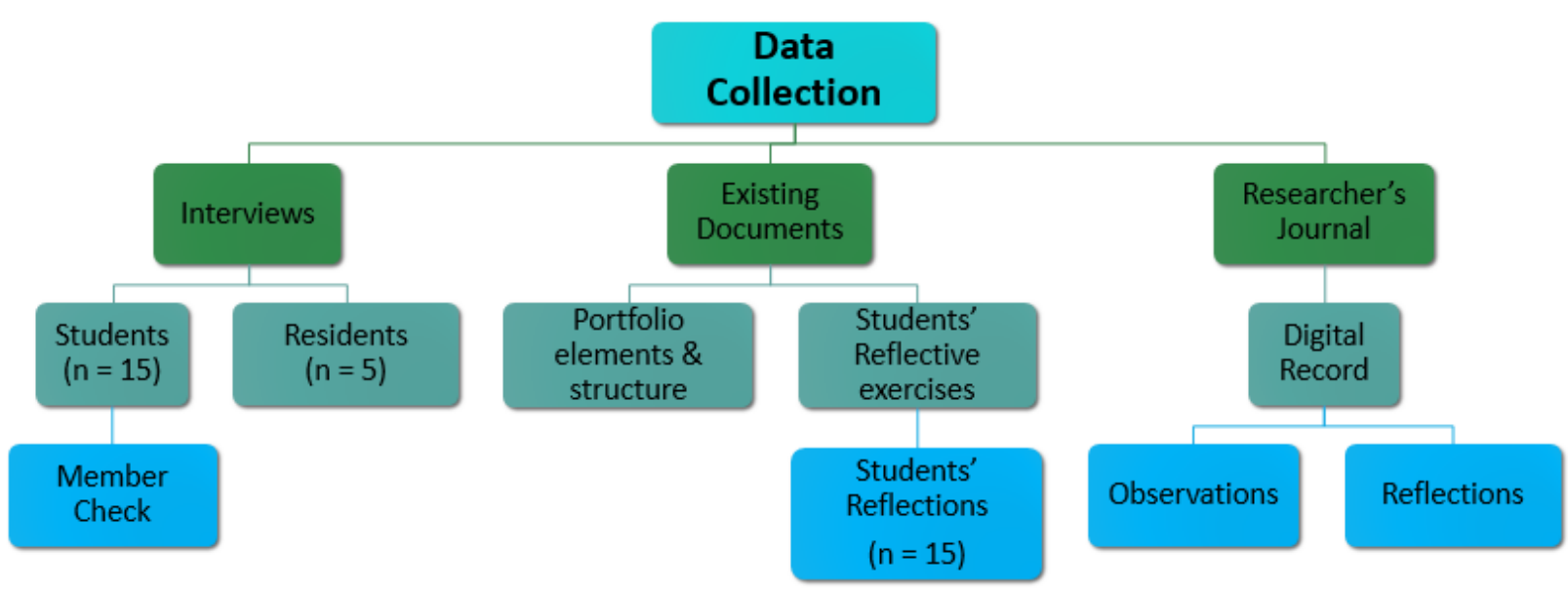

Figure 4. Summary of data collection strategies.

Interviews. Open-ended interviews add "depth, detail, and meaning at a very personal level of experience" (Patton, 2002, p. 17). As such, the researcher utilized a flexible interview guide (Appendix B) to ascertain students' perceptions of the SoM electronic portfolio. The interview questions were designed to target specific, and in some cases, multiple research questions, as well as to elicit additional information relevant to the researcher. For example, interview question A1 is intended to help the researcher uncover bias in the use of portfolios based on students' prior experiences with and knowledge of either paper or electronic portfolios, but does not specifically target a research question. Table 5 illustrates the alignment of interview and research questions, though depending on participants' responses other alignments occurred. 
Table 5

Alignment of interview and research questions.

\begin{tabular}{|c|c|c|c|c|c|c|c|c|c|c|}
\hline RQ1 & A2 & B1 & B2 & B3 & C2 & C3 & $\mathrm{C} 4$ & D1 & D2 & D5 \\
\hline RQ2 & A2 & B3 & D1 & D3 & D4 & & & & & \\
\hline RQ3 & B1 & B2 & B3 & B4 & D2 & D4 & & & & \\
\hline RQ4 & $\mathrm{C} 1$ & $\mathrm{C} 2$ & C3 & $\mathrm{C} 4$ & $\mathrm{C} 5$ & D4 & & & & \\
\hline RQ5 & D4 & MS2C & & & & & & & & \\
\hline RQ6 & D1 & D3 & D4 & & & & & & & \\
\hline
\end{tabular}

Prior to conducting interviews with MS2 and MS3 students $(\mathrm{n}=15)$ and graduate medical residents $(n=5)$, a pilot study was conducted with two MS4 students $(n=2)$ to test the original interview questions for understanding, quality and alignment with research questions. The pilot interviews resulted in minor revisions to the flexible interview guide, including the elimination of one question. The eliminated question (Can you recall a time when you felt you were having difficulty reflecting on your learning?) was removed based on piloted feedback. Another question (If you were asked how to best integrate the electronic portfolio into your daily life, what would you suggest?) was revised to include how students would best integrate the electronic portfolio into the curriculum or their daily life. The revision was in response to student feedback and the inability to respond to the question as it was originally stated.

Once students agreed to participate, they were provided a date and time frame for participation in a face-to-face or Skype interview. The researcher made every effort to avoid high-stress times, such as the end of a block or rotation when subject exams are scheduled, in order to not interfere with participant study time. Additionally, a private small-group room was reserved within the School of Medicine for ease of access and minimized distraction. The interview participants were introduced to the purpose of the research study, as well as verification that interview data would remain anonymous to preserve the integrity of the subjects 
and encourage them to speak freely. The researcher provided and went over the cover letter (Appendix C) with each participant and assigned a pseudonym to each participant for ease of reporting their stories. The in-depth, face-to-face interviews were conducted with each student and graduate medical education resident in an informal, conversational style adhering to the flexible, open-ended question prompts (Appendix B) and additional probing and clarifying questions from the interviewer when necessary. Students agreed to the interviews being audio recorded using a free application called Smart Recorder ${ }^{\mathrm{TM}}$ that was loaded onto the researcher's mobile device. Four of the 15 student participants opted to use Skype for the interview, which was also digitally recorded using the Smart Recorder ${ }^{\mathrm{TM}}$ application. The interview length ranged between 17 minutes and 39 seconds and 35 minutes and 13 seconds, with an average interview length of 24 minutes and 30 seconds. Data collection commenced in late January 2015 and occurred over a six-week time frame. All data were collected using password-protected tools and stored in encrypted file folders on the researcher's password protected computer.

Existing portfolio structure and contents. The current design structure, organization and required components of the electronic portfolio served as a secondary data source. As the designer of the SoM portfolio, the researcher is familiar with the existing structure and organization and will use it to cross-check findings from student and resident interview data in an effort to support or refute findings.

Student reflections. Since the intent of the existing reflection prompts is to demonstrate compliance with the program learning objectives PBLI 4 and PBLI 5 (see Appendix A), the researcher collected the student participants' reflections to see if the specific learning objectives were being met based on student reflections. The students' reflections were also analyzed against students' interview responses in an effort to analyze whether findings regarding students' 
attitudes about the act and purpose of reflection were contradicted or supported based on their portfolio reflection entries.

Researcher's personal reflections. According to Creswell (2007), to uncover the deeper meaning of any phenomenon, it is imperative to eliminate all preconceived judgments or notions. In accordance with the interpretivist paradigm, which requires that the researcher distinguishes how her own experiences and background may impact the research, the personal reactions and reflections of the researcher were collected in a digital journal throughout the study. The researcher's reflections recorded and refined data collected during interviews and document analyses, as well as noted observations of particular interest during the research process. Notes concerning students' misunderstandings, insights, and recommendations were also recorded for analysis and inclusion in the findings and conclusions.

\section{Data Analysis}

Inductive content analysis was used to (1) condense text data into a summary format, (2) establish links between the research questions and the summary data, and (3) uncover patterns and themes in the data (Patton, 2002). According to Thomas (2006), "the primary purpose of the inductive approach is to allow research findings to emerge from the frequent, dominant, or significant themes inherent in raw data" (p. 238). Patton (2002) explains that in inductive analyses, "Categories or dimensions of analysis emerge from open-ended observations as the inquirer comes to understand patterns that exists in the phenomenon being investigated" (p. 56). Analytical strategies used by the researcher to identify themes included the identification of word and phrase repetitions and similarities and differences in participants' responses. Themes were derived or induced from the data using open coding to process the interview text (Creswell, 2007). 
Interviews. The researcher transcribed all digitally recorded interviews, and subsequently proofed the transcript against the recording to locate errors and make necessary corrections. This process necessitated listening to the recording multiple times and contributed to the multiple readings of each transcript. The numerous reads of the transcripts was an important step in familiarizing the researcher with the data and initiating an in-depth analysis of that data. Open coding was utilized to generate units of data that emerged from the initial analysis of the interview transcripts. The units of data were in the form of direct quotes, expressions or key words that informed the research questions or stood out as important from the raw interview data (Lincoln and Guba, 1985).

Each identified quote, expression or key word was imported into Evernote with a reference to who said it, in what context, and the lines in which it appeared in the transcript. Each digital note or card was also tagged with the corresponding research question(s). A sample digital note or card is illustrated in Figure 5 with the tag and indigenous label highlighted.

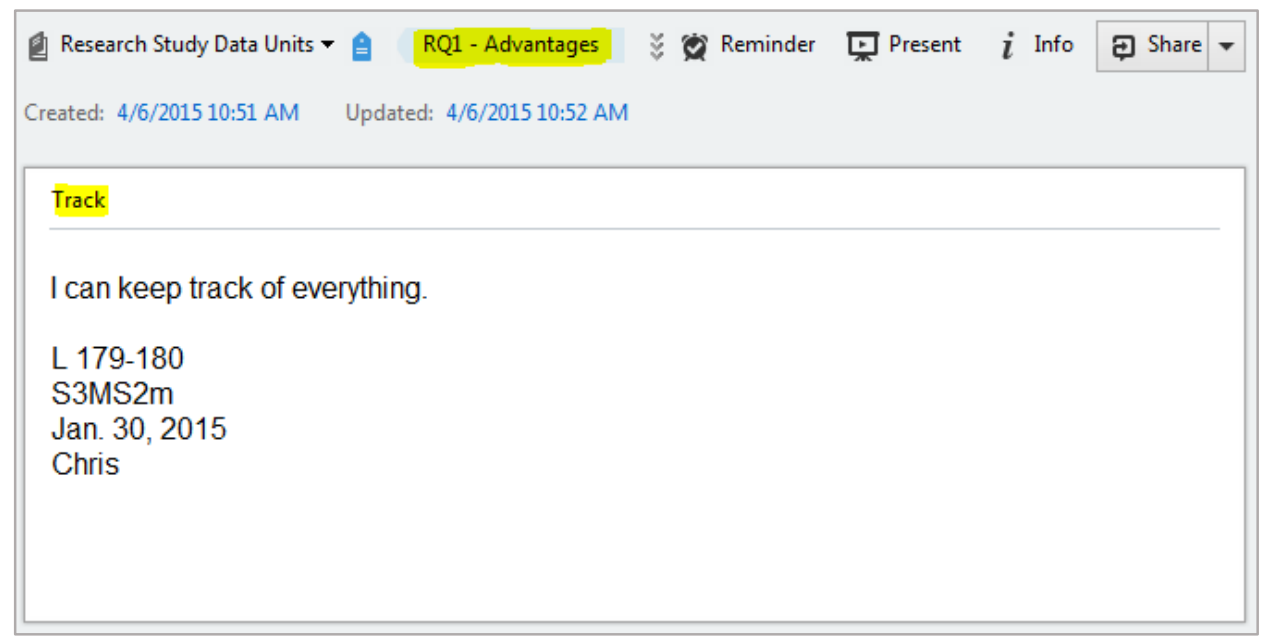

Figure 5. Sample digital note used to label and sort units of data in Evernote. 
A digital card sort analysis was used to arrange and organize the units of data (each note) into similar piles (notebooks) to help extract and reduce narrative findings into meaningful categories. Similar notes were merged into a single note, as can be seen in Figure 6.

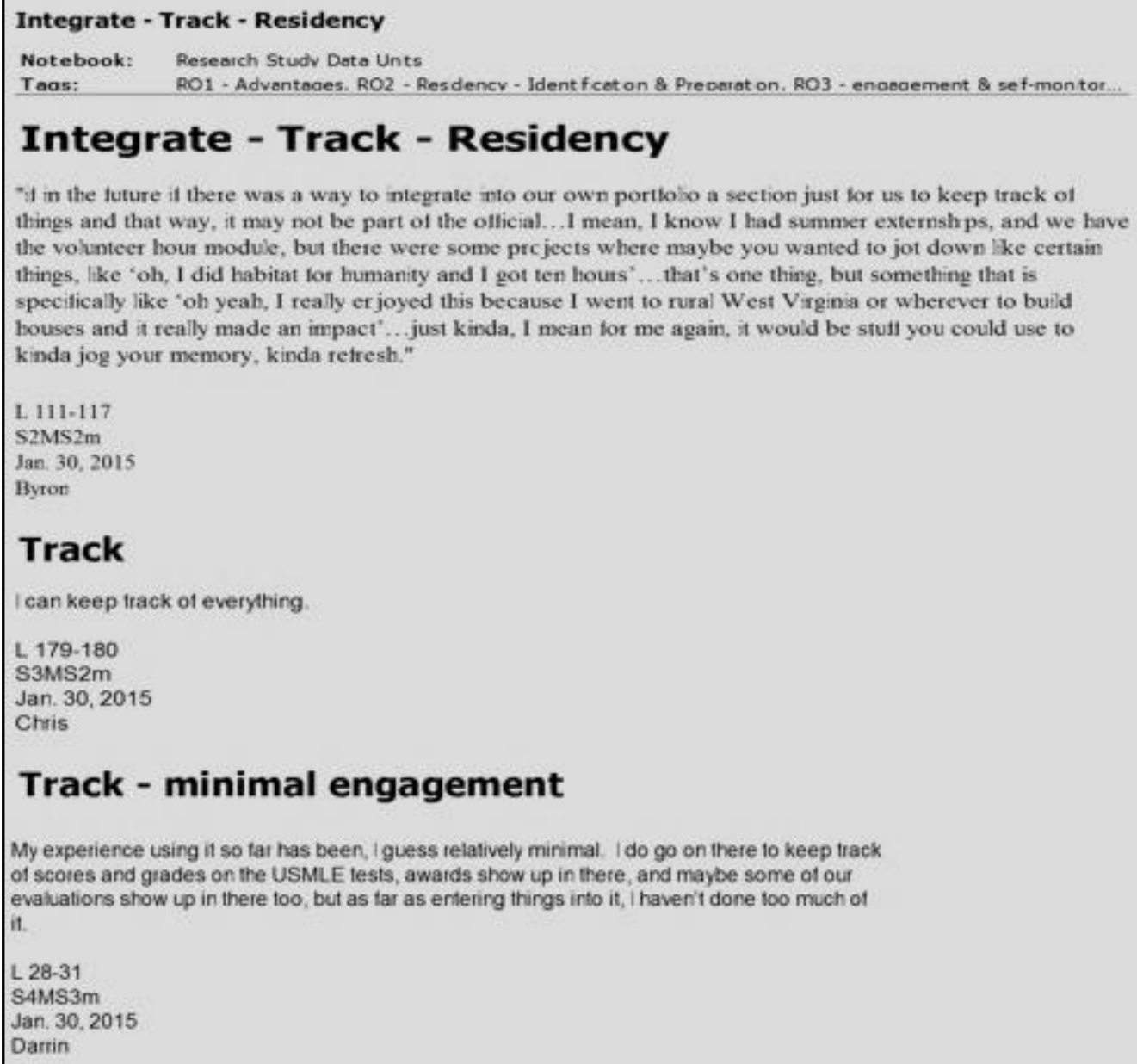

Figure 6. Sample of merged digital notes used to identify categories and emerging themes.

The resulting piles of broad categories (notebooks) aided in the identification of key themes in students' perceptions and attitudes that informed the understanding and organization of the data. The research questions were also used to further organize words, phrases and related key themes. Data were continuously analyzed throughout the study and frequency counts were also noted. 
Portfolio Analysis. The document analysis of the content, components and structure of the electronic portfolios was compared to the narrative data obtained from students and residents in order to check for consistency in data findings. The current design structure, organization and required components of the electronic portfolio were examined and compared to the data collected during student and resident interviews in order to uncover additional content and themes and for data triangulation. The researcher focused attention on portfolio items that received positive and negative responses from students in an effort to recognize which portfolio components and tasks are recognized as enhancing or hindering learning, reflection and documentation of competency attainment.

Reflection Analysis. A portfolio reflection analysis was also conducted for each participant $(n=15)$ to determine if the quality of reflections they provided align with the feelings they articulated regarding portfolio reflection activities during the interviews. Such reflection analyses permitted the researcher to examine whether feelings about portfolio reflection activities elicited during the interviews correspond with the reflections students wrote in their portfolio. The student reflections were also analyzed to determine whether there is consistency in students' feelings about portfolio reflection exercises and the quality of their reflections along with alignment of the reflective exercises with the PBLI 4 and PBLI 5 program learning objectives. Since the intent of the existing reflection prompts is to demonstrate compliance with the program learning objectives PBLI 4 and PBLI 5 (see Appendix A), the researcher analyzed the student reflections to see if the specific learning objectives are being met based on the reflection prompts provided and the students' responses. Such analyses will help detect potential design flaws within the portfolio's reflection prompts and vertical alignment with the program learning objectives. 
Researcher's Journal. The researcher's personal reflections and observation were documented during both data collection and analysis to help eliminate preconceived judgments or notions and distinguish how their own experiences and background may impact the research. The researcher's reflections were analyzed to strengthen and/or refute findings, contribute to the overall discussion, and inform the research implications for practice and future research. A summary representation of the data analysis process is depicted in Figure 7.

- Verbatim Transcription

- Multiple Readings

- Inductive Analysis

- Open Coding

- Digital Card Sort

- Closed Coding

- Source Triangulation of medical students' perceptions perceptions and residents'

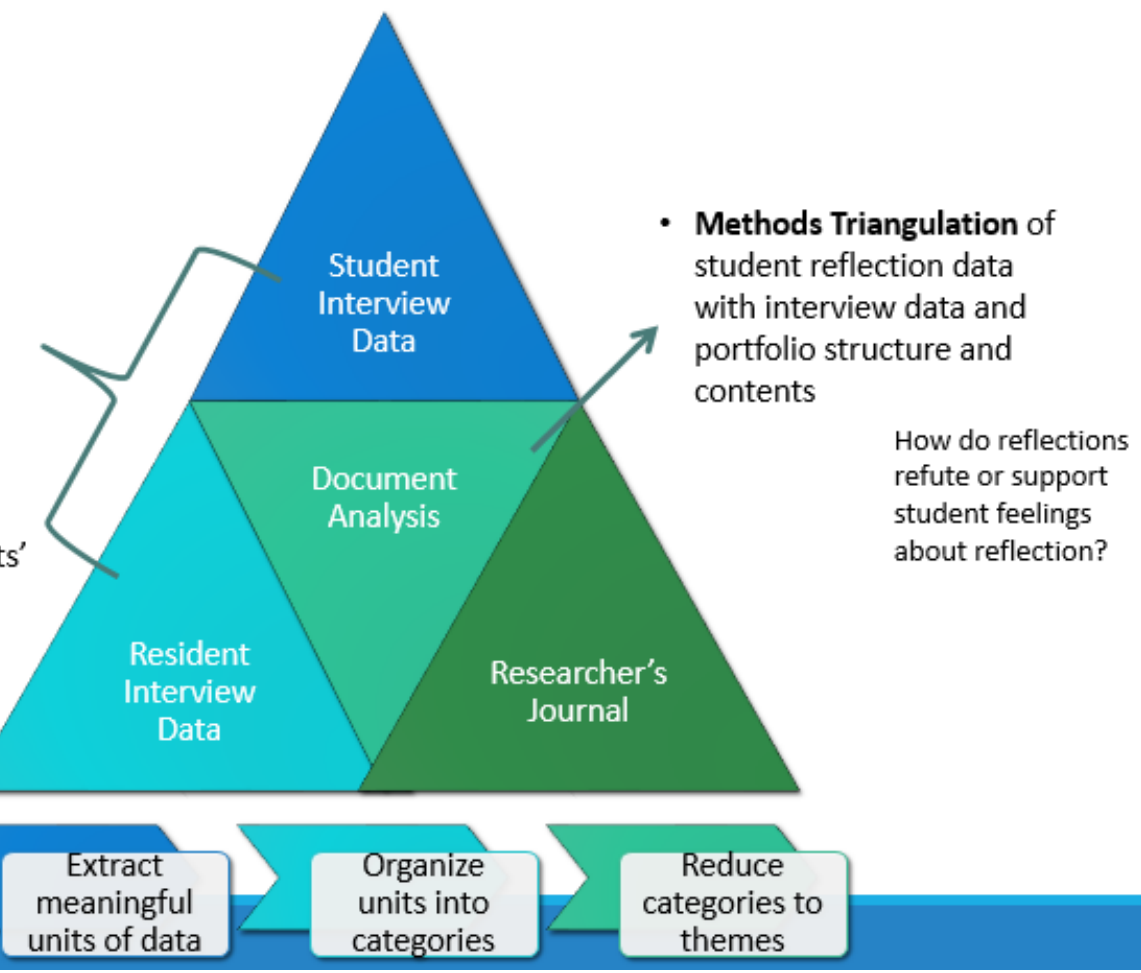

Figure 7. Summary of data analysis procedures.

The recorded interviews from students and residents, notes from document analyses, and personal reflections of the researcher are electronically stored in a password protected file folder and on a password protected computer. 


\section{Qualitative Trustworthiness}

Multiple methods of data collection (interview transcriptions, the existing portfolio structure and student reflections, and the researcher's personal reflections and observations) and multiple data sources (medical students, medical residents, portfolios and researcher's journal) were used to "provide cross-data consistency checks" (Patton, 2002, p. 556). Additionally, repeatedly listening to the recordings and reading the transcripts familiarized the researcher with the data.

Triangulation. Data triangulation was used for specific research questions to facilitate a deeper understanding of the phenomenon and to maximize trustworthiness of findings. The findings from triangulation are presented within the respective research questions in chapter 4 .

Methods triangulation. Methods triangulation was employed for RQ4 to evaluate the consistency of findings from different data collection methods. Specifically, the personal reflections (documents) of students in their portfolios was triangulated with their interview responses to examine consistency in responses regarding their experience using the portfolio against the quality of reflections and their alignment with program learning objectives. An analysis of the portfolio contents and components was also used to strengthen or refute student interview data regarding the utility of the electronic portfolio system.

Source triangulation. Source triangulation was used for RQ3 to cross-check medical student and medical resident data collected from interviews. The triangulation of resident and student interview data was used to strengthen findings regarding helpful components of electronic portfolios as students' progress toward residency application. The researcher's journal and the analysis of the structure, organization and contents of the portfolio were additionally used to corroborate findings. 
Member Check. An additional method to increase the trustworthiness of the data was achieved through a member check approach. Before in-depth analysis was completed, the researcher provided medical students with the transcripts of their interview in order to clarify their responses and ensure an accurate representation of their experiences.

\section{Summary}

In summary, the phenomenological qualitative methodology allows the researcher to understand how the design and implementation of electronic portfolios influences documenting and reflecting on learning in the medical doctor degree program from the student's perspective. Through semi-structured interviews, inductive analysis of the interview transcripts, document analysis of portfolios and reflections, and a researcher journal, the researcher was able to uncover themes and patterns in students' thinking and experience regarding use and design of electronic portfolios in medical education. The document analysis of the portfolio and medical student reflections and the researcher journal were triangulated with the themes that emerged from the inductive analysis and closed coding to help in determining the strength of these themes as well as any assertions. 


\section{Chapter Four: Findings and Discussion}

The central research question is concerned with how we design and integrate electronic portfolios in the medical doctor degree curriculum so that the learner experience is captured in a way that minimizes frustration, yet maximizes reflective practice and documentation of competency attainment. A phenomenological approach was used to collect and comprehend medical students' lived experiences using the WVU SoM competency-based electronic portfolio system. This chapter presents the findings from data as a means to advance understanding of how medical students perceive, experience and interact with the WVU SoM electronic portfolio. The chapter is organized by individual research question with the associated findings compiled and analyzed.

A semi-structured interview guide (Appendix B) was developed to collect data from 15 medical students ( 4 female and 4 male in second year and 3 female and 4 male in third year) and five medical residents ( 2 female and 3 male) during face-to-face or Skype (four medical students) interviews with the researcher. The flexible interview guide included open-ended questions that aligned to research questions, as well as questions aimed at understanding students' prior experiences with and utility of portfolio systems. One of the first questions posed to participants, for example, was to recount previous experiences with or knowledge of portfolios, paper or electronic, prior to medical school. Of the 15 student participants, only three had direct experiences with electronic portfolios previous to medical school and two participants disclosed that they had portfolio-like resources during their undergraduate education for tracking relevant items for the creation of a $\mathrm{CV}$ and/or for the medical school admissions process. Inquiring about participants' experiences and knowledge of portfolios was important in order to 
help the researcher recognize preexisting notions based on past expectations or negative associations.

A digital card sort analysis using Evernote was employed to organize initial units of data. Following multiple close reads of the transcripts, open coding was used to label chunks of data and assign properties to each code. The labels used to identify units of data emerged from both indigenous statements or key words used repeatedly by participants and from researcher generated labels (analyst typologies) based on related terms and phrases expressed by participants. Initial findings were arranged, grouped and tagged by research question(s) into repeating units to generate categories. The data categories generated themes among medical students and residents regarding the use of electronic portfolios for documentation of competency and reflection on learning. Inductive analysis was used to open code and establish themes, followed by closed coding of the categories that fell out in order to confirm themes.

Triangulation was employed to facilitate a deeper understanding of students' experiences with the WVU SoM electronic portfolio. Through document analysis of required annual reflections that students must record in their electronic portfolios, along with analysis of the interview data, methods of triangulation allowed for a cross-check for consistency with responses that elicited students' attitudes and perceptions about experiences with portfolio reflection activities. Moreover, the researcher's journal was used throughout the study to substantiate key ideas and observations, including not only personal reflections on the stories and experiences students shared, but also those on which they did not expound. The researcher's journal and observations were used to inform data analysis and conclusions. Source triangulation (medical students and residents) was also utilized to strengthen findings from the medical student data. A member check was also conducted with each participant to improve the 
trustworthiness of the data and is discussed at the close of this chapter. In order to conceal the identities of participants, pseudonyms, as opposed to real names, were used throughout the presentation of findings.

\section{RQ1: What Are the Advantages and Disadvantages of Using Electronic Portfolios to Document and Self-Assess Competency and Performance as Perceived by Medical}

\section{Students? (Interview)}

The interview data elicited from medical student participants uncovered both advantages and disadvantages for using electronic portfolios to document and self-assess competency and performance. Following data analysis, central themes emerged and are discussed independently below.

\section{Advantages.}

Convenience. Students commented that the electronic portfolio functioned as a pragmatic tool for documenting and self-assessing performance and attainment of competency largely because it allowed them, as well as administrators, to easily and quickly locate, appraise and reflect on significant metrics at any time from an Internet-enabled device. Such convenient access permitted students the capability to continuously self-monitor performance and adjust study strategies, behaviors and skills as needed depending on the quantitative and qualitative feedback provided by faculty and peers that is stored in the electronic portfolio. Specifically, Emily was genuinely "happy it's online because it's easier to access than having to go into the school." Nick agreed that "it was useful because you can get in it whenever you want. You don't have to go in to the office to like look at it."

Greta, when asked to describe her experiences with the electronic portfolio, shared in Emily's praises that "it's nice to have it all in one place" when elucidating feedback from her 
peers, especially those from her small Problem-Based Learning sessions and Clinical Learning Groups. She no longer had "to go through each individual [evaluation] to look at the comments" since they are now collated within the Professionalism folder of the portfolio, thereby reducing the number of steps and time needed to access peer feedback.

Storage and organization. Isaac, who by self-description, has always been organized through the utilization of spreadsheets and digital file folders to track his own accomplishments, illustrated how the storage and organization of the electronic portfolio has "alleviated the necessity to do things that [the electronic portfolio] does for me." For example, he no longer has to keep track of publications, score reports and other artifacts since the portfolio provides a secure location to archive important records. Likewise, Byron portrayed his experiences using the electronic portfolio by explaining how it effectively exhibits the "aggregate of a lot of the stuff I used to spend so much time looking for.” Having previously documented similar items using his own document management methods_- paper and random electronic documents_Byron upheld that the portfolio is "more organized than just a bunch of separate thoughts, you know, a sheet of paper somewhere in my office that I eventually lose, forget or end up deleting." Coupled with the notion that the portfolio keeps all of your performance statistics and accomplishments together, Byron was certain that when it comes time to craft his $\mathrm{CV}$, he will not need to frantically search multiple locations to locate his records because "it's all in one website...You don't need to go to PubMed to get your references - it's all just right there."

Performance tracking. Students frequently expressed that the data contained within the electronic portfolio - particularly feedback from faculty and peers, National Board of Medical Examiners (NBME) score reports, self-reflections, Committee on Academic and Professional Standards (CAPS) communications, and competency attainment status-helped them examine 
their performance trajectory and in response correct learning approaches, abilities and behaviors. Byron shared how he was able to easily track and monitor his performance because everything he needed was in the portfolio. He said that "all of my evaluations are here and I've got comments here and I've got scores here." The ability of the portfolio to chronologically catalog performance metrics was recurrently referenced as an advantage.

The electronic portfolio, as reported by Harriett, is a "tool that's designed to show you...how far you've come and to be able to really assess your strengths and put them out there...in the best way possible." Students believed that the grades and narratives, score reports, and performance on individual exams prompted them to informally reflect on their learning as a means to monitor and self-assess performance. As Byron noted, you can look back on your work to see "how you've changed. You can look at things and say 'I can see changes here." Darrin added that it also serves “to remind students what they've done and to give them the opportunity to look back and try to reflect on everything that they've learned." Kathy's response that the portfolio "helps me gauge where I'm at" further supports students' perceptions and experiences with the electronic portfolio as an effective performance tracking tool.

\section{Disadvantages.}

Interface accessibility and user friendliness. Though students identified convenience as an advantage, they did isolate four key access barriers to using the electronic portfolios for documenting and reflecting on learning: (1) limited access on mobile devices, (2) disabling the pop-up blocker, (3) inability to use their WVU ID (user name and password used to access all university wide systems) and (4) confusing interface for uploading documents and entering reflective exercises. Students did downplay these aspects as disadvantages, yet it was noted that students would access the electronic portfolio more often if these barriers could be eliminated, 
specifically since students in the third and fourth years of the curriculum only have access to their electronic portfolios on mobile devices when training in the clinical setting. It is worth noting that the specified interface limitations are not within control of the WVU SoM since they utilize a commercial system to support the electronic portfolio.

Limited access on mobile devices. The majority of student participants described the limited access on their mobile phones and how it prohibited them from fully engaging in portfolio activities as a barrier to portfolio access and application. Emily, Chris and Darrin, all third year students, voiced that they would access the portfolio more often if it were more mobile-friendly. Emily clarified that she does not typically carry her laptop with her to the hospital when on rounds, but does "always have [her] phone." She explained that "It's really hard to [access and reflect] from a phone or tablet...some things are really easy to do on the phone and other things are not easy at all." She specifically acknowledged that "the portfolio is one of those things that's not easy to use from mobile devices." Darrin added that "not being able to use an iPad or a phone" to reliably access the portfolio presented a challenge for using it when in patient care settings.

Disabling the pop-up blocker. Multiple students detailed how the pop-up blocker embedded in the $\mathrm{E}^{*}$ Value website is prohibitive to accessing the electronic portfolio. This disadvantage was often mentioned in conjunction with using a mobile device. Like many other students, Darrin blamed "the popup thing with mobile devices" as being one of the main access barriers for using the electronic portfolio. This observation was a repeating theme, particularly among third year students who are spending time in a hospital or other clinical setting, as opposed to the classroom where access is less obstructed. Julie recounted how the pop-up blocker frustrated her when she was trying to complete the annual reflective exercise following 
first year. She spoke about how she "was in a moment of panic" and could not understand why the portfolio was not working for her. After a classmate reminded her that she had to disable the pop-up blocker, she claimed that accessing and navigating the portfolio was less challenging; however, the experience did present frustration from the student perspective.

Different login than WVU MyID. Though login credentials are distributed to students prior to orientation and they can request forgotten passwords directly from the $\mathrm{E}^{*}$ Value website, as well as reset their password to their liking, Julie argued that she has "no idea what [her] login is." She, like four other students, indicated that they usually have to go back to an old email or go through the Secure Online Learning Environment (SOLE) to access a direct link to the portfolio. Byron proposed making the access link to $\mathrm{E}^{*}$ Value "more prominent on the SOLE site" and explained how it would have served to not only remind him to access his portfolio more often, but would have also made access less arduous.

Confusing interface for uploading documents and entering reflective exercises. Students remarked that the interface for using the portfolio was confusing as it pertains to uploading documents and reflecting on learning and experiences. They labeled the editing functionality of the interface as ambiguous with too many steps or clicks required to complete a task. To illustrate, Mike shared his first experience entering his Step 1 score report by detailing how "there was a very specific sequence of buttons you had to click" to upload the report. The interface, as depicted by Alex, was "weird" and not "super user-friendly." Reports such as those expressed by Mike and Alex were echoed by others using various terms, such as Nick's use of the word "chunky" to define the text editing and document uploading functionality of the interface. Students postulated that a more streamlined process for uploading artifacts and entering reflections would enhance the user experience and improve engagement with portfolio 
components and activities.

\section{Knowledge of core competencies and use and purpose of electronic portfolio. A} repeatedly discussed drawback for using the portfolio was students' self-declared lack of knowledge concerning the meaning or expectations of the core competencies. As Emily explained, "just making us more aware of the competencies we're supposed to be attaining" would be a good start. Though the competencies are often addressed and can be found in the student handbook and within the portfolio itself, Emily admitted that she "couldn't specifically name them." Students also frequently expressed uncertainty regarding the evidence used to demonstrate attainment of each competency domain.

Frieda pointed to the need for "clearer expectations" on the proper use and purpose of the portfolio. By informing students that the portfolio can act as a channel for expressing "your feelings and your experiences" as you advance in the curriculum and prepare for residency, she argued that student engagement with the portfolio would be enriched. Alex posited that it would be helpful if students were reminded of the importance of the portfolio more often. He felt it would be useful if "someone got up there and was like this is why it's important. This is how we can use it to help you get into residency and this is how we can use it to help get to know you."

Students attributed their lack of knowledge for the use and purpose of the portfolio to the limited and ill-timed training opportunities. Multiple students identified the timing of the introduction of the portfolio (during orientation) as being unconducive to their comprehension of its purpose and appropriate use owing to the volume of information presented to them and the limited timeframe available during orientation to process information. Greta reasoned that changing "the timing of the introduction" or at minimum revisiting the appropriate use and 
purpose of the portfolio a few more times throughout the curriculum would help to improve students' understanding for having an electronic portfolio to document and reflect on learning.

Frequency of use. One surprising disadvantage from the student perspective is that they are not required to use the portfolio to self-assess performance and document competency attainment frequently enough for there to be a notable impact. Of the 15 participants interviewed, 7 mentioned that it should be mandatory that they reflect on their learning more often, with 3 participants suggesting that reflection be required after the completion of each semester.

A misconception that surfaced was that the electronic portfolio was planned primarily for students in the third and fourth years of the curriculum. Three of the seven second year student participants commented that they did not currently use the portfolio regularly because it is intended more for preparing for residency and will be used later in the curriculum. For example, Julie stated that she "think[s] that a lot of the function is for third and fourth year." Chris expanded on Julie's perception that students are not using the portfolio consistently in the first and second years of the curriculum when he added: "I haven't used it too much...I'm going to try to change that after MS3 and MS4 to keep track of everything."

To gain insight into frequency of use and purpose for access students were asked, "How often would you say you access your WVU SoM electronic portfolio? Why? What makes you go there?" The responses varied from one time per semester among second year medical student participants to once per block (every 6 weeks) by third year students. The finding suggested that participants engage with the portfolio more often as they progress through the curriculum, particularly during the clerkship years because the triggers that entice them to visit the portfolio (narrative feedback from faculty, peer professionalism evaluations, and NBME score reports 
with detailed performance breakdowns on specific content learning objectives) are posted to the portfolio at more regular intervals than during the first and second years of the curriculum.

Value of portfolio for reflections. Positive student perceptions regarding the value of the portfolio for reflection were negligible. Students attributed this mainly to the lack of emphasis on their personal growth and development. Additionally, the electronic portfolio platform itself had minimal impact on learning or reflection according to Emily. In fact, she declared that "we uploaded those reflections to the portfolio, but if we had to upload them on SOLE, I don't think it would have made any kind of difference as to what I wrote or anything like that." Additional information regarding the value of portfolio reflections is presented in research question 4.

\section{RQ2: In What Ways do Students Feel the Portfolio Components Will Help Them to Prepare for and Identify a Suitable Residency Program? (Interview)}

Students described the portfolio as a tool that has the capacity to support them in the identification of and preparation for residency program. Specifically, students in the third year of the curriculum reference the narrative feedback provided at the end of each clerkship as informing them of whether the specialty is a suitable area of practice for them. Students also recognized how the storage and documentation of important records, such as score reports, awards, research and publications aid them in the development of their CV and personal goal statement; however, students displayed mixed positions on how the electronic portfolio reflections will help them to identify and prepare for residency. They designated this aspect of the portfolio as a weakness. Compared to second year medical students, third year students tended to articulate more ways that the electronic portfolio can be helpful for identifying and preparing for residency. This might be attributable to the frequency in which third year students 
access their portfolios versus second year students, but is likely a consequence of students in the third year becoming more aware of the residency application process.

The most noted components of the electronic portfolio that were viewed as helpful for identifying and preparing for residency were the narrative evaluations - submitted by clerkship directors and available in the students' portfolios_-as well as the NBME score report breakdowns and class rank listings. The majority of third year students indicated that the rich feedback they received from clerkship directors helped them to hone their skills in the six core competencies in an effort to adjust their approaches to patient care, professionalism, and interpersonal and communication skills.

As a second year student, Isaac's impression was that the electronic portfolio is going to be "really good when it comes down to getting ready for interview season and going through the match.” The National Residency Matching Program (NRMP) provides a uniform time for residency applicants and programs to make their training selections. Isaac trusts that this will be a time "when you're really going to see people really interested in using [the electronic portfolio] to its maximum potential." Unfortunately, the misconception that the portfolio is a tool intended primarily for third and fourth year students has resulted in limited engagement with portfolio contents among first and second year students. On the other hand, the student perception that one of the projected purposes of the WVU SoM electronic portfolio is to help medical students for the eventual preparation for residency is noteworthy.

There were also items identified as missing from the electronic portfolio as it pertains to residency preparation and that will be explored more fully under research question 5. As reported by Harriett, class standing and scores are important, "But I think too, the things that make you stand out... one of my attendings calls it the hook. You know, what do you have that 
hooks you and that makes you impressive or extra special?" Nearly every student made reference to the fact that the portfolio activities, particularly reflection prompts, do very little to help better understand themselves as an individual or to help them understand themselves and their growth towards professional practice.

Darrin, like other student participants, agreed that there are benefits to the portfolio when applying for residency programs since relevant documents are stored there. For instance, in reference to the Patient Care folder, he reported that licensing services require evidence that students have completed or, at minimum, participated in a list of patient procedures and encounters. He envisioned the procedure logging requirements that represent evidence of the Patient Care competency to be helpful when applying for residency because students will be able to sit with their portfolio and verify that they have had the appropriate experiences and are competent with everything documented in their portfolio. He supplemented his response with a reminder that the contents and organization of the portfolio provides "a way to standardize and show that our school doesn't have some huge deficit, in say ob/gyn where students have never seen a birth or anything." By showing "that we have at least [been] provided the opportunity and capability" to observe or perform essential skills in various clerkships, he postulated that students' residency applications can now be supported with evidences of experiences.

Relative to the reflection activities, students portrayed their reflecting experience as "doing what they thought administrators wanted to hear." They suggested that the portfolio reflection activities could do a better job preparing them for residency if the prompts specifically targeted commonly asked residency interview questions or included prompts that were more clinically or personally structured, as opposed to broad questions about summer experiences, for instance. Participants did stress that the reflection prompts that required them to set goals and 
then reflect on those goals at a later time had benefits as they prepare for a residency career.

These findings will be discussed further under research question 5, but as Nick pointed out:

It would be helpful if either at the beginning of first year, or throughout medical school, as part of the reflections, they ask us some of those esoteric interview questions like, if you didn't do med school what other profession would you have done and stuff like that. Things programs ask you on residency interviews. That would be super helpful to continually think about questions like that.

\section{RQ3: How Does the Structure and Organization of the Portfolio Influence How Medical Students Engage With Portfolio Activities and Self-Monitor Performance and Competence? (Interview)}

Students routinely noted that not only were there numerous folders within the portfolio structure, but also that they had limited knowledge of each folder's purpose. They communicated that many of the portfolio components are not currently used or they are uncertain of their purpose. Specifically, they exhibited mixed feelings regarding the nomenclature used to identify folders within the portfolio. While over half of the participants regarded the competency-based layout as beneficial, they indicated that it is simultaneously challenging to find an item in the portfolio due to the labels used to identify the folder structure. Emily pointed out that though "the essential layout of [the portfolio] is fine," the naming of folders is confusing. She suggested a "more obvious" nomenclature rather than "naming [folders] by the competencies." She continued to say that she feels as if it is "not super intuitive as to what would be organized where...I usually have to click through a bunch of them before I find the one that I'm looking for." 
It was articulated that the naming of folders be more reflective of the contents in order to make searching for particular items more intuitive. Students questioned why folders are not simply labeled with terms that accurately describe the nature of their contents. For example, why is a folder labeled as Professionalism as opposed to Peer Evaluations? Or, why is the Practice-Based Learning and Improvement folder not simply labeled as Reflections to be illustrative of the contents? Students assured that such labeling would minimize their frustrations and the time they expend locating information within the portfolio. A third year student, Alex, recounted his experience with the current organization: "I feel like there's maybe too many categories that kind of sit empty or else I don't know what they are supposed to be used for."

Comments from students described competency-based layout as cumbersome since they have limited knowledge on what each competency means and how portfolio contents are organized within each competency folder. For instance, to Chris, the cumbersome nature was analogous to "dig[ging] through the manure." He suggested that the organization could be a little more straightforward if the submenus were structured in a way that reduced the need for expansion of submenus or scrolling. Though, like others, he explained that "you eventually find" what you're looking for, he was clear that it would be easier and more efficient if the use of submenus were eliminated.

Referencing the researcher's journal, which included notes obtained during the data collection and analysis processes, it was evident that the majority of students recognized value with the competency-based approach to portfolio folder organization since it aligns with the Program Learning Objectives (PLOs), but were still unclear on the meaning and types of evidence needed to demonstrate competence in each area. From the administrative perspective, 
such organization is instinctual for not only easily tracking students' success through the program, but also for demonstrating how the curriculum ensures comprehensive coverage of the PLOs. However, the portfolio's intended design is to engage students, and thus the competencybased approach to folder identification is a limiting factor.

RQ4: How Do Student Attitudes and Perceptions (Elicited from the Interviews) About the Act/Purpose of Reflecting in the Electronic Portfolio Compare to the Content and Alignment of their Reflections to the Corresponding Program Learning Objectives? (Document Analysis and Interview)

Medical students' attitudes and perceptions about the act/purpose of reflection. Nearly every student indicated that their performance on exams and feedback from faculty and peers provoked personal reflection on what they can do differently to improve. It was not apparent whether students initiated reflective practice during the actual learning process, but it was evident that they reflect on why they performed the way that they did and identified potential strategies they may exercise to improve future performance. Students communicated that they informally reflect often and their stories reminiscing on the last time they reflected are varied. Three students shared how they regularly reflect by discussing their performance and experiences with their spouse. Other students indicated that their reflections most frequently occur when they are alone, for example while walking to or from class, following an exam or after the posting to their portfolio of performance metrics or evaluative feedback.

Descriptions of their experiences using the electronic portfolio for formal written reflection uncovered a lack of knowledge concerning the purpose or act of reflecting among students. Their reasons were diverse and wide-ranging, from not knowing who was reading their personal reflections, to only writing what they think administration wants to hear. Students 
also described how the act of reflecting, along with the purpose of the required reflection prompts do little to highlight their personal qualities or stimulate them to reflect on how their learning experiences are shaping them into compassionate and caring physicians.

Students acknowledged that reflection is an integral measure of knowledge and personal and professional growth, but they consistently conveyed that the act of formal written reflection was not something that they do regularly. Students did admit that they constantly reflect informally on their learning and voiced mixed feelings on the value of recording reflections in their portfolios. For Darrin, reflection occurs "almost daily" on what he is learning and how what he is learning will be useful, but he "never ever set[s] aside actual time to reflect on something particularly deeply." Greta said when she was first asked to reflect that she was not thrilled; however, she did indicate that the prompt that required her to reflect on performance and articulate strategies to put in practice to improve performance was helpful because it "gave [students] some direction."

Lois recalled the first reflection activity that students were required to do on their summer experience. She said it was helpful since the "act of making the reflections kind of makes you remember why you're in medical school and makes you try and connect what you're learning to ...where you want to go." She elaborated that "you can kind of get bogged down in the test to test kind of mindset," and insisted that "staying focused on your goals" is a "helpful...and very healthy exercise." Julie also viewed formal reflection as advantageous. She professed that "reflecting on something now and being able to go back into it and sort of see how you felt at that point in time and how your progression is going" has its benefits as a medical student navigates the curriculum. Similar to Lois and Julie, Chris emphasized that the reflections were interesting in that they permitted him to see how he "changed from first year to second year, and 
what [he] assume[s] will be second year to third year." He described the reflection aspect of the portfolio as a "keystone where you can look back at yourself" and examine whether you have changed or if you are "continuing on the same path."

Other participants expressed that the reflection activities are not particularly constructive since they stimulate feedback that, as Greta explained, is presented from the student perspective as “what would I want to hear [as an administrator]? 'Okay, I participated. I wasn't tardy'. You know?" She pondered whether more "clear-cut direction about the reflection" activities would help scaffold students' reflections and as a result, they "might get more out of them and whoever is looking at them might also get more." Like many of her fellow students, Greta described selfreflections as akin to "walking a fine line between bragging about yourself and being way too hard on yourself."

Frieda echoed Greta's opinion when she mentioned that the self-reflections were not something she would place much value on "because you're not going to say anything bad about yourself, like 'I was terrible'." She elaborated that students might give themselves constructive criticism, but not too much detail because they are "not really going to pull those skeletons out of the closet."

For Byron, formal written reflections appeared to be something that medical students need training and support in, as well as routine opportunities to compose their feelings in order for it to become a lifelong habit. When recollecting on the last time he reflected, he described how he "never articulated in words, just vague notions in [his] head." He explained that "if it was part of...like a routine, you know you actually sat down and reflected on things...I think it would encourage that behavior later." Byron supposed that students should document events or experiences that have happened. By reflecting on them, he held that it would make you "much 
more aware of how things would affect you and kind of how you're viewing things... You know understanding...putting things down into words, it really kind of solidifies and makes these abstract thoughts much more visible and more concrete.”

Harriett suggested that, in addition to the required reflections at the close of each academic year, students should also have the ability to "just log in...things that you've done...like a resume type style of bulleted points." She believed the portfolio should provide the student the ability to express not only what and how they have performed during their training, but also how they felt about it.

Students believed that it would be challenging and require more introspection if they were asked to document where they can improve as opposed to vague questions that permit them to only focus on their positive attributes. They feel reflection activities should concentrate on their experiences with patients and how those experiences shape their thinking and interest in medical specialties. They also felt the reflection prompts should not be too general, which gives the impression that they are meant to only check a box that they have reflected; the prompts should be well thought out and carefully designed to help them understand their new professional identity or to prepare them for questions they might encounter during a residency interview. In essence, prompts that require them to examine themselves beyond academic performance metrics would enhance engagement with portfolio reflection.

A significant revelation emerging from the data was that the portfolio's strong focus on metrics do not distinguish WVU SoM medical students from the other 35,000 U.S. and international medical students applying for first-year residency positions. Students felt there should be ample opportunities for their personalities to surface within the portfolio. Students maintained that prompts aimed at understanding themselves as a person and future physician are 
more valuable than performance data since the personal aspect will help set them apart when preparing for interviews and residency application.

Student attitudes regarding the act and purpose of reflecting often referenced career planning and development. For example, when Chris was discussing the reflective piece in the portfolio, he said he "looked at it as an opportunity to figure out what I liked and what I want to pursue" and the reflections helped him to redirect his career aspirations from one specialty to another. Accordingly, he felt that reflection prompts that specifically target commonly-asked residency interview questions rather than general questions about summer experiences would be more beneficial.

Greta suggested that requiring students to review their peer comments and asking them whether they agree with them or not would be powerful. She explains that "there's going to be some good ones, there's going to be some bad ones, but how a person... reacts to what their peers say... is a really important part of knowing who someone is."

Overall, students' attitudes regarding formal reflection in the portfolio were mixed. They mentioned that reflective prompts currently embedded in the portfolio, though satisfactory, did little to prepare them for residency and had minimal impact on their personal and professional growth. For example, one student, Alex, stated that "doing [reflections] more frequently or maybe more specific prompts, not like what did you do this summer... what did you learn from that, like what do you want to be when you grow up?" was not a good use of a student's time. Nearly every participant indicated that the prompts should be structured in a way that proves beneficial when they are applying to and interviewing for residency positions. They also indicated that questions that ask them to reflect more on their weaknesses than on their strengths will aid them in strategizing improvement plans. Students did express that reflecting 
can demonstrate their change over time. For instance, Byron reasoned that the reflections show “how you've changed. You can look at things and say 'I can see changes here' and for good or for worse, whatever they are."

Alignment of reflections with Program Learning Objectives. As for alignment of student attitudes regarding reflection with the actual reflections they documented in the portfolio, triangulation of the interview data with the reflections supports that the targeted competency outcomes are being met. For example, the program learning objective Problem-Based Learning and Improvement 4 (PBLI4) states that students will develop the skills necessary for lifelong learning, as evidence by demonstrating independent and self-directed study. The reflection activities in the portfolio, based on student experiences, have contributed to the development of the PBLI4 competency, as does specific contents of the portfolio that often engage students in independent and self-directed study, such as performance breakdowns in various content areas. This finding is evidenced by the fact that participant responses repeatedly indicated that the contents of the portfolio, specifically NBME score report details and assessment data from course performance triggered independent reflection. One could argue that the students' selective experiences also demonstrate compliance with the PBLI4 learning objective since students independently pursue learning opportunities and then reflect on how the experience helped them towards fulfilling their goals and career interests. From this perspective, the data support the finding that even though students meet this expectation, the reflective activities are a mere summarization or documentation of the experience. In other words, the reflective exercise itself is not fulfilling the objective, merely documenting that it occurred. 
The actual reflection of a MS2 is included below in its entirety. The attitudes expressed by students about reflective activities being written based on audience (administration) and that they do little to advance student self-understanding is evident in the passage.

What activities did you do to satisfy the requirements for the summer course? This summer I completed the Family Medicine Summer Externship Program and the Internal Medicine Preceptorship. Reflecting on your first-year grades and narratives and your summer experiences, what are your goals as a second year student? These summer experiences were a wonderful introduction to clinical medicine. They reminded me of why I chose to enter medical school. Throughout these experiences, I found that some of the best doctors were those that were able to briefly explain to the patients the physiology of their condition and how pharmaceutical or lifestyle interventions would impact their body. This motivated me to really engage in the MS2 curriculum. These summer experiences also reviewed all the history taking and physical exam techniques from PDCI 1. One of my goals for the upcoming year is to practice these skills weekly. How will achieving your goals help you pursue career interests? Engaging in the MS2 curriculum should prepare me for the USMLE Step 1 exam. Continuing to practice physical exam skills \& history taking will be good preparation for MS3 rotations. Both of these goals will allow me to explore different areas of medicine, while keeping my options open.

Students noted in their reflections that the self-selected experiences they participated in during the summer, such as research opportunities, helped them to identify goals for improvement and hone their interests in medical education. Nick, for instance, noted that 
"Although my research may not be ground breaking, the experience has really taught me a lot and has helped me to form a more thoughtful and precise way of thinking about things." Oliver similarly believed the research experience "will greatly help me be more prepared when I begin[s] the clinical years." The reflections illustrated how students self-directed their learning experiences to identify areas of interest in medical specialties and research opportunities that will help them develop the skills necessary for lifelong learning.

As for the PBLI5 learning objective, which states that students will utilize strategies to identify and analyze strengths, deficiencies, and limits in one's knowledge, collaboration skills, and professionalism, an analysis of the reflective activities recorded in the students' portfolios revealed well-written and comprehensive responses to the question prompts posed. Students effectively identified and reflected upon their NBME score report breakdowns and communicated plans for correcting deficiencies in content knowledge. Reflections also analyzed strengths, deficiencies and limits in knowledge, collaboration skills, and professionalism. Nick noted in his reflection that he hoped to "improve [his] patient communication skills and develop a good bedside manner" while on his third year rotations. Emily's reflections also revealed that students' responses align with the PBLI5 objective. She recognized how "fatigue came on quickly and my grades slipped" as a result. She continued to write that she wanted to focus her third year studies on:

Learn[ing] to integrate book knowledge with practical skills and outcomes. Some of my other goals include not losing my humanity and compassion. I didn't realize how much I enjoy talking to and working with patients until my surgery rotation started. Seeing my patients before rounds and doing post-op checks on them is the highlight of my day...Achieving my goals of deciding on a career 
choice, developing my skills as a student-doctor, not losing my compassion, and succeeding academically will all help me pursue my as yet undetermined career interests by contributing towards a strong residency application and successful match.

Analysis of the students' portfolio reflections does indicate that competency PBLI5 is being met; however, student interview data indicate that their reflections are not completed in a meaningful way. Many students suggested that they only submitted reflections that they thought administration wanted to hear. It was evident from the students' stories conveyed during the interviews that they routinely reflect informally on their strengths, deficiencies and limits in knowledge, collaboration skills, and professionalism, and indicated that portfolio components triggered such reflection (e.g., peer evaluations, grades and narratives, detailed NBME score reports, and other evaluation data).

Students' portfolio reflections confirmed that they do reflect on learning and discuss how they made or plan to make changes. As one student noted in his personal reflection, "I did not perform up to my standards on the first block exam of the year, but quickly learned new study habits and methods and, by the 3rd block, I felt comfortable again." Harriett shared that she "felt like...[she] had finally achieved a healthy balance between academics, wellness, and spending time with friends and family" and how as a third year student, she hopes she "can continue this balance while managing rotations."

Alex's personal journal reflection illustrates how students use the portfolio reflections to identify strengths and weaknesses:

I was pretty happy with my step 1 score, but I was not happy with dropping from the second to the third quartile. My goals for the next school year are to improve 
my class rank from third to second quartile and score as high as possible in my surgery rotation. Currently, I am most interested in ophthalmology and other specialties in surgery. I think that scoring highly in surgery and performing well in an ophthalmology elective as well as improving my quartile will make me a stronger residency candidate. I would also like to be involved in research or more case studies in the future to further explore my interests in ophthalmology and surgery. Over the course of the next year, I plan to use NRMP, FREIDA, and CiM as well as counseling from the deans in order to find out more about residencies and careers.

As was evident with Alex's portfolio reflection, the prompt elicited straightforward responses that answered most of the questions posed, but failed to provoke self-awareness of how the student is growing or personally changing as they navigate the curriculum. The reflective piece does serve as a strategy or tool to promote student self-assessment of strengths and deficiencies, as stated in the PBLI5 objective. Participant feedback indicated that the rewording of reflection prompts would motivate them to take the experience more seriously.

RQ5: According to the Researcher and Medical Students, Which Electronic Portfolio Components are Missing and/or Over/Under Utilized in a Way that Limits their Engagement in Competency Attainment and Reflective Practice? (Interview and Document

\section{Analysis)}

An analysis of student interview data, the portfolio contents and folder structure, and the researcher's journal uncovered elements of the WVU SoM portfolio that were deemed missing or over/under utilized by students. The following sections detail the findings. 
Missing. The researcher's journal outlined components deemed missing by students as conveyed through the interview, including (1) emphasis on CV generation, (2) focus on personal growth and character, and (3) opportunities to freely enter text outside of the designated reflection assignments.

Emphasis on $\boldsymbol{C V}$ generation. Like most students, Emily would like to take advantage of today's technology to "enter awards and research and other things...kind of like a CV generator almost." She thought if the electronic portfolio provided a structure for the creation of a CV, students would appreciate the time and effort required to populate it with important documents. She said that there are "tons of different ways" to structure a CV and "it would be easier if [the electronic portfolio] kind of helped you organize" everything for the creation of a CV since “everything was already in there." A document analysis of the portfolio contents and organization revealed that there is a place to upload a CV in the electronic portfolio (Counseling and Career Advising folder); however, it does not auto generate based on the others contents stored in the system. Additionally, research and publication can be stored in the Interpersonal and Communication Skills folder.

Focus on personal growth and character. The utilization of the portfolio to showcase students' personal growth and development was also noted as a missing component of the portfolio. Students elaborated on this primarily when discussing the reflection prompts they are required to respond to at the close of each academic year. As the findings from research question 4 revealed, the portfolio is missing an opportunity to connect reflection activities with career planning and advising.

Opportunities to freely enter text outside of the designated reflection assignments and rigid folder structure. Students perceived that the ability to freely log things that they have done 
outside of the structured areas of the portfolio was missing. For instance, Harriett mentioned that it would be very helpful to be able to quickly enter

things that you've done....like a resume type style of bulleted points. You know, 'how I've done this and I've done that, and by the way, I've been able to be the president of this club, it's been really interesting for me, and blah, blah, blah. I think that those are important things.

Under-Utilized. In addition to students' observations that the reflection piece of the portfolio is under-utilized and should be integrated more freely throughout the curriculum, students also revealed that sufficient emphasis is not placed on the development and documentation of their personal accomplishments. For example, Byron indicated that, due to the rigid structure of the portfolio, there was not a defined area within the portfolio for him "to keep track of things...I mean, I know I had summer externships, and we have the volunteer hour module, but there were some projects where maybe you wanted to jot down like certain things...to kind of jog your memory, kind of refresh...and that is not currently promoted." An analysis of the portfolio structure confirmed Byron's statement that there is not an actual place to freely document experiences since every folder is predefined with the expected contents. Students also indicated that a greater emphasis be placed on their volunteer efforts, participation in clubs and organizations, and leadership roles as potential ways to strengthen the role of the portfolio in their daily life and the curriculum.

A remediation plan for underutilization is supported by student remarks concerning unrelated interview questions. Expressions such as (1) require students to reflect more often, (2) expect them to reflect on meaningful or personal attributes and (3) provide multiple opportunities for training, support the finding that active engagement with the portfolio is negligible. 
Students indicate that they still receive a great deal of paper-based evaluations and other documents, such as performance in the Simulation Center. Additionally, the logging of community and school service hours are not included in the portfolio. Alex mentioned that students still receive paper evaluations "on a lot of rotations third year."

Oliver indicated that a component of the portfolio that he senses to be particularly beneficial is the inclusion of the Way to Go! evaluations. The Way to Go! evaluations were designed as a means for peers, faculty, administrators and staff to recognize a student for quality performance or professionalism outside of the regularly scheduled evaluation activities. Though they are an existing component of the electronic portfolio, Alex reasoned that this type of feedback is helpful for the in-the-moment, informal constructive feedback that is not necessarily a component of the final evaluation submitted for residency (the Medical Student Performance Evaluation or MSPE). He felt the feature was underutilized in the curriculum.

Over-Utilized. Students did not identify any areas that are over-utilized in the electronic portfolio, though they did often stress the over-utilization of course and faculty evaluations as a deterrent for accessing their electronic portfolios ( $E^{*}$ Value) more frequently. It was evident that students' negative associations with E*Value in general influenced their perspectives and experiences with the electronic portfolio. For example, Alex was certain that others view the numerous faculty and peer evaluations "as pretty tedious because of the way they are setup in E*Value." He argued that students "relate [evaluations to be completed] too much to portfolios and reflection" and insisted that "the association [of the portfolio] with E*Value is deterring." 
RQ6: What can be Gleaned from Graduate Medical Education Residents When Asked to Retrospectively Reflect on Electronic Portfolio Components they Feel Will be Beneficial to a Medical Student? (Interview)

Residents from obstetrics and gynecology $(n=3)$ and family medicine $(n=2)$ were interviewed using the designated flexible interview guide as a means to ascertain if residents' perspectives did or did not align with research findings from medical students regarding electronic portfolio components that students feel are beneficial. Data analysis revealed that residents believe there is value in medical student electronic portfolios; however, they were consistent in their responses that reflection is of little intrinsic value unless is relates directly to preparation for the residency application and/or interview. Residents were in agreement that the reflective portion of the electronic portfolio should offer a glimpse into the personal traits and characteristics of medical students; the traits that make the student stand out. They also explicated how performance metrics are valuable, but certified that when thousands of medical students apply to a residency program with similar performance metrics the only thing that stands them apart is their personal and unique attributes.

Like medical student participants, medical residents agreed that the portfolio is a valuable tool for organizing and documenting growth and performance over time. According to Patrick, a second year Ob/gyn resident, the portfolio is a helpful tool for preparing for residency. He expressed:

I mean getting into residency and moving forward with your career requires that you have your ducks in a row, so to speak, and have easy access to a lot of different... a lot of different information...scores and letters and other 
accomplishments. So [the electronic portfolio] gives you a one-stop-shop to pick up those things.

When it comes to the types of information that should be documented in a medical student's portfolio, Queta saw value in including the research they participated in, the lectures and extra sessions they have attended, and the volunteer work they have completed. When it came time to apply for a residency program, she saw the portfolio as a strength since students "could easily reference it and put it right into their ACGME application."

\section{Themes across Research Questions}

A theme that emerged across multiple research questions was that of time. Both student and resident participants described the portfolio as a tool to increase efficiency in record keeping, reflection and performance monitoring. In brief, the portfolio consolidates vast amounts of data and makes it readily available in a single application. To illustrate, Emily stated that she no longer had to go to the office to view records of her performance; Greta added that she no longer had to filter through comments since all the peer comments are aggregated in a specific folder within the portfolio.

A second theme that emerged across multiple research questions was the limited role of the portfolio reflections to help mirror the personal attributes of the student. Several students and residents commented on the importance of the portfolio as a tool to showcase both the academic and personal characteristics of students.

A final finding that emerged across research questions was that of training. Students openly expressed the need for more frequent training opportunities to not only aid them in the proper use and navigation of the portfolio as a technology tool, but also to provide them a more 
structured understanding of how they are being evaluated for competence. Students indicated that they are not clear on what each competency means and how it is assessed.

\section{Unexpected Findings and Unique Positions}

The researcher's journal documented the unexpected findings from the research study. One notable finding was students mentioned that the portfolio reflection activities should be embedded at regular and frequent intervals in order to engage students in using the portfolio to make connections between what they are learning and how what they are learning is a means to support them in the development of such learning habits. Another unexpected finding was students' limited knowledge of the core competencies and how they are used to assess overall student performance. That a couple of students announced that they were not sure who actually has access to their portfolio was also unexpected.

Students also expressed unique views or dissenting opinions from the rest of the group. Byron voiced an interesting perspective about how reflecting on learning and experience will "affect a lot how I communicate and kind of understand other people, or at least interpret things." One unique perspective that was mentioned by two medical students (and the researcher noted similar observations based on interactions with three additional students) was that the students associate their portfolios with $\mathrm{E}^{*}$ Value or completing evaluations and thus have a negative reaction.

\section{Trustworthiness}

The researcher utilized both a member check and method and source triangulation to increase the trustworthiness of the findings. Each is described below.

Member Check. A member check was used to provide confirmation of student participants' responses to the interview questions. Following verbatim transcription of the first 
interview, the researcher sent the transcription to each participant and asked them to read through the transcript. Subsequently, the researcher contacted each participant for an informal second interview or member check to ascertain their level of agreement with the transcribed data and to offer opportunities for the participants to clarify and/or elaborate on their original stories. Each participant agreed with his/her transcript as presented, with one student requesting modifications in an effort to "clean up" his use of the word "like" throughout. No requests were made for changes to the content or meaning of responses. Another student, Nick, elaborated on his initial interview with:

It would be helpful if either at the beginning of first year or throughout medical school as part of the reflections they ask us some of those esoteric interview questions like, if you didn't do med school what other profession would you have done and stuff like that that programs ask you on residency interviews. That would be super helpful to continually think about questions like that. Nick's feedback was presented in the findings, but since it was an addendum to his original interview responses, no changes were made to the transcript as a result of the member check. The researcher is confident that what was presented in the original transcripts is presented within the findings and represents the true perceptions and experience of medical students.

Triangulation. Following the member check, data were triangulated with the themes that emerged from the inductive analysis and closed coding to help in determining the strength of themes as well as any assertions. Methods triangulation was employed for RQ4 to evaluate the consistency of findings from different data collection methods. Source triangulation was used for RQ3 to cross-check medical student and medical resident data collected from interviews. 
The triangulation of data provided the researcher with a deeper understanding of the electronic portfolio design, implementation and impacts on learning based on the similarities and differences in the reported data. These findings from triangulation have already been presented within the respective research questions. 


\section{Chapter Five: Summary, Conclusions, Implications and Recommendations}

\section{Summary}

The medical education paradigm has shifted from knowledge acquisition to knowledge application, from an emphasis on summative assessment to more formative measures, and from a teacher-driven to learner-centered curricular experience. Medical education has fundamentally evolved from a structure- or process-based focus to an outcomes- or competency-based framework (Carraccio, Wolfsthal, Englander, Ferentz, \& Martin, 2002). As a consequence, instruments for documenting and assessing student performance and competency attainment are being developed, one being the electronic portfolio. One definitive characteristic of a student electronic portfolio is that it provide evidence of competence and reflective practice (Barrett, 2006; Pitts \& Ruggirello, 2012; Snadden \& Thomas, 1998).

The WVU SoM adopted the use of electronic portfolios in the fall of 2012 in an effort to engage students in the documentation of and reflection on performance, residency preparedness, and to demonstrate that targeted Program Learning Objectives were being met. The available literature assessing the effectiveness of electronic portfolios for assessment, showcase of achievement and self-reflection is abundant in the literature, particularly in teacher education; however, few research studies have examined how the design and utility of electronic portfolios impacts student's engagement from the medical student perspective.

This study aimed to answer six research questions based on medical students' lived experiences. The questions concentrated on understanding

1. the advantages and disadvantages of using electronic portfolios to document and self-assess competency and performance; 
2. ways in which the portfolio components help students prepare for and identify an appropriate residency program;

3. the influence the structure and organization of the portfolio has on student engagement and self-monitoring of performance and competence;

4. student attitudes and perceptions about the act/purpose of reflecting in the electronic portfolio, as well as how the reflections aligned to the Program Learning Objectives;

5. which electronic portfolio components are missing and/or over/under utilized that limits student engagement in documenting competency attainment and reflective practice; and

6. which portfolio components will be beneficial to medical students from the graduate medical residents perspective.

To uncover how the design and integration of electronic portfolios in the medical doctor degree curriculum can be improved so that the learner experience is captured in a way that minimizes frustration, yet maximizes reflective practice and documentation of competency attainment, medical students' voices needed to be heard. Through in-depth and semi-structured interviews with second and third year medical students $(n=15)$ and medical residents $(n=5)$, as well as an analysis of portfolio contents and students' portfolio reflections, this phenomenological study aimed to describe, in their own words, the perceptions of medical students toward the use of an electronic portfolio for learning. More importantly, the study aimed to reveal how the design and implementation of the electronic portfolio impacts medical students' abilities to self-reflect, along with the impact the electronic portfolio might have on their competency development and career preparedness. 
Inductive content analysis was used to organize and interpret units of transcribed data and to generate categories and themes based on medical students' experiences using the electronic portfolio system. A member check and triangulation of methods (interview, student reflections and portfolio design analyses) and sources (medical student, medical resident and the researcher's journal) were used to strengthen findings and improve the trustworthiness of the study. Following multiple reads of the transcripts and analysis of student reflections and the portfolio design and structure, the researcher identified major themes based on students' lived experiences.

The findings of the study are summarized by research question and are presented based on the lived experience or personal accounts and interpretations of medical students who utilized the electronic portfolio over the course of the past three years.

RQ1. Medical students' perceptions of the WVU SoM electronic portfolio as a tool for the documentation of and reflection on learning and competency attainment was generally positive in that students often used terms like organized, good idea, convenient, one place and tracks performance to describe the advantages of its design and structure. Students confirmed that the portfolio aids them in tracking and thinking about their performance. The ability to access grades, evaluations and other indicators of performance was labeled as beneficial and convenient.

A number of disadvantages that surfaced pointed to the user interface, as opposed to how the electronic portfolio is implemented in the WVU SoM. For instance, accessibility barriers such as disabling the pop-up blocker, not remembering login credentials and limited usability on mobile devices were often discussed by students as restricting engagement with portfolio contents. A second disadvantage named by students was the frequency of use of the electronic 
portfolio. Students indicated that they are not expected to use the portfolio often enough for them to identify a notable impact on learning and reflection. Moreover, students were uncertain of not only the purpose and proper use of the portfolio, but also the building blocks of its design - the six core competency domains.

RQ2. Students identified four key components of the portfolio that they feel will help them prepare for residency: (1) narrative feedback from faculty, (2) detailed breakdowns of performance on the NBME subject exams, (3) peer evaluation data, and (4) documentation of awards, research and publications. Relative to the required self-reflections, students felt the prompts used could be restructured in order to help get to know or understand them as an individual, as well as to help them understand themselves and their growth towards professional practice. They also suggested that the reflection activities could do a better job preparing them for residency if the prompts specifically targeted commonly asked residency interview questions or included prompts that were more clinically or personally structured. Resident interviews support the finding that reflection prompts should aim to develop a better understanding of the student and what makes them stand out among thousands of other students with similar performance metrics.

RQ3. The naming of folders by competency was identified as an obstacle to actively engaging with the portfolio. Though students recognized the importance of the naming system, they felt they were not well-informed on what each competency means or the evidence used to demonstrate attainment of each. Consequently, they struggled when trying to locate items in the portfolio and felt insecure when adding documents or reflections to their portfolio because of their uncertainty. 
RQ4. Attitudes regarding formal reflection in the electronic portfolio were mixed, with some students describing the existing reflection prompts as adequate, especially those that require them to establish future goals for improvement; however, they repeatedly mentioned that reflection activities that aim to showcase who they are as a person or to help them shape who they will become as a future medical doctor were absent. Students' portfolio reflections, though robust in content and in alignment with the program level learning objectives-PBLI4 and PBLI5 - did little to offer personal insights about who they are as a medical student or how the curriculum or their performance is changing their personal or professional identity. Students believed that more meaningfully constructed reflection prompts could be implemented to improve the value of the activity.

RQ5. An analysis of medical student interview responses, as well as the portfolio contents and organization uncovered missing and underutilized electronic portfolio components. Students named three things missing from the electronic portfolio that limited their engagement in documentation and reflection: (1) limited emphasis on CV generation, (2) minimal focus on personal growth and character, and (3) limited opportunities to freely enter text outside of the designated reflection assignments and rigid folder structure. Additionally, students stated that over-utilization of course and faculty evaluations was a deterrent for accessing their electronic portfolios more frequently; it was evident that students' negative associations with E*Value influenced their perspectives of and interactions with the electronic portfolio.

RQ6. Graduate medical residents reasoned that reflection is of little intrinsic value unless is relates directly to preparation for the residency application and/or interview. They also echoed medical students' perspectives that the reflective portion of the electronic portfolio should be an indication of the personal traits and characteristics of medical students, i.e., the 
traits that make the student stand out. Though performance metrics are valuable, they explained that when thousands of medical students apply to a residency program with comparable academic metrics, the only thing that separates them from the group is their individual and unique attributes and the portfolio provides a medium for students to begin cultivating their personal and professional identity.

\section{Conclusions}

Four major conclusions emerge from this phenomenological study that investigated medical students' experiences in using the WVU SoM electronic portfolio system as a means to document and reflect on their learning and can be summarized as: (1) convenient storage and organization promotes self-assessment of performance, (2) multiple barriers limit students access, and accordingly, the extent to which they embrace this tool; (3) electronic portfolio contents and reflection activities inadequately demonstrate personal growth and development; (4) limited training opportunities for electronic portfolio use and purpose inhibits student engagement; and (5) electronic portfolio integration and involvement does not engage students from all four years of the curriculum.

\section{Conclusion 1: Electronic portfolios provide medical students with convenient} storage and organization, thus promoting efficient self-assessment of performance. It was evident that students perceived the electronic portfolio as a convenient tool for storing and organizing relevant academic performance and achievement documents. Students repeatedly credited the portfolio with their ability to track their performance and make changes in study strategies and behaviors based on exam scores and competency-based evaluations. In accordance with Batson (2011), the electronic portfolio encourages self-regulated learning through the self-monitoring of performance. 


\section{Implication for practice 1. Encourage students to self-assess and reflect on}

performance on a regular basis. Asking medical students to regularly identify their strengths and deficiencies in knowledge, set goals for learning and improvement, and analyze performance and implement changes is a primary objective of the practice-based learning and improvement competency (Swing, 2007). Providing students more opportunities and structure to complete such tasks can help students develop the life-long learning skills needed as they progress to medical practice.

Conclusion 2: Multiple barriers limit student access to their electronic portfolios, and accordingly, the extent to which they embrace this tool. In an attempt to minimize students' frustrations with the design and use of an electronic portfolio system, access to the system must be relatively easy and available from variety of devices. The findings from medical student participants during interviews revealed that accessing the electronic portfolio was often bothersome due to multiple barriers that limited engagement with its use. The student electronic portfolio system should be semi-intuitive by eliminating any unnecessary barriers such as special browser requirements and alternate logins. It should additionally be accessible on various Internet-enabled devices. For example, students struggled with opening the portfolio from mobile devices, which further impeded engagement with portfolio components and activities, specifically for students in the third year of the curriculum. The research conducted by Garrett and Jackson (2006) supports the conclusion that ease of access on mobile devices elicits positive attitudes from medical students in the clinical setting; however, minimal research is available in this area.

Implication for practice 2. Preventable barriers to electronic portfolio access must be minimized. It was evident from participant data that ease of access is a dominant factor for the 
frequency at which students access their electronic portfolios. The WVU SoM should work closely with the Health Sciences Center Information Technology Services (WVU HSC ITS) to further promote the use of the Secure Online Learning Environment (SOLE) as a home base or portal for accessing the electronic portfolio system. Additionally, as a part of trainings, alerting students to access barriers and potential ways to avoid them will provide students with remedies for the identified barriers when they surface. For instance, regular reminders to students that SOLE can be used to access the portfolio in the event they forget their login information or regular reminders that the browser requires that the pop-up blocker be disabled, will help to eliminate some of the barriers. Additionally, training is needed on how to effectively use a mobile device to access the portfolio since it is compatible with mobile technologies.

Minimizing access barriers would relieve student frustrations with using the tool for one of its intended purposes: documentation of and reflection on learning and performance in preparation for residency application.

\section{Conclusion 3: Electronic portfolio contents and reflection activities inadequately} demonstrate personal growth and development. The findings presented by Tosh et al. (2005), which concluded that failure to engage students with their electronic portfolio will result in it becoming "another hoop to jump through," were similar to the conclusions of this study relative to reflection activities. The common attitudes about the purpose and act of reflecting in the electronic portfolio among medical students was that the reflections must be meaningful and required on a more frequent basis. Examples of meaningful reflection prompts included those that directed the student to express their feelings about performance, as well as prompts that help students shape their character. According to participants, generic reflection prompts encourage students to simply respond in a way that pleases the reader, rather than well-constructed prompts 
that promote true reflective practice. Portfolio activities should also be embedded at regular and frequent intervals throughout the curriculum to engage students in its use and scaffold their reflection abilities. Students endorse more frequent requirements for reflection as a means to help them develop habits of reflection and to help them track their personal and professional growth. The findings revealed that the portfolio does an adequate job at representing their academic performance, but does little to showcase the personal attributes that set them apart as a person and future physician. Dr. Helen Barrett (2008) explained that electronic portfolio reflection is intended to raise self-awareness and is "a prerequisite to building up lifelong learning capabilities" (para 3). The portfolio reflection prompts currently used in the medical student portfolio only partially meets this description.

Implication for practice 3. Reflection activities must be constructive, meaningful and aim to enhance personal growth and development. Students should be asked to respond to prompts that allow the them to freely discuss their feelings and emotions, who they are as a person, how the medical school experience is changing them, and how what they are learning and experiencing shapes their future plans for training and/or interactions with patients. Participants indicated that carefully constructed reflection prompts might better prepare them for the next stage in their training-residency. For example, it would be beneficial to incorporate reflection prompts that showoff a student's personal attributes and characteristics, or as one student called it, their "hook," that which makes them stand out from other applicants. Reflection prompts that help not only medical school administration get to know the student at a personal level, but also helps the student develop their voice and personal and professional identity. 


\section{Conclusion 4: Limited training opportunities for electronic portfolio use and}

purpose inhibits student engagement. Effectively communicating the purpose of the portfolio, its uses and capabilities, and the long-term benefits is challenging in many settings (Meyer \& Latham, 2008). Medical students must be provided with multiple and ongoing training and mentoring opportunities to facilitate expressive engagement with their electronic portfolios. They need training on how to effectively reflect on learning, navigate the portfolio platform and understand the purpose and importance of the contents. They need an avenue to discuss hard topics that change them as a person (patient illness and death). Most of all, they need regular and structured training opportunities to help them develop the skills needed to effectively use their portfolio as a tool for learning, reflection and residency preparation, as opposed to a document repository.

Implication for practice 4. A continuous professional development plan with a selfmonitoring component must be introduced to reinforce the purpose, importance and expectations of the electronic portfolio. Students should be provided with a rubric or checklist that outlines each core competency and how it is assessed. The rubric should comprise a single folder in the electronic portfolio to provide a snapshot of student progress at achieving the goals of the program and to serve as a formative guide to help students self-direct their learning approaches, seek advising and track performance. Training opportunities should be better timed and should stress both the short and long-term purpose and benefits of the electronic portfolio. Research participants consistently responded that they needed more training to understand how to effectively use the electronic portfolio. 


\section{Conclusion 5: Electronic portfolio integration and involvement does not engage}

students from all four years of the curriculum. It was evident to the researcher that students use the portfolio more as a repository to view their progress in the curriculum, as opposed to a tool that can be used to monitor and reflect on performance. Students rarely visited their portfolios unless something was added to it or a reflection assignment was required. Their experiences with the current portfolio contents have been minimal—almost always limited to viewing past performance on exams and the review of evaluative feedback from faculty and peers. Electronic portfolio activities should be embedded throughout all stages of the curriculum and involve students in the maintenance and discussion of their individual portfolio contents. This conclusion supports the work of Driessen et al. (2007), who found that electronic portfolios are effective tools for both scaffolding and assessing development of competence among medical students, but only if portfolio activities are integrated in the curriculum and if the support of a tutor or mentor is available. Though students did not mention mentors, they did often suggest that more training opportunities were needed.

\section{Implication for practice 5. Electronic portfolio activities must be embedded across the}

curriculum to encourage use and habit. Since the majority of electronic portfolio contents are added by SoM staff, student engagement is limited. Additionally, students are only required to access their portfolio during first and second year to enter their annual reflection. The adoption of a shared approach to the population of the electronic portfolio would necessitate that students access the portfolio more regularly. Students during the third year of the curriculum accessed the portfolio more often (every 6 weeks versus once per semester) than second year students; however, the reasons for access centered on viewing evaluations, not to reflect or update their portfolios. A curriculum integration plan should be developed to ensure regular access to and 
active engagement with electronic portfolio components. Additionally, more opportunities for open-ended reflection across the curriculum will encourage use and habit.

\section{Limitations}

The main limitation to the study was the relatively short time frame. It was not within the scope of the study to examine the long-term implications of electronic portfolio design and implementation on student perceptions as they progress to residency education and on to a career as a practicing physician. To abate this limitation, graduate medical residents $(n=5)$ were interviewed and their responses were triangulated with the findings from medical students.

Another limitation is the difficulty generalizing the findings to other medical students or institutions based on the flexibility of design and implementation characteristic of electronic portfolios. The minimal use of the electronic portfolio by medical students could also be viewed as a limitation, since it was found that students only access their portfolio following the addition of grades and narratives, as well as NBME score reports. Such infrequent use and familiarity with the utility and navigation of the portfolio could be seen as a limitation.

A final limitation of the study was the potential bias of the researcher who designed and implemented the electronic portfolio. The researcher attempted to modulate this limitation through the use of neutral, open-ended interview questions and a researcher's journal where personal reactions and observations were recorded.

\section{Recommendations for Future Research}

The results of this study indicate a need for continued research on the design and implementation of electronic portfolios in the medical doctor degree curriculum. Particularly, research is needed on how to design reflection prompts that help students navigate the challenges of preparing for and applying to residency, as well as how to organize electronic portfolios in a 
way that maximizes students' engagement. A holistic inductive analysis of student reflections could also be utilized to help identify needs in the structure of open-ended reflection prompts. A recommendation for future research that surfaced from the data is the need to use the electronic portfolio to prepare students for the residency application and the interview process from day one. Research should examine common residency interview questions and model reflection prompts after these questions. A study presenting the relationship between such reflection prompts and student interview preparation might offer insights that can enhance the career counseling and advising aspect of medical education. Additionally, a longitudinal study that tracks medical students who embraced a portfolio embedded with the before mentioned implications for practice into their residency in order to gain their perceptions of how well it really did prepare them.

Future research should also focus on how to better integrate the electronic portfolio into the preclinical years of the medical doctor degree curriculum. Research should center on how to develop and put into practice training modules and mentoring programs that aid medical students in not only the use of the portfolio, but also meaningful application of reflection on learning. The inclusion of advisors, mentors or coaches to scaffold the development of life-long learning skills among students to help them in their reflective practice and overall use of the electronic portfolio system would be an important factor for increasing student involvement with its use. Thus, future research should attempt to elucidate how each of these entities can best facilitate medical student engagement, including reflective practice, with electronic portfolios. 


\section{References}

Ambrose, G., \& Ambrose, L. (2013). The blended advising model: Transforming advising with ePortfolios. International Journal of EPortfolio, 3(1), 75-89. Retrieved from http://www.theijep.com/pdf/IJEP97.pdf

Barrett, H. (2004, June 1). Selecting e-portfolio software. [web log comment]. Retrieved from http://eportfoliosblog.blogspot.com/2004/06/selecting-eportfolio-software.html

Barrett, H. (2004). Professional development for implementing electronic portfolios. Retrieved from http://electronicportfolios.com/teachers/profdev.html

Barrett, H. (2006). Using electronic portfolios for formative/classroom-based assessment. Connected Newsletter (Classroom Connect), 13(2):4-6. Retrieved March 26, 2015 from http://electronicportfolios.org/portfolios/ConnectedNewsletter.pdf

Barrett, H.C. \& Wilkerson, J. (2004). Conflicting paradigms in electronic portfolio approaches. Retrieved from http://electronicportfolios.com/systems/paradigms.html

Bashook, P., Gelula, M., Joshi, M., \& Sandlow, L. (2008). Impact of student reflective eportfolio on medical student advisors. Teaching and Learning in Medicine, 20(1), 26-30.

Baston, T. (2011). Situated learning: A theoretical frame to guide transformational change using electronic portfolio technology. International Journal of ePortfolio, 1(1):107-114.

Biggs, J. (2003) Aligning teaching for constructive learning. Discussion paper from the Higher Education Academy, UK. Retrieved August 15, 2014, from http://www.bangor.ac.uk/adu/the_scheme/documents/Biggs.pdf

Black I. (1994). New directions in portfolio assessment. Reflective practice, critical theory and large-scale scoring. Portsmouth, NH: Boynton/Cook, Heinemann. 
Burch, V.C. \& Seggie, J.L. (2008). Use of a structured interview to assess portfolio-based learning. Medical Education, 42: 894-900. doi: 10.1111/j.1365-2923.2008.03128.x

Butler P. (2006). A review of the literature on portfolios and electronic portfolios. Palmerston North, New Zealand: Massey University College of Education; October 2006. eCDF ePortfolio Project. http://www.uoguelph.ca/tss/projects/ePresources/Review\%20of\%20literature\%20on\%20 portfolios\%20and\%20ePortfolios.pdf. Accessed December 20, 2014.

Carney, J. (2005). What kind of electronic portfolio research do we need? Paper presented at the SITE 2conference. Available: http://it.wce.wwu.edu/ carney/Presentations/presentations.html

Carraccio C., Wolfsthal S., Englander R., Ferentz K., \& Martin C. (2002). Shifting paradigms: From Flexner to competencies. Academic Medicine, 77(5):361-367

Challis, M. (1999). AMEE Medical Education Guide No. 11 (revised): Portfolio-based learning and assessment in medical education. Medical Teacher, 21(4), 370-386.

Chen, H.L., \& Black, T.C. (2010). Using e-portfolios to support an undergraduate learning career: An experiment with academic advising. EDUCAUSE Quarterly Magazine, 33(4).

Creswell, J. (1998). Qualitative inquiry and research design: Choosing among five traditions. Thousand Oaks, CA: Sage.

Creswell, J. (2003). Research design: Qualitative, quantitative, and mixed methods approaches. ( $2^{\text {nd }}$ ed.). Thousand Oaks, CA: Sage.

Dannefer, E.F., Bierer S.B., \& Gladding, S.P. (2012). Evidence within a portfolio-based assessment program: What do medical students select to document their performance? Medical Teacher, 34, 215-220. 
Davis, M.H., Ponnamperuma, G.G., \& Ker, J.S. (2009). Student perceptions of a portfolio assessment process. Medical Education; 43(1), 89-98. doi: 10.1111/j.13652923.2008.03250.x.

Delandshere, G., \& Arens, S. (2003). Examining the quality of the evidence in preservice teacher portfolios. Journal of Teacher Education, 54(1), 57-73. Retrieved, September 1, 2014, from http://www.castleton.edu/PT3/delandshere.pdf

Driessen, E.W., Van Tartwijk, J., Overeem, K., Vermunt, J.D., \& Van Der Vleuten, C.P.M. (2005). Conditions for successful reflective use of portfolios in undergraduate medical education. Medical Education, 39, 1230-1235.

Driessen, E.W., Van Tartwijk, J., Van Der Vleuten, C., \& Wass, V. (2007) Portfolios in medical education: Why do they meet with mixed success? A systematic review. Medical Education, 41(12), 1224-33.

Dysthe, O. (Director) (2002, July 3). Theoretical background for portfolios as learning and assessment tools in teacher education. NERA/NFPF Conference. Lecture conducted from Tallin, Estonia.

Elango, S., Jutti, R.C., \& Lee, L.K. (2005). Portfolio as a learning tool: Students' perspective. Annals Academy of Medicine, 34:511-514.

Freedman, J. (2013, May 16). Residency match 2013: Was it really that bad? Retrieved from http://studentdoctor.net/2013/05/residency-match-2013-was-it-really-that-bad/

Friedman, B.D.M., Davis, M.H., Harden, R.M., Howie, P.W., Ker, J., \& Pippard, M. (2001). AMEE medical education Guide No. 24: Portfolios as a method of student assessment. Medical Teacher, 23(6): 535-551. 
Garrett, B., \& Jackson, C. (2006). A mobile clinical e-portfolio for nursing and medical students, using wireless personal digital assistants (PDAs). Nurse Education in Practice, 6(6), 339-346.

Gay, L., \& Airasian, P. (2012). Educational research: Competencies for analysis and applications (10th ed.). Boston: Pearson.

Goldkuhl, G. (2012). Pragmatism vs interpretivism in qualitative information systems research. European Journal of Information Systems, 21(2), 135-146. http://dx.doi.org/10.1057/ejis.2011.54

Grant A.J., Vermunt J.D., Kinnersley P., \& Houston, H. (2007). Exploring students' perceptions on the use of significant event analysis, as part of a portfolio assessment process in general practice, as a tool for learning how to use reflection in learning. BMC Medical Education, 7(5). doi:10.1186/1472-6920-7-5

Groenewald, T. (2004). A phenomenological research design illustrated. International Journal of Qualitative Methods, 3(1). Article 4. Retrieved September 20, 2014 from http://www.ualberta.ca/ iiqm/backissues/3_1/pdf/groenewald.pdf

Hall, D. (1992). Professional development portfolios for teachers and lecturers. British Journal of In Service Education, 18, 81-86.

Hall, P., Byszewski, A., Sutherland, S., \& Stodel, E.J. (2012). Developing a sustainable electronic portfolio (ePortfolio) program that fosters reflective practice and incorporates CanMEDS competencies into the undergraduate medical curriculum. Academic Medicine, 87(6), 1-7.

Huang J., Yang S., Chiang P., \& Tzeng, L. (2012). Building an e-portfolio learning model: Goal orientation and metacognitive strategies. Knowledge Management \& E-Learning: An 
International Journal (KM\&EL), 4(1), 16-36. http://kmel-

journal.org/ojs/index.php/online-publication/article/viewFile/163/131.

Izatt, S. (2007). Educational Perspectives: Portfolios: The next assessment tool in medical education? NeoReviews, 8(10), 405-408.

Jarvis, R., O'Sullivan, P., McClain, T., \& Clardy, J.A. (2004). Can one portfolio measure the six ACGME general competencies? Academic Psychiatry, 28(3), 190-196.

Lewis, K., \& Baker, R. (2007). The development of an electronic educational portfolio: An outline for medical education professionals. Teaching and Learning in Medicine, 19(2), $139-47$.

Lorenzo, G., \& Ittelson, J. (2005). Demonstrating and assessing student learning with eportfolios. ELI Paper 3: Educause Learning Initiative. October 2005, Educause. Retrieved July 15, 2014, from http://net.educause.edu/ir/library/pdf/ELI3003.pdf

Kampschuur, M., \& Chatterton, P. (2007). Assessment and electronic portfolios. Retrieved from http://etec.ctlt.ubc.ca/510wiki/Assessment_and_Electronic_Portfolios

Marshall, C., \& Rossman, G. (1999). Designing qualitative research. (3rd ed.). Thousand Oaks, CA: Sage.

McEwen, L., Griffiths, J., \& Schultz, K. (2015). Developing and successfully implementing a competency-based portfolio assessment system in a postgraduate family medicine residency program. Academic Medicine, 2015 May 18. [Epub ahead of print] http://www.ncbi.nlm.nih.gov/pubmed/25993277

MedBiquitous Curriculum Inventory Working Group Standardized Vocabulary Subcommittee. (2012). Curriculum Inventory standardized instructional and assessment methods and 
resource types (September 2012 version). Washington, DC: Association of American Medical Colleges.

Mertens, D.M. (2005). Research methods in education and psychology: Integrating diversity with quantitative and qualitative approaches. (2nd ed.). Thousand Oaks, CA: Sage.

Meyer, B., \& Latham, N. (2008). Implementing electronic portfolios: Benefits, challenges, and suggestions. EDUCAUSE Quarterly, 31(1), 34-41.

Milman, N.B., \& Kilbane, C.R. (2005). Digital teaching portfolios: Catalysts for fostering authentic professional development. Canadian Journal of Learning and Technology, 31. Retrieved from http://cjlt.csj.ualberta.ca/index.php/cjlt/article/view/95/89

Morse, J.M. (1994). Designing funded qualitative research. In Norman K. Denzin \& Yvonna S. Lincoln (Eds.), Handbook of qualitative research (2nd ed., pp.220-35). Thousand Oaks, CA: Sage.

Palomba, M.B., \& Banta, T.W. (1999). Assessment essentials: Planning, implementing, and improving assessment in higher education. San Francisco: Jossey-Bass.

Patton, M.Q. (2002). Qualitative Research and Evaluation Methods. (3rd ed.). Thousand Oaks, CA.: Sage.

Pinsky, L.E., \& Fryer-Edwards, K. (2004). Diving for PERLs: Working and performance portfolios for evaluation and reflection on learning. Journal of General Internal Medicine, 19(5), 582-587.

Pitts, W., \& Ruggirello, R. (2012). Using the e-Portfolio to document and evaluate growth in reflective practice: The development and application of a conceptual framework. International Journal of ePortfolio, 2(1), 49-74. Retrieved from http://www.theijep.com/pdf/IJEP43.pdf. 
Rees, C., \& Sheard, C. (2004). Undergraduate medical students' views about a reflective portfolio assessment of their communication skills learning. Medical Education, 38, 125128. doi: 0.1046/j.1365-2923.2004.01750.x

Rickards, W.H., Diez, M.E., Ehley, L., Guilbault, L.F., Loaker, G., Hart, J.R., \& Smith, P.C. (2008). Learning, reflection, and electronic portfolios: Stepping toward an assessment practice. The Journal of General Education, 57(1), 31-50. doi: 10.1353/jge.0.0008

Sewell, M., Marczak, M., \& Horn, M. (2007). The use of portfolio assessment in evaluation. Retrieved from The University of Arizona, Cyfernet Evaluation Web Site, http://methodenpool.unikoeln.de/portfolio/USE\%20OF\%20PORTFOLIOS\%20IN\%20EVALUATION.htm

Sherry, A.C., \& Bartlett, A. (2005). Worth of electronic portfolios to education majors: A 'two by four' perspective. Journal of Educational Technology Systems, 33(4), 399-419.

Silverman, D. (2005). Doing qualitative research. London: Sage Publications. Retrieved from http://fasstasticmethodologygroup.files.wordpress.com/2009/09/silverman2005.pdf

Snadden, D. \& Thomas M. (1998). The use of portfolio learning in medical education. Medical Teacher, 20(3),192-199. Retreived from http://www.evavalpa.org/modulos/modulo_04/portfolio.pdf.

Stolle, C., Goerss, B., \& Watkins, M. (2005). Implementing portfolios in a teacher education program. Issues in Teacher Education, 14(2), 25-43. Retrieved from http://files.eric.ed.gov/fulltext/EJ796413.pdf

Swing, S. (2007). The ACGME outcome project: retrospective and prospective. Medical Teacher, 29, 648-654. doi: 10.1080/01421590701392903 
Tosh, D., Light, T., Fleming, K., \& Haywood, J. (2005). Engagement with electronic portfolios: Challenges from the student perspective. Canadian Journal of Learning and Technology, 31(3). Retrieved from http://www.cjlt.ca/index.php/cjlt/article/view/97/91

Truer P., \& Jensen J. (2003). Electronic portfolios need standards to thrive? EDUCAUSE Quarterly, 26(2), 34-41. Retrieved from https://net.educause.edu/ir/library/pdf/eqm0324.pdf.

Ward, K. (2008, June). From first year to career: Connecting advising syllabi to electronic portfolios. Academic Advising Today, 31(2). Retrieved November 1, 2013 from http://www.nacada.ksu.edu/Resources/Academic-Advising-Today/View-Articles/FromFirst-Year-to-Career-Connecting-Advising-Syllabi-to-Electronic-Portfolios.aspx

Ward, M., \& Ellis, R. (2007, June). E-portfolio report. USyd eLearning. Retrieved June 15, 2014, from http://tinyurl.com/l14hm7

Wills, K. \& Rice, R. (2013). ePortfolio performance support systems: Constructing, presenting, and assessing portfolios. Fort Collins, Colorado: The WAC Clearing House.

Zeichner, K., \& Wray, S. (2001). The teacher portfolio in U.S. teacher education programs: What we know and what we need to know. Teaching and Teacher Education, 17, 613621. 
APPENDIX A

WEST VIRGINIA UNIVERSITY SCHOOL OF MEDICINE PROGRAM LEVEL

LEARNING OBJECTIVES

\begin{tabular}{|c|c|c|c|}
\hline \multirow{2}{*}{ Competency } & \multirow{2}{*}{$\begin{array}{c}\text { Program Level } \\
\text { Objectives }\end{array}$} & \multicolumn{2}{|c|}{ Outcome Measures } \\
\hline & & Formative Assessment & Summative Assessment \\
\hline \multirow[t]{3}{*}{$\begin{array}{l}\text { Practice-Based } \\
\text { Learning } \\
\text { and Improvement: } \\
\text { demonstrate the } \\
\text { ability to investigate } \\
\text { and evaluate their } \\
\text { role in the care of } \\
\text { patients, to appraise } \\
\text { and assimilate } \\
\text { scientific evidence, } \\
\text { and to continuously } \\
\text { improve their role in } \\
\text { patient care based on } \\
\text { constant self- } \\
\text { evaluation and } \\
\text { learning. }\end{array}$} & $\begin{array}{l}\text { PBL1 } \\
\text { Locate, appraise and } \\
\text { assimilate evidence } \\
\text { from scientific studies } \\
\text { including basic, } \\
\text { clinical, translational, } \\
\text { and community } \\
\text { (population) based } \\
\text { research }\end{array}$ & $\begin{array}{l}\text { Clinical Documentation Review, } \\
\text { (PxDx logs) } \\
\text { Exam - Institutionally } \\
\text { Developed, Written/ Computer- } \\
\text { based, Audience Response, } \\
\text { Quizzes } \\
\text { Mid-block /Course Formative } \\
\text { Feedback Session } \\
\text { Narrative Assessment } \\
\text { Oral Patient Presentation } \\
\text { Attendance/Participation }\end{array}$ & $\begin{array}{l}\text { Exam - Institutionally } \\
\text { Developed, Written/ } \\
\text { Computer-based Exams } \\
\text { Licensure Exams, } \\
\text { Written/ Computer- based } \\
\text { (USMLE Step 2CK and } \\
\text { CS) } \\
\text { Clinical Documentation } \\
\text { Review, } \\
\text { (PxDx logs) } \\
\text { Oral Patient Presentation } \\
\text { Multisource Assessment } \\
\text { (faculty, peer, self) } \\
\text { Postgraduate Training } \\
\text { Evaluation }\end{array}$ \\
\hline & $\begin{array}{l}\text { PBL2 } \\
\text { Apply knowledge of } \\
\text { study designs and } \\
\text { statistical methods to } \\
\text { appraise studies. }\end{array}$ & $\begin{array}{l}\text { Clinical Documentation Review, } \\
\text { (PxDx logs) } \\
\text { Exam - Institutionally } \\
\text { Developed, Written/ Computer- } \\
\text { based, Audience Response, } \\
\text { Quizzes } \\
\text { Mid-block /Course Formative } \\
\text { Feedback Session } \\
\text { Narrative Assessment } \\
\text { Oral Patient Presentation } \\
\text { Attendance/Participation }\end{array}$ & $\begin{array}{l}\text { Exam - Institutionally } \\
\text { Developed, Written/ } \\
\text { Computer-based Exams } \\
\text { Licensure Exams, } \\
\text { Written/ Computer- based } \\
\text { (USMLE Step 2CK and } \\
\text { CS) } \\
\text { Clinical Documentation } \\
\text { Review, } \\
\text { (PxDx logs) } \\
\text { Oral Patient Presentation } \\
\text { Multisource Assessment } \\
\text { (faculty, peer, self) }\end{array}$ \\
\hline & $\begin{array}{l}\text { PBL3 } \\
\text { Use information } \\
\text { technology to manage } \\
\text { information and }\end{array}$ & $\begin{array}{l}\text { Clinical Documentation Review, } \\
\text { (PxDx logs) } \\
\text { Exam - Institutionally } \\
\text { Developed, Written/ Computer- }\end{array}$ & $\begin{array}{l}\text { Exam - Institutionally } \\
\text { Developed, Written/ } \\
\text { Computer-based Exams } \\
\text { Licensure Exams, } \\
\text { Written/ Computer- based }\end{array}$ \\
\hline
\end{tabular}




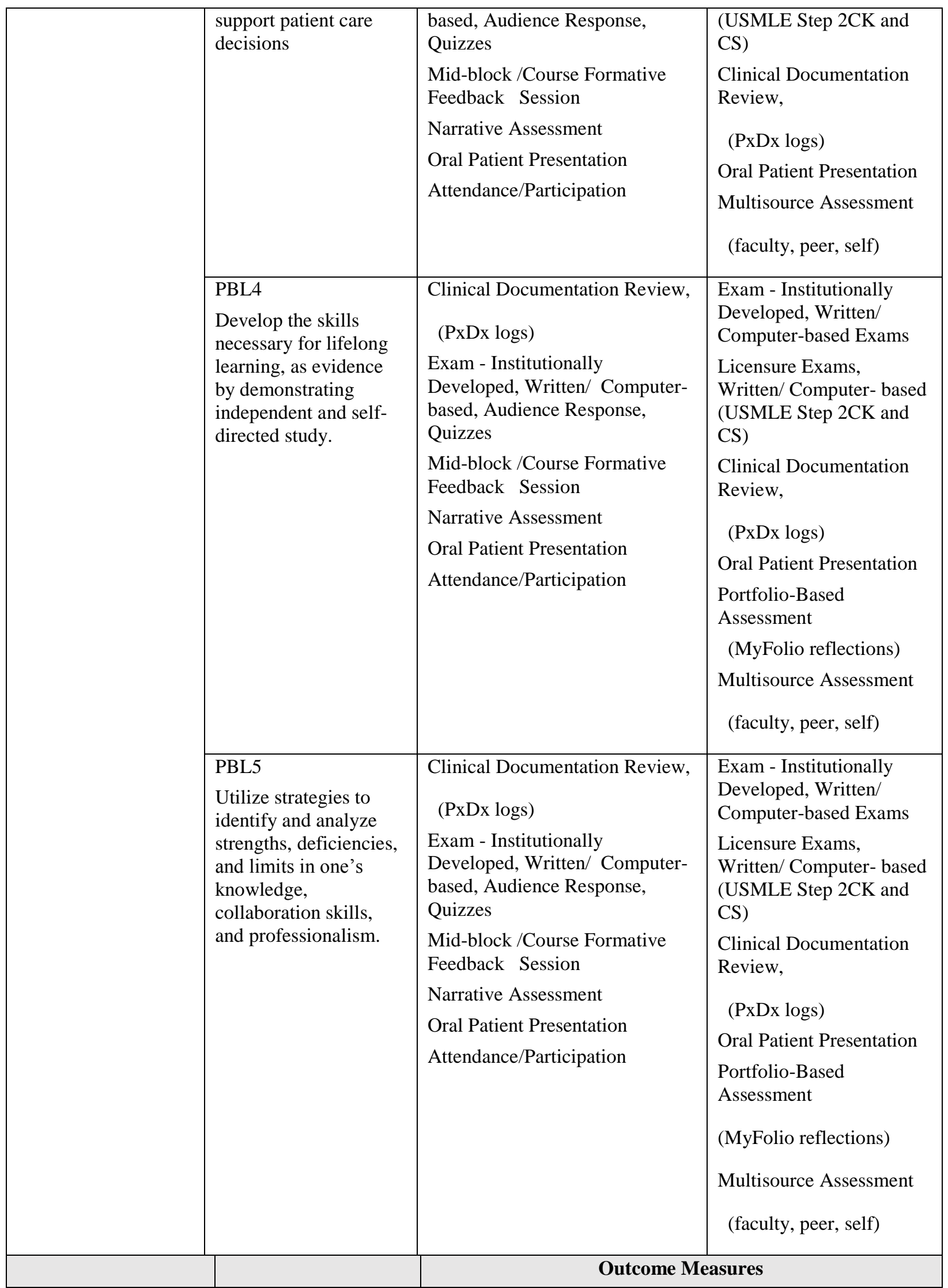




\begin{tabular}{|c|c|c|c|}
\hline Competency & $\begin{array}{c}\text { Program Level } \\
\text { Objectives }\end{array}$ & Formative Assessment & Summative Assessment \\
\hline \multirow[t]{2}{*}{$\begin{array}{l}\text { Interpersonal and } \\
\text { Communication } \\
\text { Skills: demonstrate } \\
\text { interpersonal and } \\
\text { communication skills } \\
\text { that result in the } \\
\text { effective exchange of } \\
\text { information and } \\
\text { collaboration with } \\
\text { patients, their families, } \\
\text { peers, and health } \\
\text { professionals. }\end{array}$} & $\begin{array}{l}\text { ICS1 } \\
\text { Communicate } \\
\text { effectively and } \\
\text { demonstrate caring } \\
\text { and respectful } \\
\text { behaviors with } \\
\text { patients and families } \\
\text { across a broad range } \\
\text { of socioeconomic and } \\
\text { cultural backgrounds. }\end{array}$ & $\begin{array}{l}\text { Mid-block /Course Formative } \\
\text { Feedback Session } \\
\text { Narrative Assessment } \\
\text { Oral Patient Presentation } \\
\text { Attendance Participation } \\
\text { Practical Lab }\end{array}$ & $\begin{array}{l}\text { Clinical Documentation } \\
\text { Review } \\
\text { (H\&Ps, patient notes, } \\
\text { PxDx logs) } \\
\text { Clinical Performance } \\
\text { Rating/Checklist } \\
\text { Exam - Institutionally } \\
\text { Developed, } \\
\text { Clinical Performance } \\
\text { (CPX, OSCE) } \\
\text { Exam - Licensure, Clinical } \\
\text { Performance (USMLE- } \\
\text { Step } 2 \text { CS) } \\
\text { Multisource Assessment } \\
\text { (faculty, peer, self) } \\
\text {-Narrative Assessment } \\
\text { Postgraduate Training } \\
\text { Evaluation }\end{array}$ \\
\hline & $\begin{array}{l}\text { ICS2 } \\
\text { Collaborate with a } \\
\text { team of health care } \\
\text { professionals to } \\
\text { provide patient- } \\
\text { focused, preventive, } \\
\text { acute, chronic, } \\
\text { continuing, } \\
\text { rehabilitative, and } \\
\text { end-of-life care. }\end{array}$ & $\begin{array}{l}\text { Mid-Block/Course Feedback } \\
\text { Session } \\
\text { Narrative Assessment } \\
\text { Oral Patient Presentations }\end{array}$ & $\begin{array}{l}\text { Attendance/Participation } \\
\text { (IPE experiences, Health } \\
\text { Care Ethics Cases) } \\
\text { Clinical Performance } \\
\text { Rating/Checklist } \\
\text { Clinical Documentation } \\
\text { Review } \\
\text { (H\&Ps, patient notes, } \\
\text { PxDx logs) } \\
\text { Exam - Institutionally } \\
\text { Developed, } \\
\text { Clinical Performance } \\
\text { (CPX, OSCE) } \\
\text { Exam - Licensure, Written/ } \\
\text { Computer- } \\
\text { based/Clinical } \\
\text { Performance } \\
\text { (USMLE-Step 2 CK \& } \\
\text { CS) } \\
\text { Oral Patient Presentation } \\
\text { (Ethics case) }\end{array}$ \\
\hline
\end{tabular}




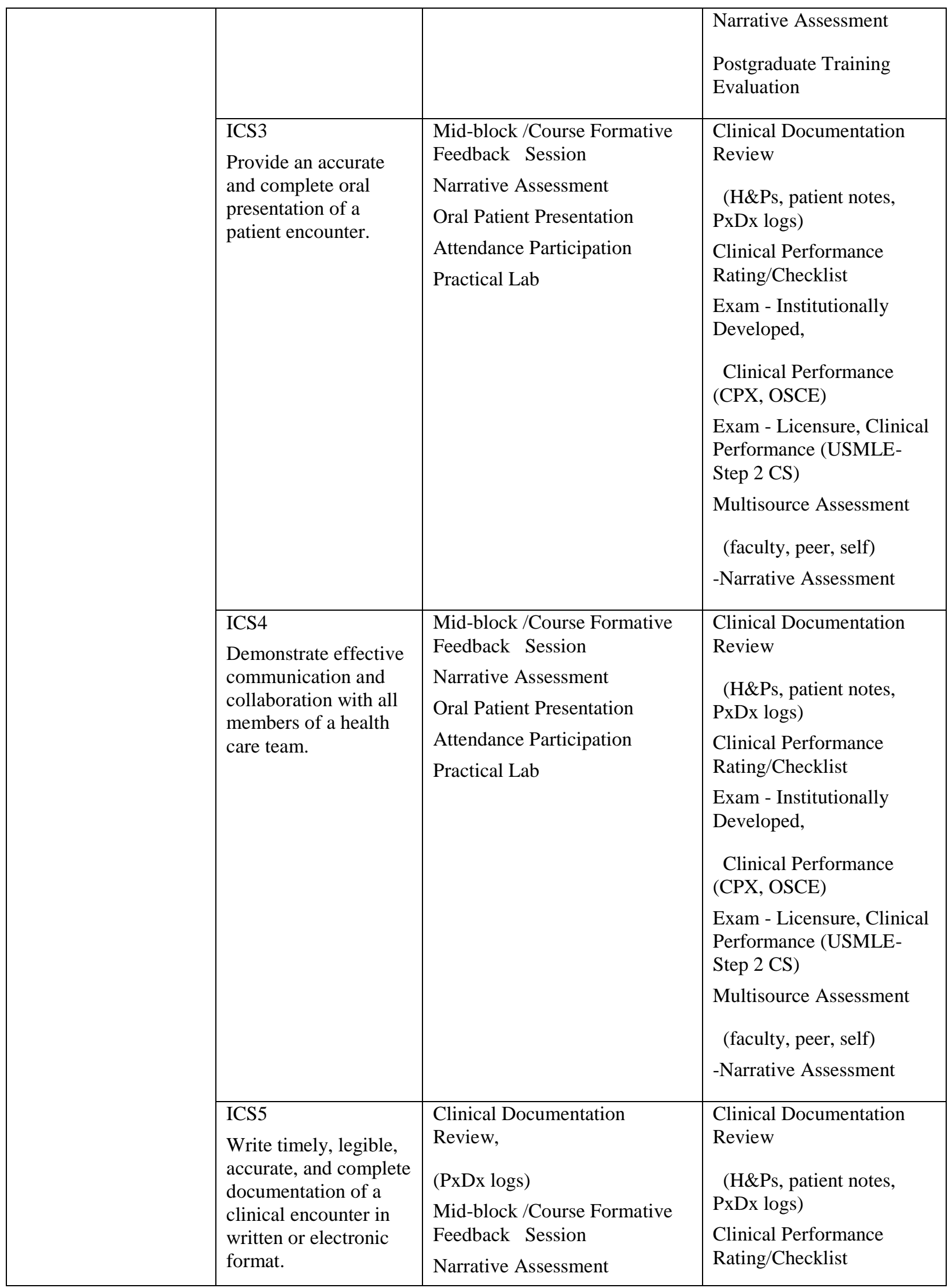




\begin{tabular}{|c|c|c|c|}
\hline & & $\begin{array}{l}\text { Oral Patient Presentation } \\
\text { Attendance Participation } \\
\text { Practical Lab }\end{array}$ & $\begin{array}{l}\text { Exam - Institutionally } \\
\text { Developed, } \\
\text { Clinical Performance } \\
\text { (CPX, OSCE) } \\
\text { Exam - Licensure, Clinical } \\
\text { Performance (USMLE- } \\
\text { Step } 2 \text { CS) } \\
\text { Multisource Assessment } \\
\text { (faculty, peer, self) } \\
\text {-Narrative Assessment }\end{array}$ \\
\hline \multirow{2}{*}{ Competency } & Program Level & \multicolumn{2}{|c|}{ Outcome Measures } \\
\hline & Objectives & Formative Assessment & Summative Assessment \\
\hline \multirow[t]{2}{*}{$\begin{array}{l}\text { Professionalism: } \\
\text { demonstrate a } \\
\text { commitment to } \\
\text { carrying out } \\
\text { professional } \\
\text { responsibilities and an } \\
\text { adherence to ethical } \\
\text { principles. }\end{array}$} & $\begin{array}{l}\text { PROF1 } \\
\text { Demonstrate respect, } \\
\text { compassion, integrity, } \\
\text { responsiveness to } \\
\text { needs of patients, } \\
\text { society, and } \\
\text { profession that } \\
\text { supersedes self- } \\
\text { interest }\end{array}$ & $\begin{array}{l}\text { Clinical Documentation } \\
\text { Review, } \\
\text { (PxDx logs) } \\
\text { Mid-block /Course } \\
\text { Formative Feedback } \\
\text { Session } \\
\text { Narrative Assessment } \\
\text { Oral Patient Presentation } \\
\text { Attendance Participation } \\
\text { Practical Lab }\end{array}$ & $\begin{array}{l}\text { Clinical Documentation } \\
\text { Review } \\
\text { (H\&Ps, patient notes, PxDx } \\
\text { logs) } \\
\text { Attendance/Participation } \\
\text { (Health Care Ethics } \\
\text { presentation) } \\
\text { Clinical Performance } \\
\text { Rating/Checklist } \\
\text { Exam - Institutionally } \\
\text { Developed, } \\
\text { Clinical Performance (CPX, } \\
\text { OSCE) } \\
\text { Exam - Licensure, Clinical } \\
\text { Performance (USMLE-Step } 2 \\
\text { CS) } \\
\text { Multisource Assessment } \\
\text { (faculty, peer, self) } \\
\text { Narrative Assessment } \\
\text { Postgraduate Training } \\
\text { Evaluation }\end{array}$ \\
\hline & $\begin{array}{l}\text { PROF2 } \\
\text { Demonstrate a } \\
\text { commitment to ethical } \\
\text { principles, including } \\
\text { provision or } \\
\text { withholding of care, } \\
\text { confidentiality, } \\
\text { informed consent, and }\end{array}$ & $\begin{array}{l}\text { Clinical Documentation } \\
\text { Review, } \\
\text { (PxDx logs) } \\
\text { Mid-block /Course } \\
\text { Formative Feedback } \\
\text { Session } \\
\text { Narrative Assessment } \\
\text { Oral Patient Presentation }\end{array}$ & $\begin{array}{l}\text { Clinical Documentation } \\
\text { Review } \\
\text { (H\&Ps, patient notes, PxDx } \\
\operatorname{logs}) \\
\text { Attendance/Participation } \\
\text { (Health Care Ethics } \\
\text { presentation) }\end{array}$ \\
\hline
\end{tabular}




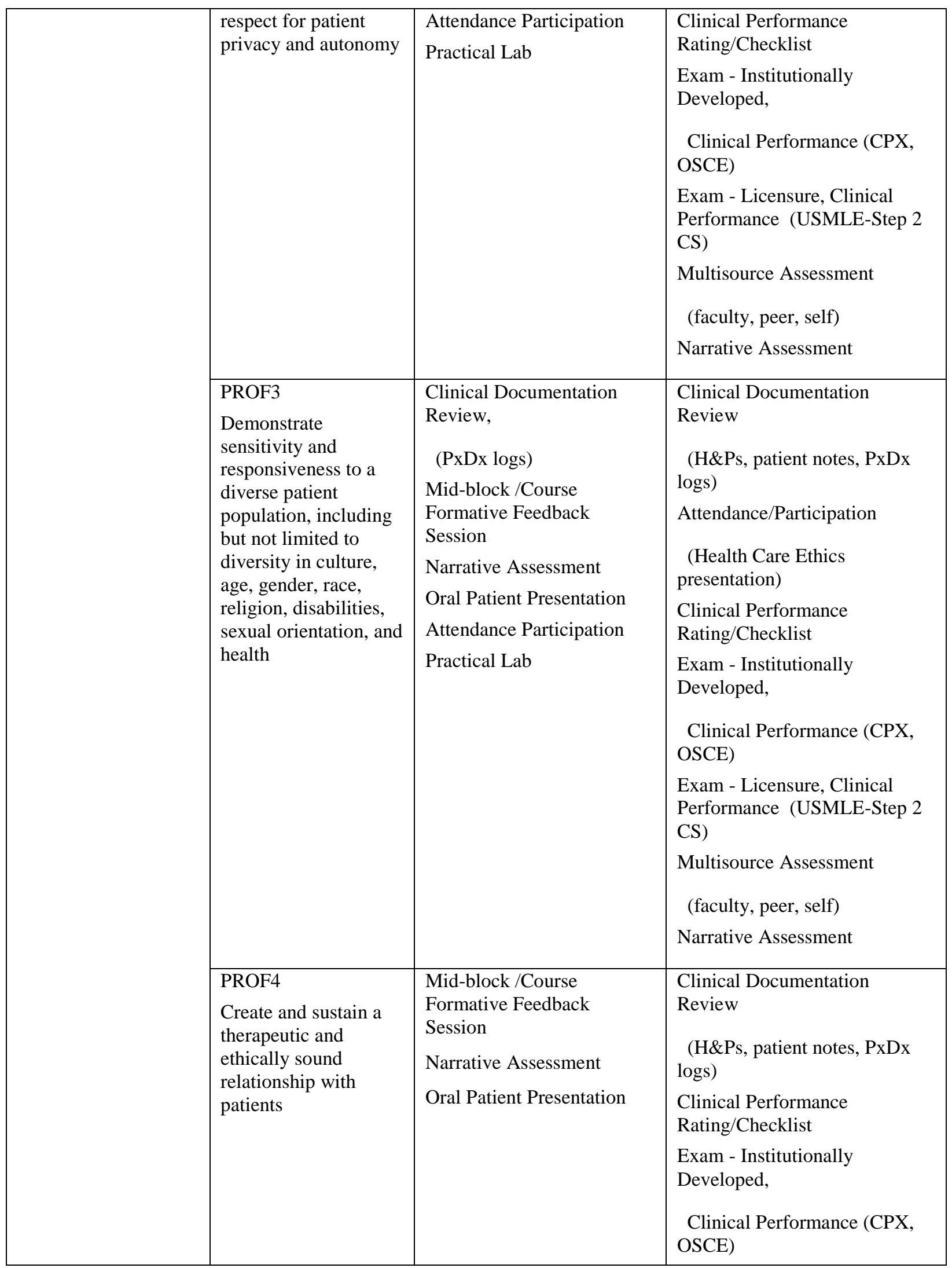




\begin{tabular}{|c|c|c|c|c|}
\hline & & & & $\begin{array}{l}\text { Exam - Licensure, Clinical } \\
\text { Performance (USMLE-Step } 2 \\
\text { CS) } \\
\text { Multisource Assessment } \\
\text { (faculty, peer, self) } \\
\text { Narrative Assessment }\end{array}$ \\
\hline & $\begin{array}{l}\text { PROF5 } \\
\text { Demonstrate } \\
\text { timeliness and } \\
\text { punctuality in the } \\
\text { execution of learning } \\
\text { and clinical duties }\end{array}$ & $\begin{array}{l}\text { Clinical Document } \\
\text { Review, } \\
\text { (PxDx logs) } \\
\text { Mid-block /Course } \\
\text { Formative Feedbac } \\
\text { Session } \\
\text { Narrative Assessm } \\
\text { Oral Patient Presen } \\
\text { Attendance Particir } \\
\text { Practical Lab }\end{array}$ & $\begin{array}{l}\text { ion } \\
\text { tion } \\
\text { tion }\end{array}$ & $\begin{array}{l}\text { Clinical Documentation } \\
\text { Review } \\
\text { (H\&Ps, patient notes, PxDx } \\
\text { logs) } \\
\text { Attendance/Participation } \\
\text { (Health Care Ethics } \\
\text { presentation) } \\
\text { Clinical Performance } \\
\text { Rating/Checklist } \\
\text { Exam - Institutionally } \\
\text { Developed, } \\
\text { Clinical Performance (CPX, } \\
\text { OSCE) } \\
\text { Exam - Licensure, Clinical } \\
\text { Performance (USMLE-Step } 2 \\
\text { CS) } \\
\text { Multisource Assessment } \\
\text { (faculty, peer, self) } \\
\text { Narrative Assessment } \\
\text { Postgraduate Training } \\
\text { Evaluation }\end{array}$ \\
\hline \multirow{2}{*}{ Competency } & Program Level & \multicolumn{3}{|c|}{ Outcome Measures } \\
\hline & & $\begin{array}{l}\text { Formative } \\
\text { Assessment }\end{array}$ & & Summative Assessment \\
\hline $\begin{array}{l}\text { Systems-Based } \\
\text { Practice: } \\
\text { demonstrate an } \\
\text { awareness of and } \\
\text { responsiveness to the } \\
\text { larger context and } \\
\text { system of health care, } \\
\text { as well as the ability } \\
\text { to learn about other } \\
\text { resources in the }\end{array}$ & $\begin{array}{l}\text { SBP1 } \\
\text { Define the roles of } \\
\text { health care } \\
\text { professionals and } \\
\text { demonstrate how } \\
\text { interprofessional } \\
\text { collaboration } \\
\text { improves patient } \\
\text { safety, patient- } \\
\text { centered outcomes, } \\
\text { and system } \\
\text { performance }\end{array}$ & $\begin{array}{l}\text { Mid-block /Course } \\
\text { Formative } \\
\text { Feedback Session } \\
\text { Portfolio-based } \\
\text { Assessment } \\
\text { (MyFolio } \\
\text { Assignments) } \\
\text { Attendance } \\
\text { Participation }\end{array}$ & $\begin{array}{r}\text { Atte } \\
\text { expe } \\
\text { Clin } \\
\text { Exa } \\
\mathrm{W}_{1} \\
\text { Nar } \\
\text { Post }\end{array}$ & $\begin{array}{l}\text { ance/Participation (IPE } \\
\text { nces) } \\
\text { Performance Rating/Checklist } \\
\text { Institutionally Developed, } \\
\text { en/Computer-based } \\
\text { ve Assessment } \\
\text { duate Training Evaluation }\end{array}$ \\
\hline
\end{tabular}




\begin{tabular}{|c|c|c|c|}
\hline \multirow[t]{3}{*}{$\begin{array}{l}\text { system to promote } \\
\text { optimal health care. }\end{array}$} & $\begin{array}{l}\text { SBP2 } \\
\text { Describe and } \\
\text { distinguish effective } \\
\text { methods of } \\
\text { organizing, financing, } \\
\text { and providing health } \\
\text { care }\end{array}$ & $\begin{array}{l}\text { Mid-block /Course } \\
\text { Formative } \\
\text { Feedback Session } \\
\text { Narrative } \\
\text { Assessment } \\
\text { Attendance } \\
\text { Participation }\end{array}$ & $\begin{array}{l}\text { Attendance/Participation (IPE } \\
\text { experiences) } \\
\text { Clinical Performance Rating/Checklist } \\
\text { Exam - Institutionally Developed, } \\
\text { Written/Computer-based } \\
\text { Narrative Assessment }\end{array}$ \\
\hline & $\begin{array}{l}\text { SBP3 } \\
\text { Describe how the } \\
\text { prevention and } \\
\text { treatment of } \\
\text { healthcare disparities } \\
\text { may affect individual } \\
\text { patients, populations, } \\
\text { and the healthcare } \\
\text { system. }\end{array}$ & $\begin{array}{l}\text { Clinical } \\
\text { Documentation } \\
\text { Review } \\
\text { (H\&Ps, patient } \\
\text { notes, PxDx logs) } \\
\text { Mid-block /Course } \\
\text { Formative } \\
\text { Feedback Session } \\
\text { Multisource } \\
\text { Assessment } \\
\text { (faculty, peer, } \\
\text { self) } \\
\text { Narrative } \\
\text { Assessment } \\
\text { Oral Patient } \\
\text { Presentation } \\
\text { Attendance } \\
\text { Participation }\end{array}$ & $\begin{array}{l}\text { Clinical Documentation Review } \\
\text { (H\&Ps, patient notes, PxDx logs) } \\
\text { Clinical Performance Rating/Checklist } \\
\text { Multisource Assessment (faculty, peer, } \\
\text { self) }\end{array}$ \\
\hline & $\begin{array}{l}\text { SBP4 } \\
\text { Advocate for quality } \\
\text { patient care, as } \\
\text { evidenced by } \\
\text { recognizing system } \\
\text { limitations and } \\
\text { failures and } \\
\text { contributing to } \\
\text { healthcare safety and } \\
\text { improvement }\end{array}$ & $\begin{array}{l}\text { Clinical } \\
\text { Documentation } \\
\text { Review } \\
\text { (H\&Ps, patient } \\
\text { notes, PxDx logs) } \\
\text { Mid-block /Course } \\
\text { Formative } \\
\text { Feedback Session } \\
\text { Multisource } \\
\text { Assessment } \\
\text { (faculty, peer, } \\
\text { self) } \\
\text { Narrative } \\
\text { Assessment } \\
\text { Oral Patient } \\
\text { Presentation } \\
\text { Portfolio-based } \\
\text { Assessment } \\
\text { (MyFolio } \\
\text { Assignments) }\end{array}$ & $\begin{array}{l}\text { Clinical Documentation Review } \\
\text { (H\&Ps, patient notes, PxDx) } \\
\text { Attendance/Participation } \\
\text { (Health Care Ethics presentation) } \\
\text { Clinical Performance Rating/Checklist } \\
\text { Exam - Institutionally Developed, } \\
\text { Clinical Performance (CPX, OSCE) } \\
\text { Exam - Licensure, Clinical Performance } \\
\text { (USMLE-Step } 2 \text { CS) } \\
\text { Multisource Assessment } \\
\text { (faculty, peer, self) } \\
\text { Narrative Assessment } \\
\text { Oral Patient Presentations } \\
\text { Postgraduate Training Evaluation }\end{array}$ \\
\hline
\end{tabular}




\begin{tabular}{|l|l|l|l|}
\hline & $\begin{array}{l}\text { Attendance } \\
\text { Participation }\end{array}$ & \\
\hline
\end{tabular}

Included with written permission from Scott A. Cottrell, Associate Dean for Student Services and Curriculum, WVU SoM. 2014 


\section{APPENDIX B}

\section{FLEXIBLE INTERVIEW GUIDE}

\section{Flexible Interview Guide - Medical Students}

Thank you for agreeing to share your thoughts and experiences with me on portfolios and the reflection process that is a part of the portfolio process. I am sincerely interested in whatever you have to tell me.

$\underline{\text { Knowledge and use of portfolios prior to medical school }}$

A1. Tell me about any experiences you have had with portfolios before entering the WVU School of Medicine.

- How did you feel about those experiences (your reaction)?

A2. Describe your reaction when you found out that you will have an electronic portfolio to document your performance on core program learning objectives and competencies in the WVU SoM?

Use of WVU SoM electronic portfolio

B1. Tell me about your experience using the WVU SoM electronic portfolio?

B2. How often would you say you access your WVU SoM electronic portfolio? Why? What makes you go to the portfolio?

- What access barriers can you identify? ( Describe)

B3. If you could make changes to the design of the portfolio, what would you suggest?

- Why (what are your reasons)?

B4. If you were asked how to best integrate the electronic portfolio into the curriculum or your daily life, what would you suggest?

- What makes you say that?

$\underline{\text { Feelings about electronic portfolio as a means to increase reflection }}$

C1. What are your thoughts about people who reflect on their learning with portfolios?

C2. What do you think about reflecting on your learning using electronic portfolios? (Give me some examples)

C3. How often would you say you self-reflect on your learning?

- What process do you use?

- In general, has the portfolio helped you to reflect or not really? Please tell me your reasons.

C4. Tell me a story about the last time you reflected on your learning experience.

- Describe how the contents of your portfolio contributed to your reflection?

C5. How do you think the portfolio can be better utilized in the curriculum to facilitate your self-reflection? 
Suggestions and Recommendations for Design and Integration of Electronic Portfolio in the medical education curriculum

D1. What do you think are some of the reasons the SoM requires you to have an electronic portfolio? The purpose of the portfolio?

D2. Tell me about any challenges you have encountered while using the portfolio?

D3. What advice would you give to students who have electronic portfolios to help them make the best use of the experience?

D4. Imagine yourself as a medical school faculty member or administrator or residency director who reviews your portfolio to assess whether you are ready to advance in the curriculum. What would you like to see?

- How should the contents be organized?

- What type of reflection prompts would you ask--give me some other examples.

D5. What effects do you think your portfolio and the activities you are required to complete in the portfolio will have on your future learning approaches?

$\underline{\text { Second Interview with Medical Students - Member Check }}$

MS.2.A. Thank you very much for looking through your responses to the questions I asked during our first interview. What changes or additions, if any, do you want to make to these responses - please start with the first addition or change?

MS.2.B. Now, the questions that I have asked may not have captured everything you would like to tell me about portfolios or your experiences with the medical school electronic portfolio. I am truly interested in anything else you would like to add or share about your experiences using electronic portfolios for documentation of and reflection on competency attainment.

MS.2.C. What should the SoM do differently with the electronic portfolio to enhance your experience with the portfolio as a means to promote reflection and competency attainment and getting to residency?

MS.2.D (as needed per initial transcript analysis).

\section{Flexible Interview Guide - Residents}

Knowledge and use of portfolios prior to medical school

A1. Tell me about any experiences you have had with portfolios before your residency training at the WVU School of Medicine.

A2. Tell me about your experience using the WVU SoM resident electronic portfolio?

Feelings about electronic portfolio as a means to increase reflection

C1. What are your thoughts about people who reflect on their learning? 
C2. What do you think about reflecting on your learning using electronic portfolios? (Give me some examples)

Suggestions and Recommendations for Design and Integration of Electronic Portfolio in the $\underline{\text { medical education curriculum }}$

D1. What do you think are some of the reasons the SoM requires medical students to have an electronic portfolio?

D3. What advice would you give to medical students who have electronic portfolios to help them make the best use of the experience? Give me some examples.

D4. Imagine yourself as a medical school faculty member or residency program director who reviews a student's portfolio to assess whether they are ready to advance in the curriculum.

- What would you like to see?

- How should the contents be organized?

- What type of reflection prompts would you ask? Give me some other examples. 


\section{APPENDIX C}

\section{INTRODUCTION LETTER}

\section{West VirginiaUniversity \\ SCHOOL OF MEDICINE}

Dear $2^{\text {nd }}$ and $3^{\text {rd }}$ Year WVU Medical Student:

This letter is a request for you to take part in a research project to assess your perceptions of the West Virginia University School of Medicine's competency-based electronic portfolio system's design and implementation. This project is being conducted by Carrie A. Calloway in the Department of Medical Education at WVU School of Medicine with supervision by Dr. Jim Rye, a professor in the College of Education and Human Services, for a doctorate degree in Curriculum and Instruction. Your participation in this project is greatly appreciated. You will be asked to participate in a face-to-face interview (approximately one hour) and a brief follow-up interview via phone or face-to-face.

Your participation is voluntary. Your interview responses will remain confidential. All data will be reported in the aggregate. You must be currently enrolled as a medical student at the West Virginia University School of Medicine and at least 18 years of age or older. I will not ask any information that should lead back to your identity as a participant. You may skip any question that you do not wish to answer and you may discontinue at any time. Your class standing will not be affected if you decide either not to participate or to withdraw. West Virginia University's Institutional Review Board acknowledgement of this project is on file.

I hope that you will participate in this research project, as it could be beneficial in understanding the impact of the design and implementation of electronic portfolios on medical students' selfreflection skills and competency attainment. Thank you very much for your time. Should you have any questions about this letter or the research project, please feel free to contact Carrie Calloway at (304) 319-2578 or by e-mail at cacalloway@ hsc.wvu.edu.

Thank you for your time and help with this project.

Sincerely,

Carrie A. Calloway

Doctoral Candidate

West Virginia University

Phone: (304) 319 - 2578

E-mail: cacalloway@hsc.wvu.edu 


\section{APPENDIX D \\ RECRUITMENT SCRIPT}

December 2014

Dear MS2 and MS3 Medical Students:

My name is Carrie Calloway and I am a doctorate student in the WVU College of Education and Human Services. This letter is to request your participation in an educational research study. The purpose of the study is to examine medical students' experiences using the West Virginia University School of Medicine's electronic portfolio. I believe that this awareness can lead to new ways of promoting the electronic portfolio as well as enhancing its design to better assist medical students in documenting attainment of the program level competencies and learning objectives required for graduation.

One of the goals of this study is to provide an account of your experiences using the electronic portfolio in your own words. If you are interested in participating, you will be required to participate in a face-to-face or Skype interview that will take approximately one hour. A brief follow-up interview, either in person or via telephone, will also be needed in order to clarify and verify my conclusions. Your participation in this project is entirely voluntary, yet much appreciated.

I look forward to talking to you and sharing your experiences as part of this research study. I declare confidentiality will be upheld so that you may speak freely about your experience. Any personally identifiable information collected during the interviews will be kept strictly confidential and stored in a password protected file. Only aggregated data will be used in my research study report.

If you agree to participate, please email me your contact information. You may also contact me if you have questions or concerns regarding my request.

A \$20 gift card will be provided to participants who complete the study requirements.

Respectfully,

Carrie A. Calloway

Doctoral Candidate

West Virginia University

Phone: (304) 319 - 2578

E-mail: cacalloway@hsc.wvu.edu 


\section{APPENDIX E}

\section{IRB EXEMPTION}

From:wvukc@mail.wvu.edu<wvukc@mail.wvu.edu>

Sent: Sunday, December 21, 2014 9:25 PM

To: James Rye; cacalloway@mix.wvu.edu

Subject: IRB Protocol Notice: Exemption Granted for Protocol 1412508006

IRB protocol number: $\underline{1412508006}$

Title: A qualitative study of medical student perceptions of the West Virginia University School of Medicine's competency-based electronic portfolio system's design and implementation

PI: James Rye

The West Virginia University Institutional Review Board approved the above-referenced protocol on 21-Dec-2014. To access this protocol, click on the protocol number link provided. Your approval letter can be found in the History subsection of the Summary \& History section located on the Protocol Actions page. For more information, see the Viewing Correspondence quick reference guide. Any future protocol action requests can be completed through the WVU+kc system.

Questions related to Expedited protocols should be directed to Barbara White at 304.293.1119 or jonathan.young@mail.wvu.edu. 


\section{APPENDIX F}

\section{SAMPLE INTERVIEW TRANSCRIPTION}

Student Interview

Class of 2017

MS2 - Female

I: So I think in the e-mail that I sent I explained the purpose of this study. I just wanted to confirm a few things before we get started. First, are you okay that I record the audio?

S5: Yeah, that's fine.

I: Okay, perfect. Hopefully this will only take between thirty minutes and an hour, depending on your responses. Do you opt for the twenty dollar gift card or the two hours of service to the school?

S5: Gift card, please.

I: Okay, that should be a no-brainer. Alright, so this is broken down into a couple of sections. I want to thank you again for agreeing to share your thoughts and experiences concerning the portfolios and the reflection process and I hope that, you know, that the information that you can provide will help to make the portfolio a better tool for future students. So again thank you and I'm interested in anything you have to say whether it be positive or negative. Please be candid, your responses are only going to help make the portfolios better. So l'll get started. The first couple of questions revolve around your knowledge and use of portfolios prior to medical school. And this can be paper portfolios, electronic portfolios. Can you tell me about any experiences you have had with portfolios before you came to the school of medicine?

S5: I don't think I really ever used one before.

I: Have you heard of them, you know, before you were introduced to them? Do you know anything about them at all?

S5: I mean I get, like they're a place to keep like your records and stuff together aware for, I guess career purposes. I know our career center in college had one. That you could use. I just never...like on their website, I just never used it.

I: Okay, describe your reaction when you found out that you would have an electronic portfolio to document your performance and competencies in the school of medicine.

S5: I don't know that I had a strong reaction, either way. I'm happy it's online because it's easier to access than having to go into the school. 
I: Okay, now l'm just going to ask you a couple of questions regarding your use of the school of medicine electronic portfolio. Can you tell me and describe your experiences so far using the school of medicine portfolio... electronic portfolio?

S5: Yeah...sometimes it's, I don't know, frustrating I feel like because it's not...I guess the first time when I opened it, because it doesn't open as like a new Internet tab, it's like a pop-up window, and so I had the pop-ups blocked, so I couldn't figure out how to open it, it took me like an hour before I figured out that that was the reason why. So that was annoying. And I feel like it could be easier to do if it opened as a tab instead of the separate window. And the... it's nice to have all of the PDFs with all of our shelf reports to look back and access because I like to compare different... and look at, especially when I'm studying for Step 1, looking at the breakdowns of how I did on them. I guess on the left hand side, the breakdowns, I know it's related to the competencies that we're supposed to have in medical school, but I feel like it's not super intuitive as to what would be organized where, necessarily. I usually have to click through a bunch of them before I find the one that I'm looking for. And, the reflections that we have to do over the summer, I feel like the way you upload those is probably one of the most confusing things about that. Because I that every time I have to read the full instructions on like where to find the button to add it, instead of just...there just being like, you know, a really simple 'oh, upload here' kind of thing. It's like a little symbol you have to hunt for.

I: Okay, so how often would you say you access your electronic portfolio?

S5: Maybe a couple times a year.

I: What makes you go there?

S5: Whenever I have a shelf and because I know the PDFs are posted there. So even if we get like an email with our score, I like to look at the whole breakdown. So every time I know that one is up, I go and look at it. And, when I had to upload my Step one report, I went on there, and then the summer reflections. But, mostly the shelf scores.

I: So you briefly mentioned a couple of things a few minutes ago, but can you identify any other access barriers and describe any barriers to accessing the portfolio?

S5: It's really hard to do it from a phone or tablet because of the pop-up window thing. And, a lot of times I like, I don't know, sometimes with the whole E*Value website, like some things are really easy to do on the phone and other things are not easy at all. And so the portfolio is one of those things that's not easy to use from mobile devices.

I: So you would prefer that it be easier to use on a mobile device?

S5: Yeah. Because a lot of times, especially this year, like I don't take my laptop to the hospital most of the time because l'm just on rounds and like wards and stuff, but I always have my phone and so it's...I can't get to a computer, it's a lot... really handy. 
I: If you could make changes to the design of the portfolio, what sort of things would you suggest and why?

S5: I guess like the essential layout of it is fine with the tabs on the left-hand side to break down. I'd just make it a lot more obvious, kind of like what would be under each one, instead of naming them by the competencies necessarily. And then, like I said, the uploading of stuff is not always really obvious, l'd make that kind of more user-friendly.

I: If you were asked how to best integrate the electronic portfolio into the curriculum or into your daily life, what sorts of things with you suggest and why?

S5: I guess the question, like why would we...use it on a daily basis?

I: Yeah, like what, how do you think it could be better used or integrated into the curriculum or into your daily life, like what sorts of things would make it more appealing, I guess, for you to use it more regularly?

S5: So I don't know that it's necessarily like not appealing to use it on a more regular basis. I just don't know why...I mean I don't feel a need to use it on a more regular basis. But...

I: Can you think of things that maybe if were added to the portfolio would make you want to use it? Not necessarily on a daily basis, but use it more regularly? Like what would make you want to go there more often if you could document certain types of things or...I know that question doesn't sound real clear.

S5: I guess, so I use the Careers in Medicine and like Frieda and everything a lot. And like I have like a list on my computer of like residency programs and stuff that I'm researching, so like maybe adding a way to keep like a running tab of like programs and kind of integrating those kinds of things into it.

I: Okay. So now l'm just going to ask you some feelings that you have about the portfolio as a means to increase reflection, but first, it's just kind of a general question. What are your thoughts about people who reflect on their learning using portfolios? Or, what are your thoughts about reflecting in a portfolio in general?

S5: I'm not opposed to it, either way. I took it fairly seriously. Like I thought a lot about what I was writing before I uploaded it. I don't know that everyone took it as seriously as I did, but I think we also don't know, like, if they actually get read or not. Like what the purpose of it is from like the school's perspective, like what they do with it.

I: How often would you say you reflect on your learning and what, what process do you use when you do reflect?

S5: I guess this year I think about it a lot more, just because we have different rotations 
to compare and contrast and there is definitely differences between how much I learn in some rotations than in others and how they group lecturers and stuff like that. But mostly just in my head or talking to my friends.

I: In general, do you think the portfolio has helped you reflect or not really and can you give any reasons?

S5: I don't think the portfolio itself has helped. I mean I know we uploaded those reflections to the portfolio, but if we had to upload them on SOLE I don't think it would have made any kind of difference as to what I wrote or anything like that. Yeah.

I: Do the contents, you know the things that are in the portfolio like your narratives and grades or shelf scores or anything like that, do they help to facilitate your reflection?

S5: Yes, they do. I like to look, sometimes, well as I mentioned, the shelf scores and the breakdowns and stuff, especially when I'm studying, but I do sometimes go back and look at the past narratives too when I was writing them.

I: Can you tell me a story about the last time you reflected on a learning experience?

S5: What kind, like any kind of learning experience?

I: Yeah, it could be like any type of learning experience, sure.

S5: I mean. So we went to the Sim Center a few weeks ago. I did like a, how to put an IV in and so we watched videos. You watch a video before you go and then you do the activity and you have to record yourself and evaluate yourself, and now we have to go to put an IV in a real patient in the hospital next week. So I was telling, me and my friends were talking about how 'oh, it would have been nice if the simulation and the activity and the actual patient encounter were closer than three weeks apart'. Because I feel like I would have been more confident about it if it had been, like the next week, when it was fresh in my mind.

I: Can you...you mentioned briefly in a previous question that the contents of the portfolio, like your grades and narratives and shelf scores and things like that, have contributed to your reflection. Can you describe that a little more? Like how... how do you use those contents to reflect?

S5: Sure. So I know when I was writing my reflection this past summer I went and read my reflection that I had written the last summer, before I started, and then seeing like, refreshing my memory on what I had written as like my goals and stuff, to see how much, I don't know I guess, that I had actually done that I wanted to do and then looking at my shelf scores and stuff to see how much and my grades to kind of see, so I had written goals about like performance, specific like numbers and stuff like that, to see how they actually aligned. 
I: Okay, so you have used the contents to help you set goals based on like your strengths and weaknesses.

S5: Yeah.

I: Now I'm going to ask you a couple of questions about your suggestions and recommendations for the design and integration of the portfolio into the curriculum, but first, what do you think are the reasons, some of the reasons I guess, that the school medicine requires that you have an electronic portfolio. So why do you think that we have the portfolio in place?

S5: To help with applying to residencies. So, as a way to like collect all of the relevant data and stuff that's going to go into like the MSPE letter and allow, like, the deans and us, to have access to it and to add things to it. In preparation for that.

I: Can you tell me in any other challenges that you have had or encountered while using the portfolio?

S5: I think I covered them all.

I: What advice would you give to other students to help them make better use of the portfolio experience?

S5: I don't know. I guess for the pop-up window thing, I mean, I'd try using...I mean I use like four different Internet browsers on my computer, so some of them are easier than others, but that's it.

I: Okay, imagine yourself as a medical school faculty member or administrator, like one of the deans or student services. Imagine yourself as one of those people who reviews your portfolio to assess whether or not you're ready to advance in the curriculum. If you were a faculty member or administrator, what would you like to see in a student portfolio?

S5: Content wise?

I: Yeah.

S5: Probably...I feel like the things that are already included, because I know our narratives have sections for not only like the academic performance, but also professionalism, comments. Things like that and for people who is interviewing students who have to repeat stuff. Like the shelf scores and stuff because they can show trends or like past problems.

I: How do you think the contents should be organized?

S5: I feel like just a whole tab labeled with score reports would be very handy and just 
have the PDFs in there. And then one with narratives and other evaluations, like Way To Go's or other...if there were problematic...I don't know what the problematic ones are... On the Fly's, I guess that would be bad, just kind of like all the, a place where like all of the narratives could go and other comments and evaluations in a section.

I: So there's a...you've even mentioned the reflections that you've been required to do at the end of each academic year, what do you think about those reflection prompts or what sort of reflection prompts do you think would be more helpful, you know, as you're preparing for residency and advancing through the curriculum?

S5: I feel like they're pretty good. At the moment, I know if I remember correctly, the last one kind of addressed like how do you think you did in the past year, based on your goals for the next year. You thought a little more about your medical specialty. I think it could incorporate more, you know, like what type of environment do you want to practice in eventually and maybe thinking more about where you want to go. Because I know like me and one of my friends used Frieda last year, but like most people didn't know what it was and never really thought about specific, like researching specific residency programs, so maybe prompting that... about that more.

I: What effects do you think the portfolio will have on like your future learning? Do you think it has any effects on the way you learn or the way you reflect on your learning?

S5: I don't think it effects the way I learn at all. I don't know, not really.

I: Okay, and what do you think the school of medicine should do differently with the portfolios to enhance your experience with them, particularly as a means to promote reflection and competency attainment...documentation of competency?

S5: I think probably just making us more aware of the competencies we're supposed to be attaining. Because I know they're in the handbook and they mention them here and there, but I know they're definitely not...I couldn't specifically name them. And I know we're supposed to learn to be professional and learn the knowledge, but I can't tell you what they are exactly, so that would be a good first step.

I: Okay. Any other things that you think would help? Anything else you think the school of medicine can do to help enhance your experience with the portfolios?

S5: I think...I think there's a section for like uploading stuff you've done to it, I guess that I forget about that. Making people more aware of like logging awards that they've gotten or other things. If you could add like a...I don't know how easy this would be to do... but like, kind of if you would like log stuff in, like awards and research and other things into there, like a...kind of like a CV generator almost. Like to help with that because I know there's tons of different ways to do that and coming up with... it would be easier if it kind of helped you organize it yourself if everything was already in there.

I: Do you think that would actually increase students' use of the portfolio if they were 
actually building their CVs as they went through the curriculum?

S5: I would definitely use it more. I don't know about other people, but I had to make one up last month from scratch, and I had to go look at all of my old ones from college, so...to remember how I had done it before. So, yeah.

I: Okay, perfect. So that's basically, really all of the questions that I have at this time. Do you want...is there any overall thoughts, maybe something I didn't ask about the portfolio or reflection that you would like to elaborate on or throw out there?

S5: Not about the reflection or portfolio part specifically, but I know like you do stuff with $E^{*}$ Value as a whole and the PxDx, it's fairly easy to add stuff on like mobile devices but it's not easy to... it's not nearly as easy to like look at your evaluations that have been completed about you by faculty. Or to see like a log of PxDx that you've logged for like a specific block, like a summary. So I feel like the mobile utility for like the whole $E^{*}$ Value... like it's important... like it would be a lot easier to use for me and I would probably go on it more if it were easier to use on my phone.

I: Okay, well that's really all the questions that I have I really appreciate you taking the time to talk with me. The next step is basically l'll be transcribing our conversation and I'll send you via e-mail the transcribed interview and that way if there's anything you want to add we can take care of it at that time and then I'm also working on securing a twenty dollar gift cards so I don't know exactly when those will be ready, but I'm guessing within a month or two so, probably not that long, but I don't want to make a false promise. So l'll notify you when those are ready and let you know. 